\title{
Fuzzy Logic Temperature Control for the Continuous Resistance Welding of Fiberglass/Polypropylene Laminates
}

by

\author{
Imad Ali Zammar \\ Bachelor of Engineering \\ A thesis submitted to \\ the Faculty of Graduate Studies and Research \\ in partial fulfillment of \\ the requirements for the degree of

\section{Master of Applied Science} \\ Ottawa-Carleton Institute for Mechanical and Aerospace Engineering \\ Department of Mechanical and Aerospace Engineering \\ Carleton University \\ Ottawa, Ontario \\ Canada
}

June $2010 \Subset$ 
Library and Archives

Canada

Published Heritage Branch

395 Wellington Street Ottawa ON K1A ON4

Canada
Bibliothèque et

Archives Canada

Direction du

Patrimoine de l'édition

395 , rue Wellington

Ottawa ON K1A ON4

Canada
Your file Votre référence

ISBN: 978-0-494-81711-7

Our file Notre référence

ISBN: 978-0-494-81711-7
NOTICE:

The author has granted a nonexclusive license allowing Library and Archives Canada to reproduce, publish, archive, preserve, conserve, communicate to the public by telecommunication or on the Internet, loan, distribute and sell theses worldwide, for commercial or noncommercial purposes, in microform, paper, electronic and/or any other formats.

The author retains copyright ownership and moral rights in this thesis. Neither the thesis nor substantial extracts from it may be printed or otherwise reproduced without the author's permission.
AVIS:

L'auteur a accordé une licence non exclusive permettant à la Bibliothèque et Archives Canada de reproduire, publier, archiver, sauvegarder, conserver, transmettre au public par télécommunication ou par l'Internet, prêter, distribuer et vendre des thèses partout dans le monde, à des fins commerciales ou autres, sur support microforme, papier, électronique et/ou autres formats.

L'auteur conserve la propriété du droit d'auteur et des droits moraux qui protège cette thèse. $\mathrm{Ni}$ la thèse ni des extraits substantiels de celle-ci ne doivent être imprimés ou autrement reproduits sans son autorisation.
In compliance with the Canadian Privacy Act some supporting forms may have been removed from this thesis.

While these forms may be included in the document page count, their removal does not represent any loss of content from the thesis.
Conformément à la loi canadienne sur la protection de la vie privée, quelques formulaires secondaires ont été enlevés de cette thèse.

Bien que ces formulaires aient inclus dans la pagination, il n'y aura aucun contenu manquant.

\section{Canadä}




\section{Abstract}

Presented in this thesis is the approach taken to implement a real-time temperature control system into the continuous resistance welding process (CRW) for thermoplastic composite materials. To accomplish this, the first step was to create a numerical model of the process. A 3D FEM heat transfer model was created in COMSOL® Multiphysics that coupled the electrostatics of the process to the heat generation. The result was a heat transfer model that predicted the weld temperature within less than $10 \%$ error of experimental values. Temperature data from this model was extracted and used to identify a second order linear model for use online in estimating the weld temperature. A fuzzy logic controller was designed and implemented in real-time with the experimental setup using the temperature estimate as the feedback signal. The result was a controller capable of controlling the weld temperature within $10 \%$ of the reference temperature. 


\section{Acknowledgements}

This thesis would not have been possible without the help of several people. First and foremost I would like to thank my supervisors Dr. Iraj Mantegh (NRC-IAR/AMTC) and Professor Mojtaba Ahmadi for their expertise and guidance. My thanks go out to Dr. Ali Yousefpour (NRC-IAR/AMTC) for providing his vast expertise on composites and their manufacturing processes. I would also like to thank Adham Salame for his knowledge in both electrical signals and COMSOL. My experiments would not have been possible without the aid of Francois Ferland and Christian Corbeil both from NRCIAR/AMTC. I would also like to offer my endless gratitude to my parents, Freida and Ali Zammar, without whom my academic career would never have been possible. To my brother Ahmed, and my sisters Amal and Jenan who have supported me all these years. And lastly, I would like to thank my precious wife Narges Altimimi, Hadi Rasol, and Israa Zammar for being patient and providing me with the inspiration I needed to complete my project and this thesis. 


\section{Table of Contents}

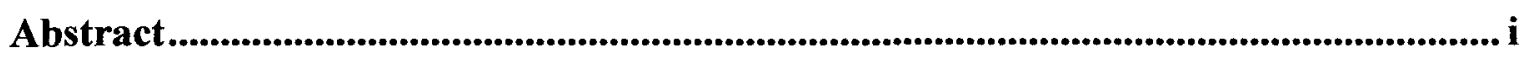

Acknowledgements....................................................................................................................................... ii

Table of Contents ..........................................................................................................................ii

List of Figures................................................................................................................... vi

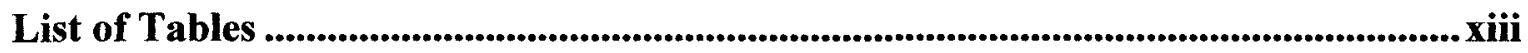

List of Appendices ......................................................................................................................... $\mathrm{xv}$

Nomenclature ............................................................................................................................................. xvi

$\begin{array}{ll}1 \text { INTRODUCTION } & 1\end{array}$

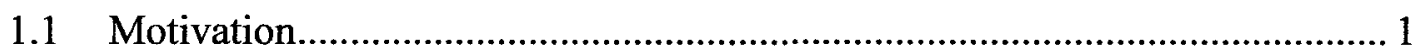

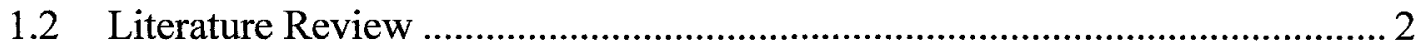

1.2.1 Thermoplastic Resistance Welding Process Modeling ….......................... 2

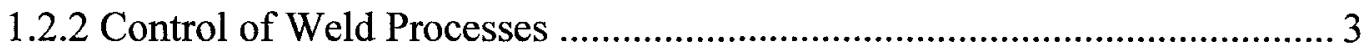

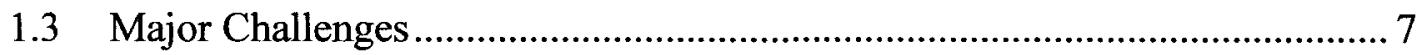

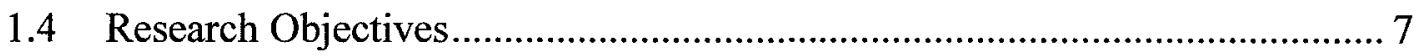

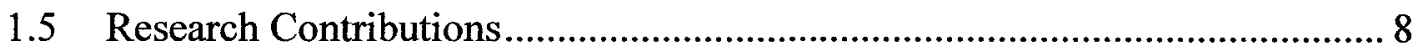

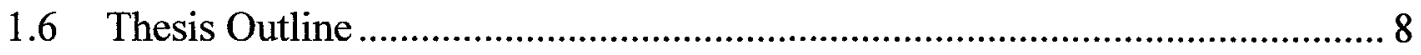

2 THERMOPLASTIC RESISTANCE WELDING

2.1 Intellectual Property Overview ................................................................. 10 
2.2 Resistance Welding Overview............................................................... 10

2.3 Static Thermoplastic Resistance Welding ..................................................... 11

2.4 Continuous Thermoplastic Resistance Welding ……..................................... 12

3 PROCESS MODELING AND VALIDATION 18

3.1 Modeling Overview .................................................................................. 18

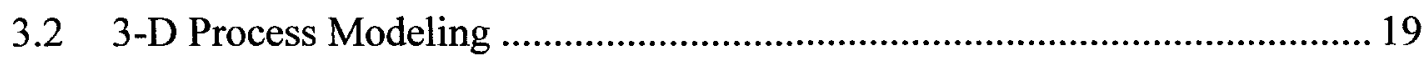

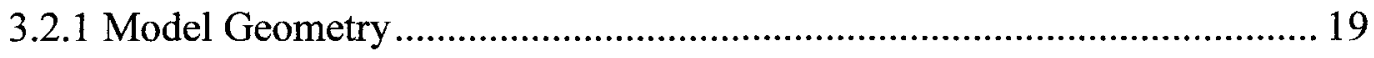

3.2.2 Electrostatic Modeling........................................................................... 21

3.2.3 Heat Transfer Modeling......................................................................... 34

4 PROCESS CONTROL $\quad 50$

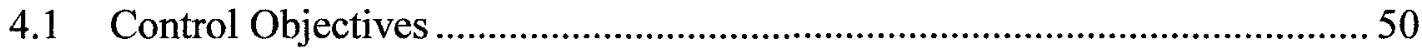

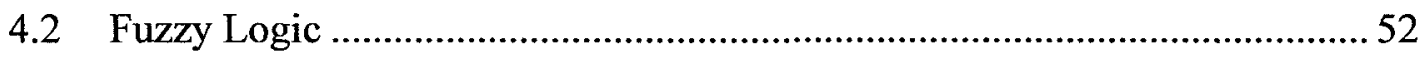

4.3 Online Temperature Estimation....................................................................56

4.3.1 Pre-Heat Temperature Approximation …………....................................... 57

4.3.2 Temperature Linear Model ................................................................... 58

4.4 Fuzzy Logic Controller (FLC) Development ………..................................... 62

4.4.1 Fuzzy Logic Controller Structure ……...................................................... 62

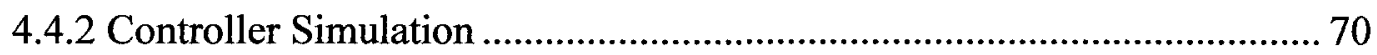

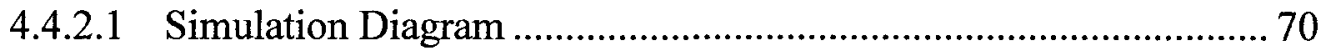

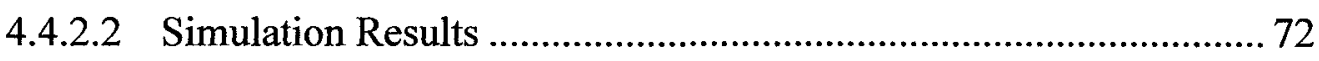

5 REAL-TIME CONTROL IMPLEMENTATION 75

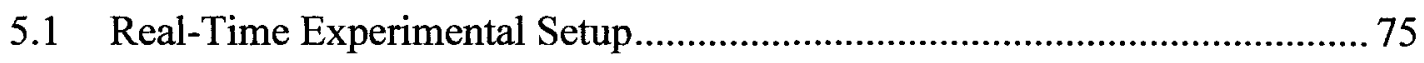

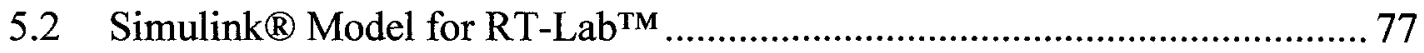




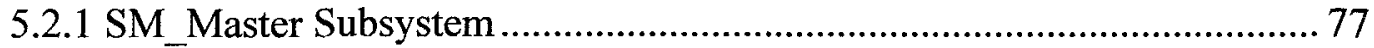

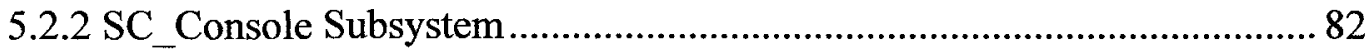

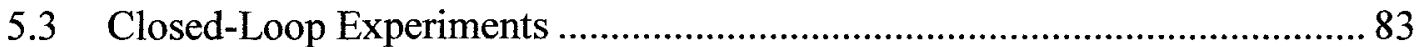

5.3.1 Fuzzy Logic Controller Results ....................................................... 83

5.3.2 Modified Fuzzy Logic Controller ......................................................... 87

6 CONCLUSIONS AND RECOMMENDATIONS 96

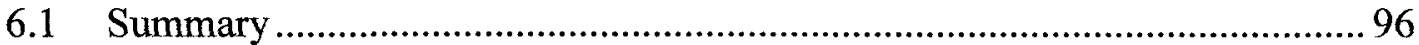

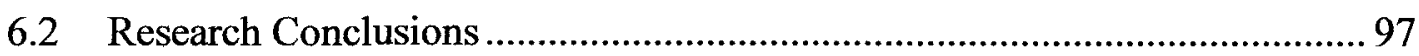

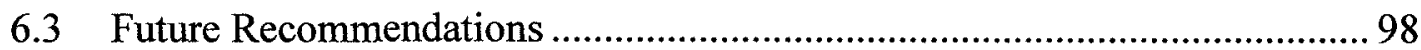

7 LIST OF REFERENCES $\quad 101$ 


\section{List of Figures}

Figure 1.1 - Adaptive fuzzy control layout for in GTAW [14]...................................... 4

Figure 1.2 - Simplified block diagram showing inputs and outputs for the FLC [15]..... 5

Figure 2.1 - Thermoplastic resistance welding stack. .................................................... 12

Figure 2.2 - End-effector with copper electrodes and aluminum pressure wheel........... 13

Figure 2.3 - Copper slip-rings traversing directly on the exposed heating element........ 14

Figure 2.4 - (a) Top view of weld stack and (b) copper tracks atop heating element. .... 14

Figure 2.5 - Complete weld setup with slip-rings, copper tracks, and compaction wheel.

Figure 2.6 - Extended compaction track that provides pressure during a weld operation.

Figure 2.7 - Addition of a rubber wheel to distribute the force from the pneumatics over

a larger area to prevent the copper tracks from bending.

Figure 3.1 - Three dimensional geometry used in FEM modeling of the weld process.. 20

Figure 3.2 - Cross sectional view of the weld stack showing all materials. 20

Figure 3.3 - (a) Triangular mesh of all components (b) Triangular mesh on heating element.

Figure 3.4 - Current measured at $2 \mathrm{~V}$ on heating element 0.5 in by 1 in by 0.0042 in. ... 22

Figure 3.5 $-C^{2}$ continuous step function used to transition the voltage from on to off. . 23 
Figure 3.6 - Location of voltage applications in the FEM model..

Figure 3.7 - Multiple grounds as a result of using step functions with zero initial output.

Figure 3.8 - All voltage boundaries set to solution variable "V", ................................. 26

Figure 3.9 - A weld showing the change in location of voltage over time...................... 26

Figure 3.10 - Electrodes transitioning between two copper blocks causing a lower equivalent resistance.

Figure 3.11 - Block diagram of hardware used in the experimental setup.....................28

Figure 3.12 - Current comparison between COMSOL and experiments at 4V............. 28

Figure 3.13 - Current comparison between COMSOL and experiments at 4.5V.......... 29

Figure 3.14 - Current comparison between COMSOL and experiments at 5V............. 29

Figure 3.15 - Current comparison between COMSOL and experiments at 5.5V........... 30

Figure 3.16 - Current comparison between COMSOL and experiments at 6V.............. 30 Figure 3.17 - COMSOL model with arrows depicting the direction of the current for the first weld section. 32

Figure 3.18 - COMSOL model with arrows depict the direction of the current for the second weld section.

Figure 3.19-COMSOL model with arrows depict the direction of the current for the third weld section.

Figure 3.20 - Resistive heating along the vertical line in Fig. 3.19 that occurs when welding the $3^{\text {rd }}$ and $4^{\text {th }}$ copper block sections as well as while transitioning between them. 
Figure 3.21 - Temperature distribution along the heating element after 7.2 seconds at $6 \mathrm{~V}$.

Figure 3.22 - Dark circles showing the location of the thermocouples in the weld stack, placed directly atop the heating element.

Figure 3.23 - Temperature comparison between simulation and experiments at $4 \mathrm{~V}$ and 4 inches per minute for the first weld section.

Figure 3.24 - Temperature comparison between simulation and experiments at $4 \mathrm{~V}$ and 4 inches per minute for the second weld section.

Figure 3.25 - Temperature comparison between simulation and experiments at $4 \mathrm{~V}$ and 4 inches per minute for the third weld section.

Figure 3.26 - Temperature comparison between simulation and experiments at $5 \mathrm{~V}$ and 4 inches per minute for the first weld section.

Figure 3.27 - Temperature comparison between simulation and experiments at $5 \mathrm{~V}$ and 4 inches per minute for the second weld section.

Figure 3.28 -Temperature comparison between simulation and experiments at $5 \mathrm{~V}$ and 4 inches per minute for the third weld section.

Figure 3.29 - Temperature comparison between simulation and experiments at $6 \mathrm{~V}$ and 4 inches per minute for the first weld section.

Figure 3.30 - Temperature comparison between simulation and experiments at $6 \mathrm{~V}$ and 4 inches per minute for the second weld section.

Figure 3.31 - Temperature comparison between simulation and experiments at $6 \mathrm{~V}$ and 4 inches per minute for the third weld section 46 
Figure 3.32 - (a) Temperature of the heating element across the $2^{\text {nd }}$ weld section while the first section has $4 \mathrm{~V}$ applied to it. (b) Shows the horizontal location of each measurement.

Figure 3.33 - (a) Temperature of the heating element across the 1st weld section while $4 \mathrm{~V}$ is applied to it. (b) Shows the horizontal location of each measurement.

Figure 4.1 - Water tank with a low level (L) sensor, a high level $(\mathrm{H})$ sensor and a valve [33].

Figure 4.2 - Membership functions for the height of the water in the tank from L to H. 53 Figure 4.3 - Membership functions for the volume flow rate ranging from $0 \mathrm{~L} / \mathrm{min}$ (valve closed) to $5 \mathrm{~L} / \mathrm{min}$ (valve fully open)

Figure 4.4 - Degree of membership for water height for (a) RULE 1 and (b) RULE 2 when the height of the water is $0.2 \mathrm{~m}$ from $\mathrm{L}$. 54

Figure 4.5 - Degree of membership on the volume flow rate for (a) RULE 1 and (b)

RULE 2 when the height of water is $0.2 \mathrm{~m}$ from $\mathrm{L}$.

Figure 4.6 - Aggregation using the maximum of the outputs from Rules 1 and 2 that were generated from Figures 4.4 and 4.5 .

Figure 4.7 - Temperature profiles in COMSOL at $6 \mathrm{~V}$ and $7 \mathrm{inch} / \mathrm{min}$ for four consecutive weld sections showing a constant pre-heat temperature.

Figure 4.8 - Temperature profile at midpoint of fourth weld section from 3D model at $5.65 \mathrm{~V}$. The horizontal line denotes the pre-heat temperature of $120^{\circ} \mathrm{C}$. 59

Figure 4.9 - Comparison of temperature between the $2^{\text {nd }}$ and $3^{\text {rd }}$ order state-space models with the COMSOL model. 
Figure 4.10 - Percentage error between the $2^{\text {nd }}$ and $3^{\text {rd }}$ order models and the $3 \mathrm{D}$ model.

Figure 4.11 - Simple control loop in Simulink showing the controller inputs and outputs as well as the location of the temperature estimator.

Figure 4.12 - Membership functions assigned to the temperature error signal.

Figure 4.13 - Temperature gradient taken from Fig. 3.29 for both the model and experiment 64

Figure 4.14 - Membership functions assigned to the error rate. 65

Figure 4.15 - Membership functions assigned to the speed output. 65

Figure 4.16 - Membership functions assigned to the voltage output. 66

Figure 4.17 - Rule surface according to rule base outlined in Table 9. 68

Figure 4.18 - Rule surface corresponding to modified rule base in table 10 69

Figure 4.19 - Rule surface for the weld speed defined by the parameters in Table $11 \ldots 70$ Figure 4.20 - Closed-loop used in Simulink ${ }^{\circledR}$ to simulate the effectiveness of the fuzzy logic controller. 71

Figure 4.21 - Switch used to model the position resetting that occurs in the process from weld section to weld section. 72

Figure 4.22 - Contents of subsystem "If-SS model" from Fig. 4.21. The "if" conditions resets the states of the linear model when the distance is larger than 0.49 inches. 72 Figure 4.23 - Temperature variations for (a) five consecutive blocks, and (b) for first block. 73

Figure 4.24 - Voltage control signal for (a) five consecutive blocks, (b) for the first block 
Figure 4.25 - Speed control signal for (a) five consecutive blocks, (b) for the first block.

Figure 5.1 - Block diagram displaying a loops present in the experimental setup with

RT-Lab ${ }^{\text {TM }}$ implemented.

Figure 5.2 - Two major subsystems used in the Simulink ${ }^{\circledR}$ model with RT-Lab ${ }^{\mathrm{TM}} \ldots . . . .77$

Figure 5.3 - SM_Master subsystem containing all I/O communications and the FLC...79

Figure 5.4 - Temp estimation subsystem contents revealing the distance switch.

Figure 5.5 - Force Calibration \& Read subsystem contents from Fig. 5.3..................... 81

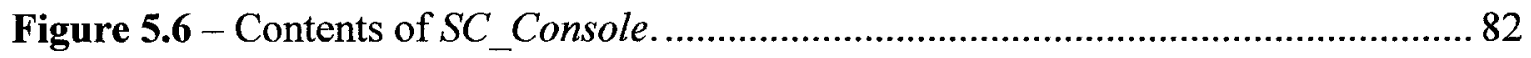

Figure 5.7 - Temperature measured at three consecutive weld sections by thermocouples, while welding under fuzzy logic control.

Figure 5.8 - (a) Voltage and (b) resulting current signals generated while welding a single section under fuzzy logic control. Time is scaled to start from zero. .84

Figure 5.9 - Weld speed in a single weld section as commanded by the FLC............... 85

Figure 5.10 - Internal view of a coupon after welding under fuzzy logic control........... 86

Figure 5.11 - View of the glass/PP laminate at the weld interface after welding under fuzzy control. It is evident that the mid-section of the coupon has not been welded. ..... 86 Figure 5.12 - Modified rule surface plotted from the modified rule base in table $12 \ldots . .87$ Figure 5.13 - Closed-loop voltage signal using the modified fuzzy logic controller......88 Figure 5.14 - Temperature measured at three consecutive weld sections while welding under the modified fuzzy logic control.

Figure 5.15 - Error between the measured temperature and the estimated temperature for the $4^{\text {th }}$ weld section of Fig. 5.14. 89 
Figure 5.16 - Error between the measured temperature and the estimated temperature for the $5^{\text {th }}$ weld section of Fig. 5.14. 90 Figure 5.17 - Error between the measured temperature and the estimated temperature for the $6^{\text {th }}$ weld section of Fig. 5.14. 90 Figure 5.18 - Interior of the weld after a closed-loop weld performed with the modified fuzzy logic controller. 91

Figure 5.19 - Comparison of the heating element in both closed-loop (left) and openloop (right) welds in terms of damages

Figure 5.20 - Comparison of the temperature of the $5^{\text {th }}$ weld-section under open-loop and closed-loop conditions 93

Figure 5.21 - Comparison of the temperature of the $6^{\text {th }}$ weld-section under open-loop and closed-loop conditions. 93

Figure 5.22 - Infrared image showing the location of the spot used to measure the top surface temperature during a controlled weld. 94

Figure 5.23 - Top surface temperature measured using a FLIR A20 Infrared Camera... 95 


\section{List of Tables}

Table 3.1 - Conductivity calculated using eq. (3.2) at different voltages

Table 3.2 - The percent error between experimental current measurements and the COMSOL model at 5 different voltages corresponding to locations shown in Figures 3.12 to 3.16 .

Table 3.3 - Material properties of heating element, polypropylene resin film and the Glass/PP Laminate.

Table 3.4 - Specific heat capacity of polypropylene at constant pressure as a function of temperature [25].....

Table 3.5 - Specific heat capacity for the $34 \%$ Glass-fibre, $66 \%$ polypropylene laminate at constant pressure as a function of temperature [26].

Table 3.6 - Percentage error between the COMSOL model and thermocouple measurements (TC) for each weld section at $4 \mathrm{~V}$. 46

Table 3.7 - Percentage error between the COMSOL model and thermocouple measurements (TC) for each weld section at $5 \mathrm{~V}$.

Table 3.8 - Percentage error between the COMSOL model and thermocouple (TC) measurements for each weld section at $6 \mathrm{~V}$.

Table 4.1 - Initial rule base for the voltage output from the fuzzy logic controller. 
Table 4.2 - Modified rule base for voltage that resulted in a smooth rule surface for control.

Table 4.3 - Rule base used for the weld speed 70

Table 5.1 - Modified rule base to extend the time spent at the "very high" voltage case 87 


\section{List of Appendices}

APPENDIX A - Voltage Boundary Conditions................................. 104 


\title{
Nomenclature
}

\author{
Alphanumeric
}

\begin{tabular}{|c|c|c|}
\hline Symbol & Description & Units \\
\hline$a$ & Left corner of triangular membership & {$\left[{ }^{\circ} \mathrm{C}\right]$ or $\left[{ }^{\circ} \mathrm{C} / \mathrm{s}\right]$} \\
$b$ & function & {$\left[{ }^{\circ} \mathrm{C}\right]$ or $\left[{ }^{\circ} \mathrm{C} / \mathrm{s}\right]$} \\
$c$ & Peak of triangular membership function & {$\left[{ }^{\circ} \mathrm{C}\right]$ or $\left[{ }^{\circ} \mathrm{C} / \mathrm{s}\right]$} \\
$A$ & Right corner of triangular membership & function \\
$C p$ & Area & {$\left[\mathrm{m}^{2}\right]$} \\
$h$ & Specific heat capacity at constant pressure & {$\left[\mathrm{J} /\left(\mathrm{kg}^{*} \mathrm{~K}\right)\right]$} \\
$H$ & Heat transfer coefficient & {$\left[\mathrm{W} /\left(\mathrm{m}^{2} * \mathrm{~K}\right)\right]$} \\
$I$ & Resistive heating & {$[\mathrm{W}]$} \\
$k$ & Current & {$[\mathrm{A}]$} \\
$l$ & Thermal conductivity & {$\left[\mathrm{W} /\left(\mathrm{m}^{*} \mathrm{~K}\right)\right]$} \\
$P P$ & Length & {$[\mathrm{m}]$} \\
$R$ & Polypropylene & - \\
$t$ & Resistance & {$[\Omega]$} \\
$T_{b}$ & Time & {$[\mathrm{s}]$} \\
$T_{\infty}$ & Temperature of body & {$[\mathrm{K}]$} \\
$Q$ & Atmospheric temperature & {$[\mathrm{K}]$} \\
$V$ & Volumetric heat generation & {$\left[\mathrm{W} / \mathrm{m}^{3}\right]$} \\
$x_{i}$ & Voltage & {$[\mathrm{V}]$} \\
$x$ & Point on universe of discourse & {$\left[{ }^{\circ} \mathrm{C}\right]$ or $\left[{ }^{\circ} \mathrm{C} / \mathrm{s}\right]$} \\
$y$ & Width & {$[\mathrm{m}]$} \\
$z$ & Length & {$[\mathrm{m}]$} \\
& Height & {$[\mathrm{m}]$} \\
\hline & & \\
\hline & &
\end{tabular}




\section{Greek}

\begin{tabular}{|c|c|c|}
\hline Symbol & Description & Units \\
\hline$\varepsilon$ & Emissivity & - \\
$\delta$ & Partial derivative & - \\
$\rho$ & Density & {$\left[\mathrm{kg} / \mathrm{m}^{3}\right]$} \\
$\sigma_{\mathrm{s}}$ & Stefan-Boltzmann Constant & $5.67 \times 10^{-8}\left[\mathrm{~W} /\left(\mathrm{m}^{2} \mathrm{~K}^{4}\right)\right]$ \\
$\sigma$ & Electrical conductivity & {$[\mathrm{S} / \mathrm{m}]$} \\
$\mu$ & Degree of membership & - \\
\hline
\end{tabular}

\section{Acronyms}

\begin{tabular}{|c|c|}
\hline Acronym & Description \\
\hline AVC & Automatic Voltage Control \\
COG & Center of Gravity \\
COA & Center of Area \\
CRW & Continuous Resistance Welding \\
FEM & Finite-Element Model \\
FLC & Fuzzy Logic Control \\
GMAW & Gas Metal Arc Welding \\
GTAW & Gas Tungsten Arc Welding \\
LTI & Linear Time Invariant \\
MRAC & Model Reference Adaptive Control \\
NN & Neural Network \\
\hline
\end{tabular}


Fuzzy Logic Membership Function Definitions

\begin{tabular}{|c|c|}
\hline Acronym & Description \\
\hline \multicolumn{2}{|c|}{ Temperature Error Membership Functions } \\
\hline $\mathrm{MC}$ & Medium Cold \\
\hline MH & Medium Hot \\
\hline $\mathrm{SC}$ & Slightly Cold \\
\hline SH & Slightly Hot \\
\hline VC & Very Cold \\
\hline VH & Very Hot \\
\hline$Z$ & Zero \\
\hline \multicolumn{2}{|c|}{ Rate of Temperature Error Membership Functions } \\
\hline GMC & Getting Medium Cold \\
\hline GMH & Getting Medium Hot \\
\hline GSC & Getting Slightly Cold \\
\hline GSH & Getting Slightly Hot \\
\hline GVC & Getting Very Cold \\
\hline GVH & Getting Very Hot \\
\hline $\mathrm{Z}$ & Zero \\
\hline \multicolumn{2}{|c|}{ Output Speed Membership Functions } \\
\hline F & Fast \\
\hline M & Medium \\
\hline $\mathrm{S}$ & Slow \\
\hline SM & Slow-Medium \\
\hline \multicolumn{2}{|c|}{ Output Voltage Membership Functions } \\
\hline MID & Middle \\
\hline MH & Medium High \\
\hline ML & Medium Low \\
\hline SH & Slightly High \\
\hline SL & Slightly Low \\
\hline VH & Very High \\
\hline VL & Very Low \\
\hline
\end{tabular}




\section{Chapter 1}

\section{Introduction}

\subsection{Motivation}

Composite materials are primarily chosen for aerospace applications because they typically possess a higher strength-to-weight ratio than most metals [1]. The use of these materials is on the rise. For example, the Boeing 777 aircraft, having taken its first flight in 1994, consisted of only $12 \%$ composites and $50 \%$ aluminum. The Boeing 787 aircraft on the other hand, having taken its first flight this year, is composed of $50 \%$ composites and $20 \%$ aluminum [2]. Use of thermoplastics in particular are increasing because of their high damage tolerance, and re-processability [1], [3]. Typically large scale composite components have a high cost of manufacturing. This can be attributed to complicated mold designs as well as the use of expensive machinery such as autoclaves. The increasing use of composites demands more efficient and cost-effective manufacturing methods. Complicated geometry could be broken down into a series of simple parts that could be later joined together. Resistance welding is a potential joining method applicable to thermoplastics. The individual components could be fusion bonded to each other to achieve a complex geometry. The cost of manufacturing these individual components would be less costly because of less complicated mold designs, and the final product would require a series of weld operations to complete the final large scale component. Further, there is also pressure from commercial airline manufacturers to fine 
tune the resistance welding process so that it can be implemented into a full scale manufacturing setting.

Literature in the field of the resistance welding of thermoplastic materials has a wealth of publications since as early as 1989 , when Jakobsen et al. published their findings on the thermal characteristics of static resistance welding [4]. With the recent rise and rapid development of composite materials and their wide-spread use in the last decade, it is necessary to take the existing technology further towards full scale implementation.

\subsection{Literature Review}

\subsubsection{Thermoplastic Resistance Welding Process Modeling}

Several models of the resistance welding process have been developed by researchers in the area of composite materials. Jakobsen et al. developed a 2-D transient thermal model that predicts melting times of APC-2 laminates [4]. A 3-D model used by Ageorges et al. [5], [6] predicted 'time to cause thermal degradation'. Identifying the process window defining the range of temperatures and pressures that achieve a sound weld was accomplished by Colak et al. using a 1-D model [7], and a 2-D model by Stavrov et al. [8]. Xiao and Hoa used a 2-D model as a guideline for selecting process parameters [9].

The models mentioned above were created using a stationary heat source and as such are not suitable for long weld control application where the tool moves. Lambing et al. designed and manufactured a welding machine, using several strips of heating elements to create a weld path [10]. Holmes et al. developed 1-D and 2-D models for large-scale applications [11]. However, for large-scale applications, such as wing sections, a sequentially moving power source is required to reduce time. 


\subsubsection{Control of Weld Processes}

The welding process poses several challenges such as distributed parameters, uncertainties, nonlinearities and lack of proper temperature measurement techniques. As a result, the recent research has focused on adaptive control schemes and fuzzy logic as an alternative to simplistic classical controllers [12], [13].

In a welding process, it is often desired to control the temperature of the weld. If the materials being welded do not reach their melting points, no bond will exist. However, there are other existing factors, specifically in resistance welding where the pressure applied to the workpieces is important to melt the two materials into each other. In spot welding there is the issue of displacement and thinning out of the welded materials. Each welding process has its unique parameter set, however the one common variable is the melting temperature of the materials.

Automatic Voltage Control (AVC) is used in the control of Gas Tungsten Arc Welding (GTAW) processes. The main objective is to maintain a constant arc length between the non-consumable electrode and the workpiece [12]. For specific shielding gases the arc length is a function of the arc voltage. This allows indirect control of the arc length by controlling the arc voltage. A specified arc voltage is programmed into the control unit, and the voltage across the arc is measured. These two voltages are then compared, and if there is a difference between the two (within a specified tolerance) the drive dc servomotor will move the electrode closer or further away from the workpieces to bring the measured arc voltage to the preset value [12].

Direct Model Reference Adaptive Control's (MRAC) objective is to have the plant output track a desired model output so that the error between the model and real system outputs is zero [13]. Ozcelik, Moore, and Naidu [13] used a fifth order nonlinear model for GMAW developed by the Idaho National Engineering and Environmental Laboratory (INEEL). The model was then linearized about some steady-state condition so that a linear time invariant (LTI) adaptive controller could be developed. The controlled variables are the wire feed speed and open-circuit voltage. The plant outputs are the arc 
voltage and current. An error signal is generated for both the arc voltage and current based on the online measurements and used as the inputs to the MRAC controller. The outputs of the MRAC controller, also known as the control variables, are respectively the displacement and velocity of the wire droplet.

Koseeyaporn, Smithmaitrie, and Cook combined MRAC techniques with a fuzzy logic controller for a GTAW process [12], [14]. The reference model used was developed by Bjorgvinsson (1992) for AVC. This controller actually utilizes two fuzzy logic controllers, as can be seen in Fig. 1.1.

One loop contains a direct fuzzy logic controller (FLC) which uses the arc voltage error and its derivative as inputs and outputs the servomotor voltage signal. The servomotor is used to control the distance of the electrode to the workpieces. Triangular membership functions were used, and the min-max inference and Center of Gravity (COG) defuzzification methods were used [14].

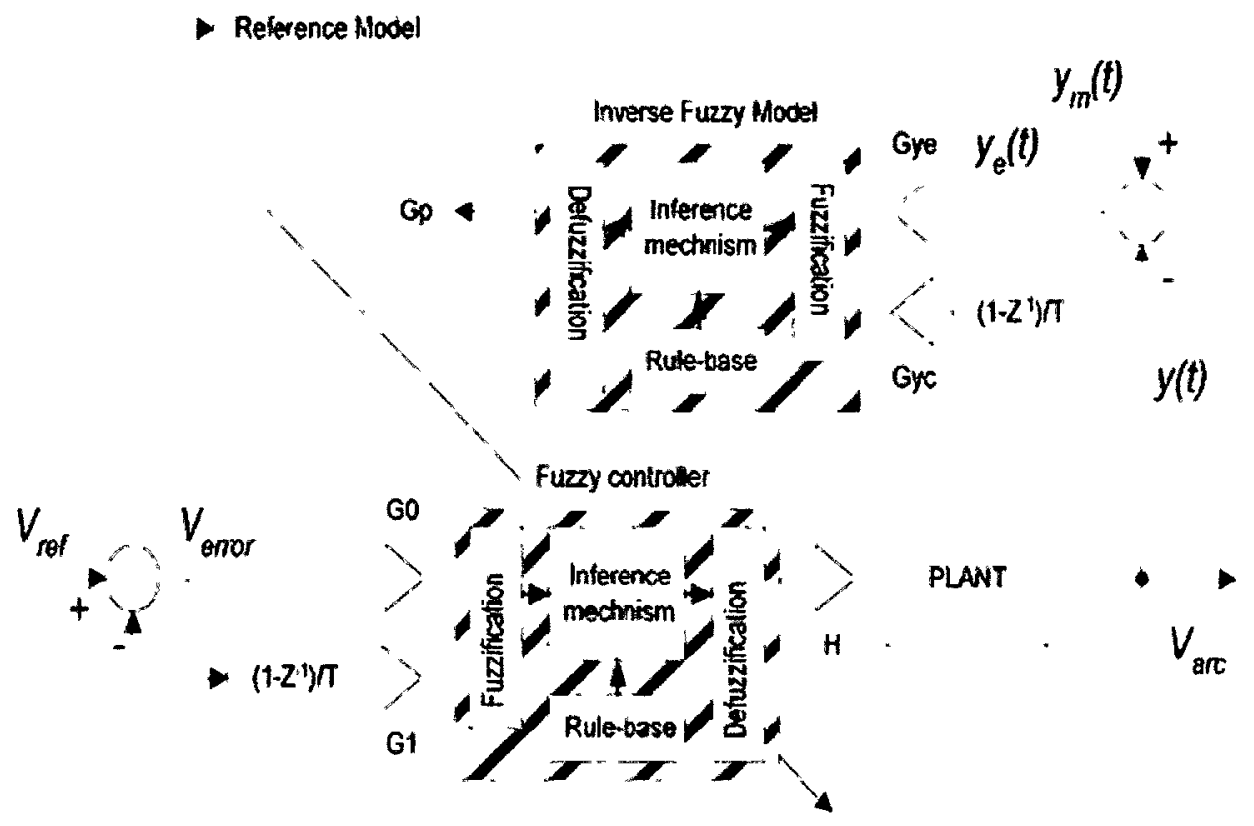

Figure 1.1 - Adaptive fuzzy control layout for in GTAW [14]. 
The outer loop contains what is known as the inverse fuzzy logic model. The inputs are the difference between the arc voltage and the model arc voltage, and its derivative [12]. Using its own rule-base, the inverse fuzzy model quantifies these errors and error rates. According to this, it will change the rule base of the direct fuzzy logic controller by means of a knowledge-based modifier. This allows the inverse fuzzy logic model to continuously change the rule-base of the direct fuzzy logic controller so that the output of the plant follows the reference model output.

Neural Networks (NN) have been proposed to be used to model welding process. They take inputs to a process at their input layers, and generate the outputs by means of pre-set weighting factors and activation functions without relying on the physics model of the process [15]. However, sufficient real input and output data are required to train the network by finding the optimum weights and biases to accurately represent the system.

The work of Messler, Jou, and Li [15] was in the control of resistance spot welding. They used a neural network in conjunction with a fuzzy logic controller to control electrode displacement and speed, where both parameters can be used to infer nugget diameter [16]. The nugget diameter is the diameter of the welded region in a spot weld. The inputs to the fuzzy logic controller are the difference between actual electrode displacement and the desired displacement, $D e$, and the electrode velocity error, $V e$. A simplified block diagram of the process is shown in Fig. 1.2.

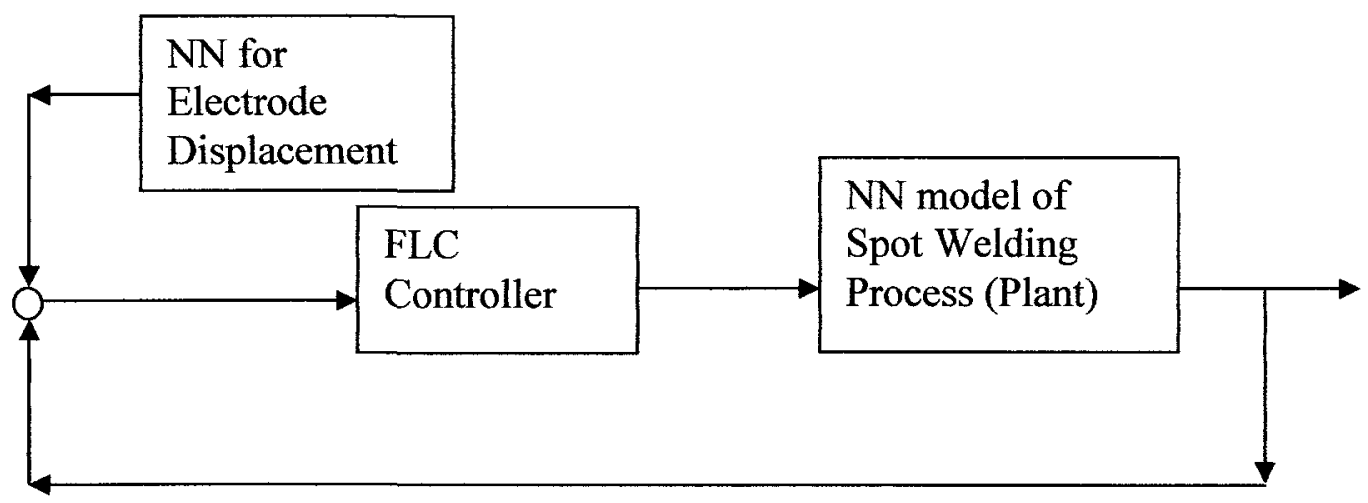

Figure 1.2 - Simplified block diagram showing inputs and outputs for the FLC [15]. 
The fuzzy rule base contains seven regions of membership. The welding process is controlled in two regions. The first region takes place after the initial softening of material due to a nominal heat input. The percent heat input is adjusted according to both electrode displacement and velocity, and is thus the reason for the large rule base. In the second region, the percent heat input is adjusted only according to the electrode displacement, as the electrode velocity is significantly reduced in this region. The authors used triangular membership functions normalized between 0 and 1 , and used the Centerof-Gravity (COG) method to defuzzify the signal to be used by the real process [15]. The COG method takes a weighted average of all possible non-zero outputs from the rule base and uses this as an output of the system to decide how it should adjust the heat being added to the process [15].

In terms of the control, the controllers presented for welding processes are adaptive or use fuzzy logic. There is little in the way of classic control, such as PID. The high non-linearity of the welding processes involved coupled with multiple variable control in most of the cases described above require a more complex control approach. On the process side, the vast majority of research being conducted in the resistance welding of thermoplastic composites seems to be in the area of static welding. This means that there is no movement of the electrodes, and thus no movement of the heat source used in the welding process. For large scale applications, a moving heat source is required to weld large components. With composite use among airline manufacturers on the rise, welding of large components such as wings would need a more practical welding approach. The research behind this thesis tries to expand on Lambing et al [10] and Yousefpour et al [1] works on the automation of the process, but applied to large scale components. The welding of thermoplastics in a continuous manner is the direct focus of this thesis. The approach is to understand the heat transfer and electrostatic physics behind the process, and using closed-loop control to improve the quality of the weld in a repeatable manner which is required for full-scale automation and implementation. 


\subsection{Major Challenges}

Resistance welding of thermoplastics comes with its own unique challenges. One of the major objectives of this work is to implement an online controller that will regulate the centerline weld temperature. Ideally, the temperature would be measured online and used as a feedback signal to generate an error signal with some reference temperature. However, in resistance welding thermoplastic materials, this is not a trivial task. This is because the two materials to be welded are sandwiched together under pressure. This makes it impossible to directly measure the weld interface temperature during the weld. Since the temperature cannot be directly measured it must be estimated in some way. To achieve this, a linear model was used in the feedback to estimate the weld temperature. The 3D FEM model was linearized about the controller operating point to generate a linear model that could be used online. The input to the linear model was the electrical current and the output is an estimate of the centerline temperature. The limitation of this approach is that once the electrical current is not within the linearized region, the linear model will no longer predict the temperature accurately. However, this approach does give the ability to investigate whether control based on estimated temperature is a feasible goal.

\subsection{Research Objectives}

The main objective of this research is to develop a control strategy and implement it for the temperature control of composite welding with a moving heat source. The following objectives were specified:

- To modify the existing resistance welding setup for large scale automation using an industrial robot.

- To develop a numerical model based on the thermal and electrical behavior of the process that can be used to estimate the weld temperature. 
- To design and implement a real-time closed loop controller using the estimated temperature as the feedback signal.

\subsection{Research Contributions}

The research contributions presented in this thesis are the following:

1. Adapted the continuous resistance welding of thermoplastic process developed at NRC-AMTC for automation using modern industrial robots to complete the task.

2. A three-dimensional FEM model of thermoplastic resistance welding was created, using COMSOL Multiphysics, which incorporates the electrostatic behaviour of the process coupled with the heat transfer characteristics of the welding process. This model can be used to test control strategies for weld-temperature control.

3. Developed an approach to estimate the weld temperature online based on the linearization of the three-dimensional FEM model.

4. Proposed and verified in simulation a Fuzzy Logic-based controller for the resistance welding of thermoplastic composites.

5. The fuzzy logic controller was programmed in C-language and implemented in real-time using the real-time operating system QNX running on a RT-Lab ${ }^{\mathrm{TM}}$ system. The online control of the process using fuzzy logic techniques was successful in controlling the heating element temperature of the weld.

\subsection{Thesis Outline}

\section{Chapter 2: Thermoplastic Resistance Welding}

The theory behind resistance welding is outlined. The existing methods of static resistance welding for thermoplastic materials is described. This chapter further describes 
the NRC patented continuous welding process for thermoplastic materials and the implementation of this continuous process using an industrial robot. Some modifications to the existing NRC setup are also presented.

\section{Chapter 3: Process Modeling and Validation}

A three-dimensional multiphysics model of the process is introduced. This section is split into two parts. First the electrostatic behaviour of the welding process is created in COMSOL and verified with experiments. Secondly, the heat generation as a result of Joule heating is coupled with the electrostatics and the results also verified with experiments.

\section{Chapter 4: Process Control}

The control objectives are defined and an introduction into fuzzy logic control follows. A linearized model based on the three-dimensional FEM model was created for online estimation of the weld temperature. The development of a fuzzy logic controller to control the process is presented followed by the simulation results used to verify the controller.

\section{Chapter 5: Real-Time Control Implementation}

A fuzzy logic controller is implemented into the experimental setup using Opal RT-Lab ${ }^{\mathrm{TM}}$ running QNX. All process loops are defined. Modifications to the fuzzy logic control are done after a set of initial experiments. The final fuzzy logic controller is then implemented and experimental closed-loop results are compared with open-loop results. 


\section{Chapter 2}

\section{Thermoplastic Resistance Welding}

\subsection{Intellectual Property Overview}

The resistance welding process for thermoplastic coupons is patented by the National Research Council of Canada (NRC) under international patent application No. PCT/CA2005/000529 (inventors A. Yousefpour, M.-A Octeau). The patent describes the resistance welding process for welded lap joints. The work in this thesis expands on this work by modifying the patented setup to weld large scale "Tee" joints using industrial robots.

\subsection{Resistance Welding Overview}

Resistance welding is a type of welding method in which heat is generated by the resistance to the electrical current being passed through the thickness of two or more materials. Sustaining this heat generation will cause the materials to melt, which upon cooling bond together. There are three major process parameters involved: heat, pressure, and compaction time. Heat $(\mathrm{H})$ is generated in the form of resistive (Joule) heating, which is a function of both the weld current (I) and electrical resistance (R):

$$
H=I^{2} R
$$


The pressure is applied for the duration of the entire welding process including before and after the application of electrical current. Before the weld, pressure is applied to the workpieces to create a full contact between them to allow the current to pass. During the weld, when the current is passed through the heating element, the applied pressure causes the melted zones of the workpieces to flow into each other. Once the electrical power is turned off, the pressure is applied to ensure that upon cooling, the two locally melted workpieces solidify together. This last step is key to ensure proper fusion [17].

The compaction time is broken down into two time frames: the weld, and postweld times. The weld-time is the amount of time that the electrical current is passed through the workpieces. It dictates the energy input to the weld. If the weld-time is too long, the workpieces will burn, and if too short, no melting or bond will be created. The post-weld time is defined as the time that the applied pressure is held after the electrical power has been switched off. Too short of a time frame could result in a poor bond due to the fact that the materials did not have adequate time to cool past their solidification temperature.

\subsection{Static Thermoplastic Resistance Welding}

The resistance welding of thermoplastic materials requires additional components than the traditional resistance welding described above. The weld stack for the process is shown in Fig. 2.1. Sandwiched between the two composite laminates is a stainless steel mesh, with a resin film on either side of it. The stainless steel mesh is referred to as the heating element [28]. An electrical current is passed along the heating element by means of copper electrodes located at the ends of the stainless steel mesh. Joule heating occurs in the heating element and gets subsequently transferred to the adjacent resin films and thermoplastic laminates [28]. Since the heating element is different from the thermoplastic composite, resin films, which are typically the same as the resin used in the laminate, are used to impregnate the heating element to achieve material compatibility on the molecular level after bonding [18]. Applying pressure during the process is required 
in the same manner as traditional resistance welding. Once the power is applied and a bond is formed the excess heating element around the workpiece is then removed.
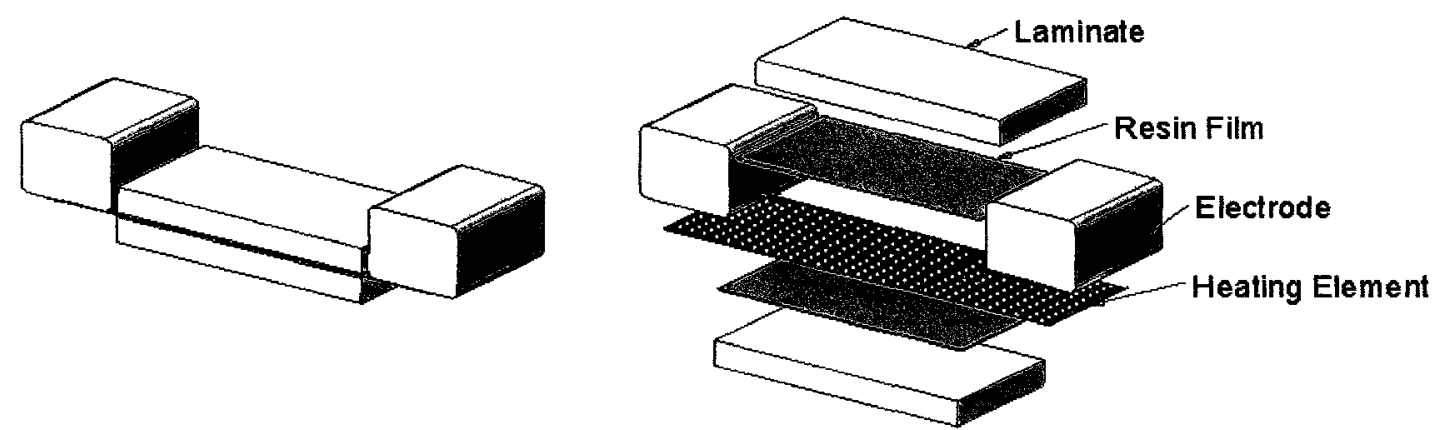

Figure 2.1 - Thermoplastic resistance welding stack.

\subsection{Continuous Thermoplastic Resistance Welding}

Manufacturing large-scale thermoplastic components requires a continuous repetition of the static resistance welding process described above. It requires a moving power source to supply the energy to subsequent weld sections, as well as a moving pressure source to continuously apply pressure to the weld sections for the proper amount of time. The weld stack is the same as the static process except that the overall length of each component is longer.

At the Aerospace Manufacturing Technology Centre (AMTC), a laboratory of the Institute for Aerospace Research (IAR) at the National Research Council of Canada (NRC), the approach was to use an industrial robot to perform the continuous movement that the large-scale process requires. A custom end-effector, as shown in Fig. 2.2, was designed by the inventors of the aforementioned patent at AMTC and mounted to the tip of the robot to achieve both a moving power source and a moving pressure source. The moving electrodes are copper slip-rings that can freely rotate about a single axis. They are firmly held in place by a pair of pneumatic cylinders which ensure that on uneven surfaces, the electrodes will not lose contact with the heating element. 
To transmit the electrical power to the heating element continuously, the copper slip-rings were traversed along the exposed portion of the heating element shown in Fig. 2.3. However, heavy sparking occurred between the slip-rings and the heating element. Since the heating element is a fine mesh, the sparks effectively cut the mesh, opening the circuit which resulted in a lack of a weld.

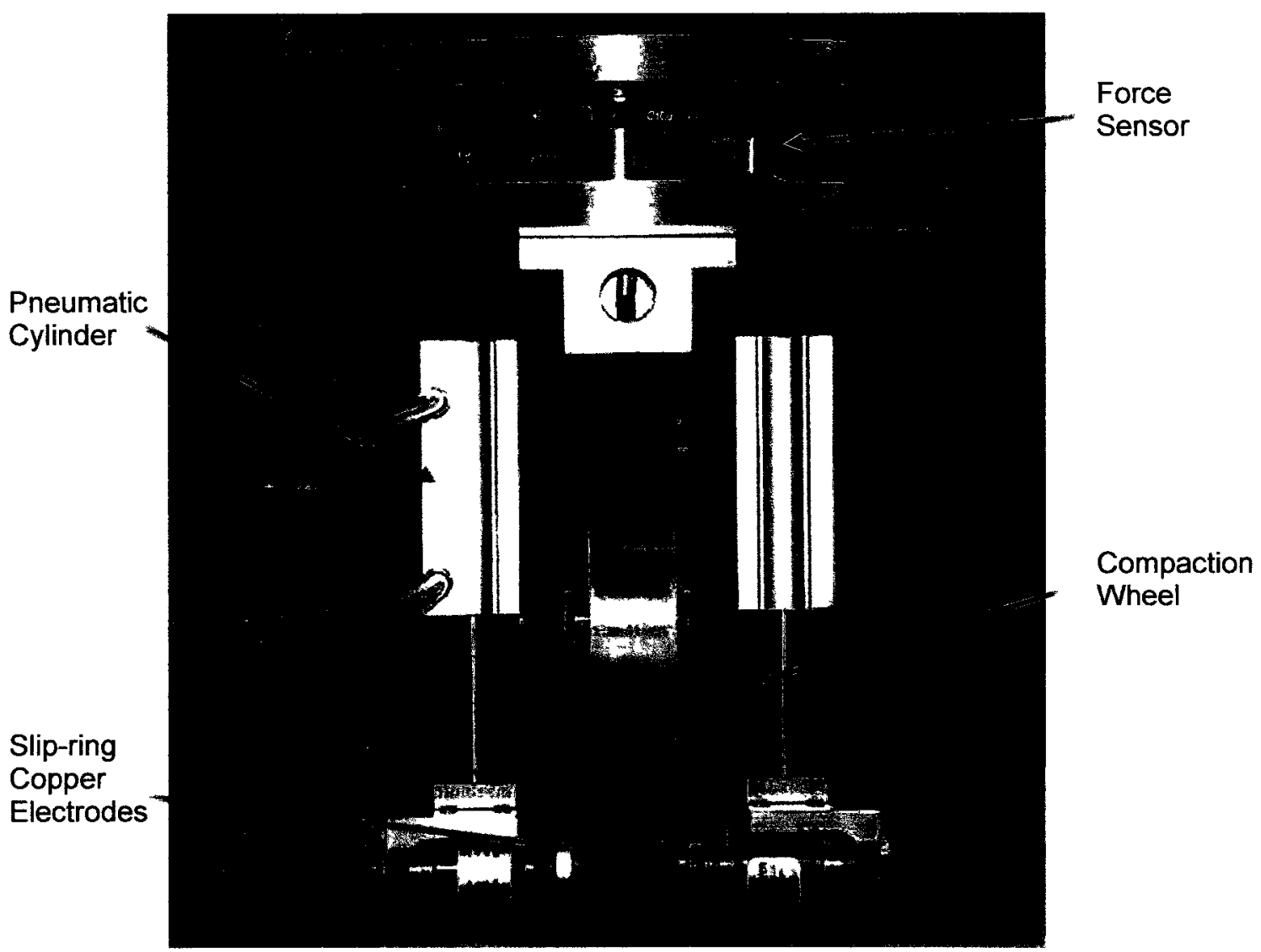

Figure 2.2 - End-effector with copper electrodes and aluminum pressure wheel designed and fabricated at NRC-IAR/AMTC.

To circumvent this problem the copper slip-rings were instead traversed along a set of copper tracks shown in Fig. 2.4. The copper blocks are 0.48 in wide with a gap of 0.02 in between each block. Several copper blocks were used instead of one long copper string to isolate the weld into several sections. One large copper strip would allow the flow of current along the copper strip away from the electrodes resulting in a larger power requirement. As the slip-rings traverse across the copper blocks, the pneumatic cylinders ensure an intimate contact between the copper block and the heating element, which is crucial to prevent sparks from damaging the heating element mesh. The welding 
pressure is controlled via a force sensor located atop the end-effector, shown in Fig. 2.2. The complete weld setup is shown in Fig. 2.5.

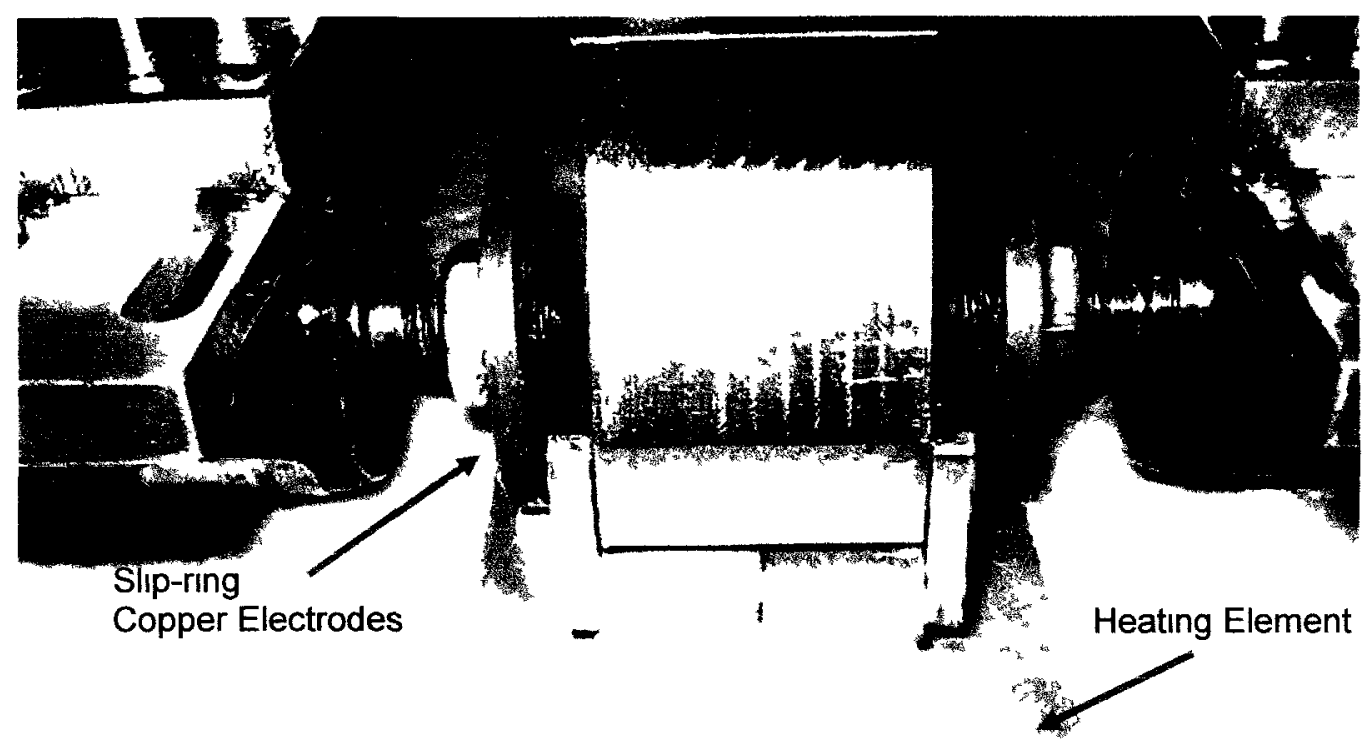

Figure 2.3 - Copper slip-rings traversing directly on the exposed heating element.

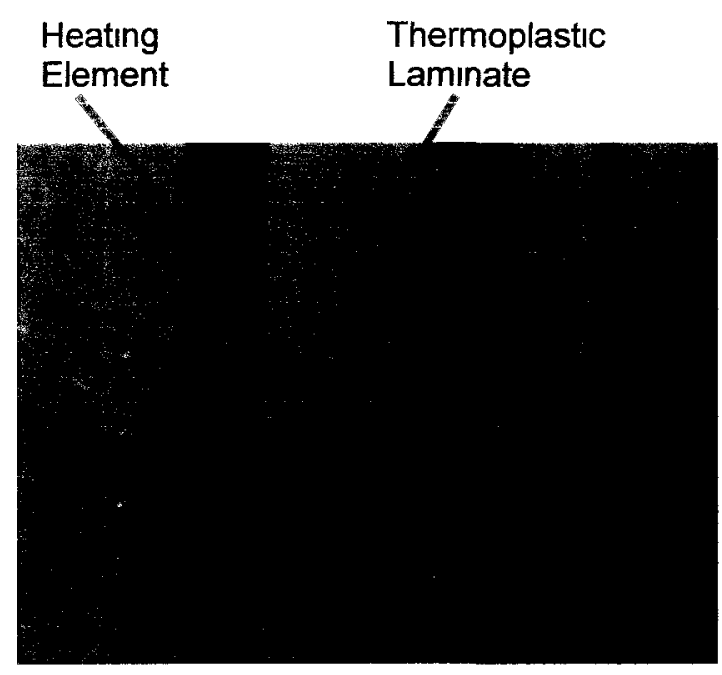

(a)

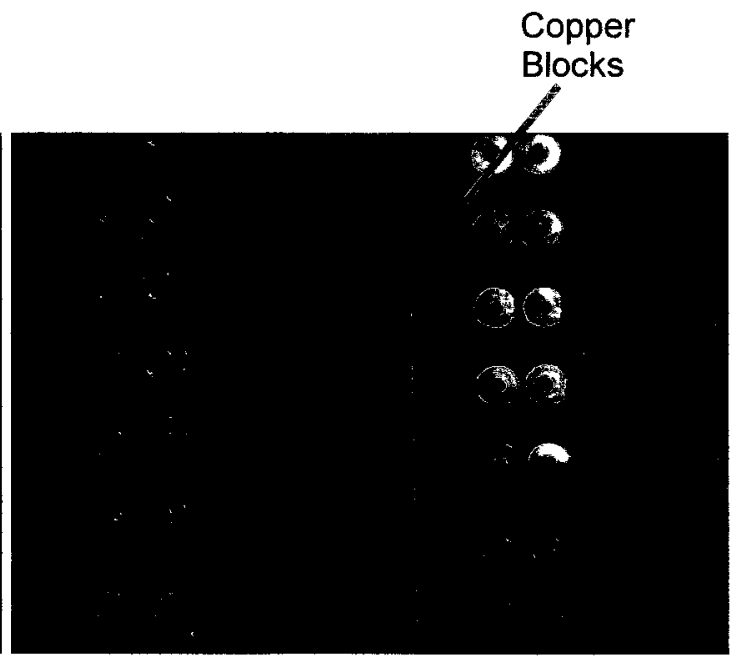

(b)

Figure 2.4 - (a) Top view of weld stack and (b) copper tracks atop heating element. 


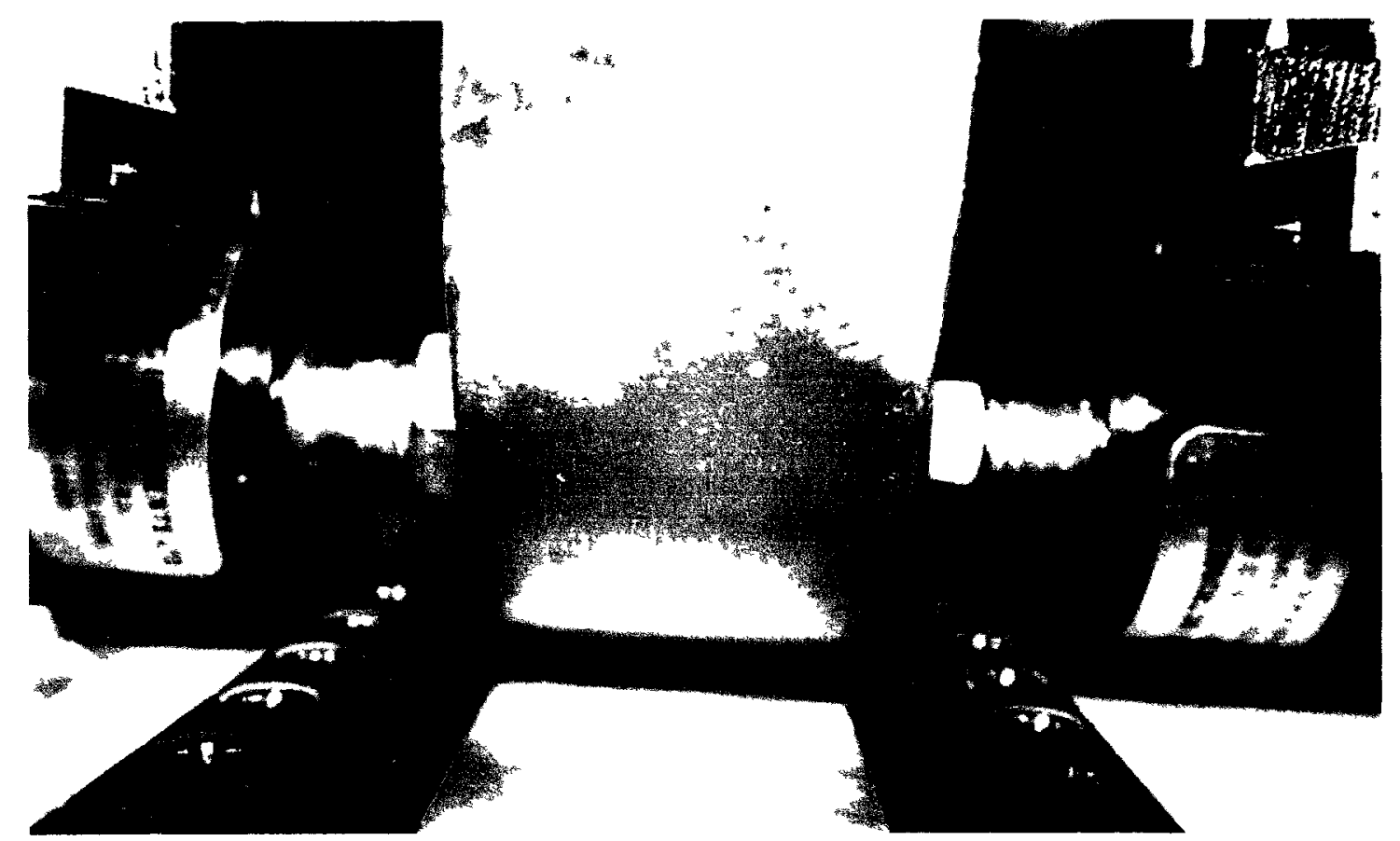

Figure 2.5 - Complete weld setup with copper slip-rings, copper tracks, and compaction wheel.

In the continuous weld setup, the power is applied by setting the voltage rather than the current. This is because when current is controlled, abrupt changes in voltage result in sparks that may damage the mesh. Along with setting the voltage, the power supplied to each weld section is then directly related to the speed at which the slip-rings, and thus end-effector, translate across a single copper block set. Furthermore, the compaction time is then a function of the linear velocity of the robot. As the electrodes pass over a section of copper blocks the amount of time that pressure is applied is reduced if the velocity is high, and increased if the velocity is low. However, traveling at a slower velocity would introduce a higher amount of energy to the heating element, increasing the temperature of the weld zone, and thus requiring a longer compaction time to consolidate properly into a strong bond. To avoid this conflict between velocity and consolidation, the compaction wheel was replaced with a longer compaction track shown 
in Fig. 2.6. The track extends backwards behind the copper slip-rings resulting in a longer compaction time.

The force exerted on a copper block by the pneumatic cylinder caused the copper block track to curve slightly along its length. Sparks resulted due to a small gap between the copper block and the heating element while transitioning between blocks. A secondary, electrically insulative wheel, shown in Fig. 2.7, was installed adjacent to the slip ring to apply the pressure caused by the pneumatic system over a large area, thus preventing a gap while transitioning between copper blocks.

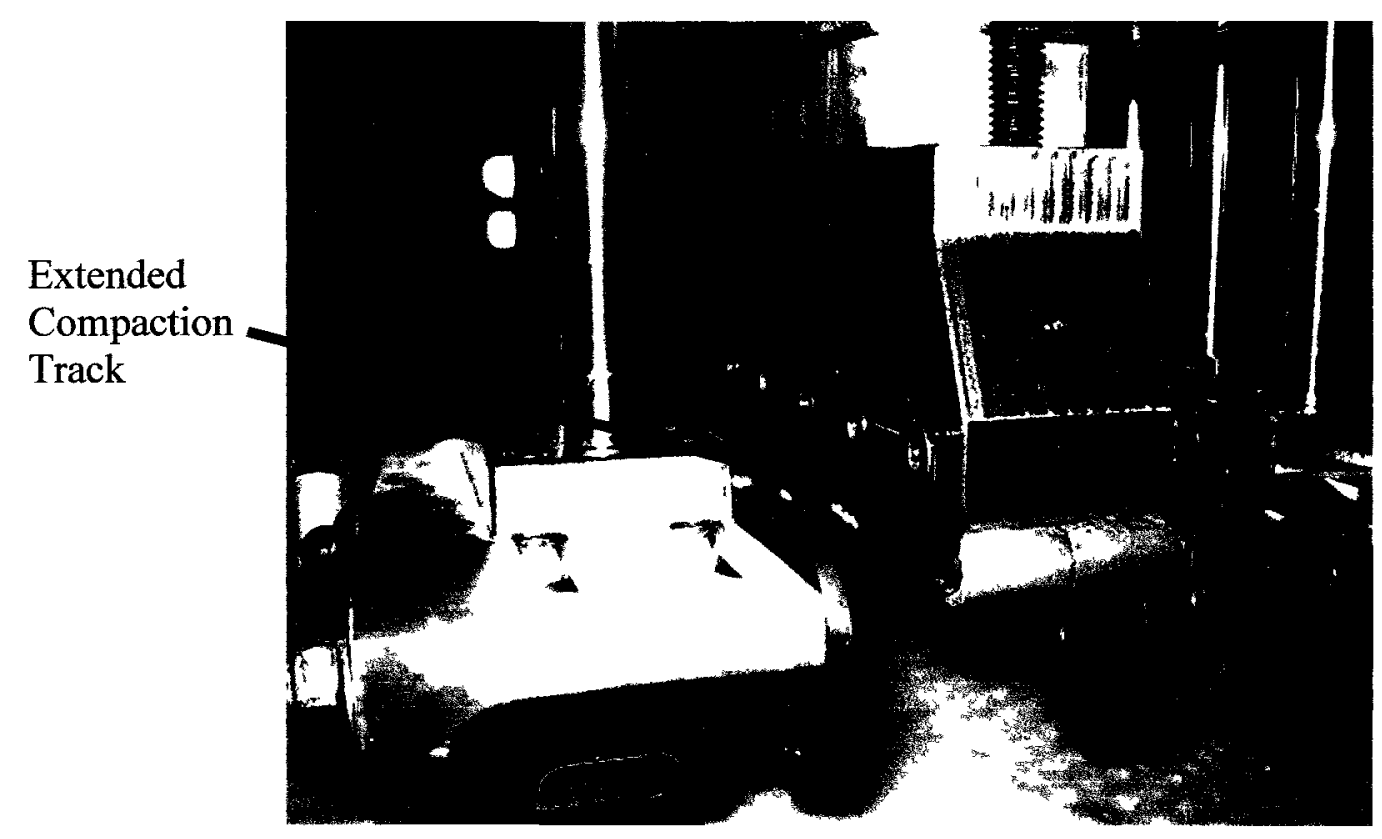

Figure 2.6 - Extended compaction track that provides pressure during a weld operation. 


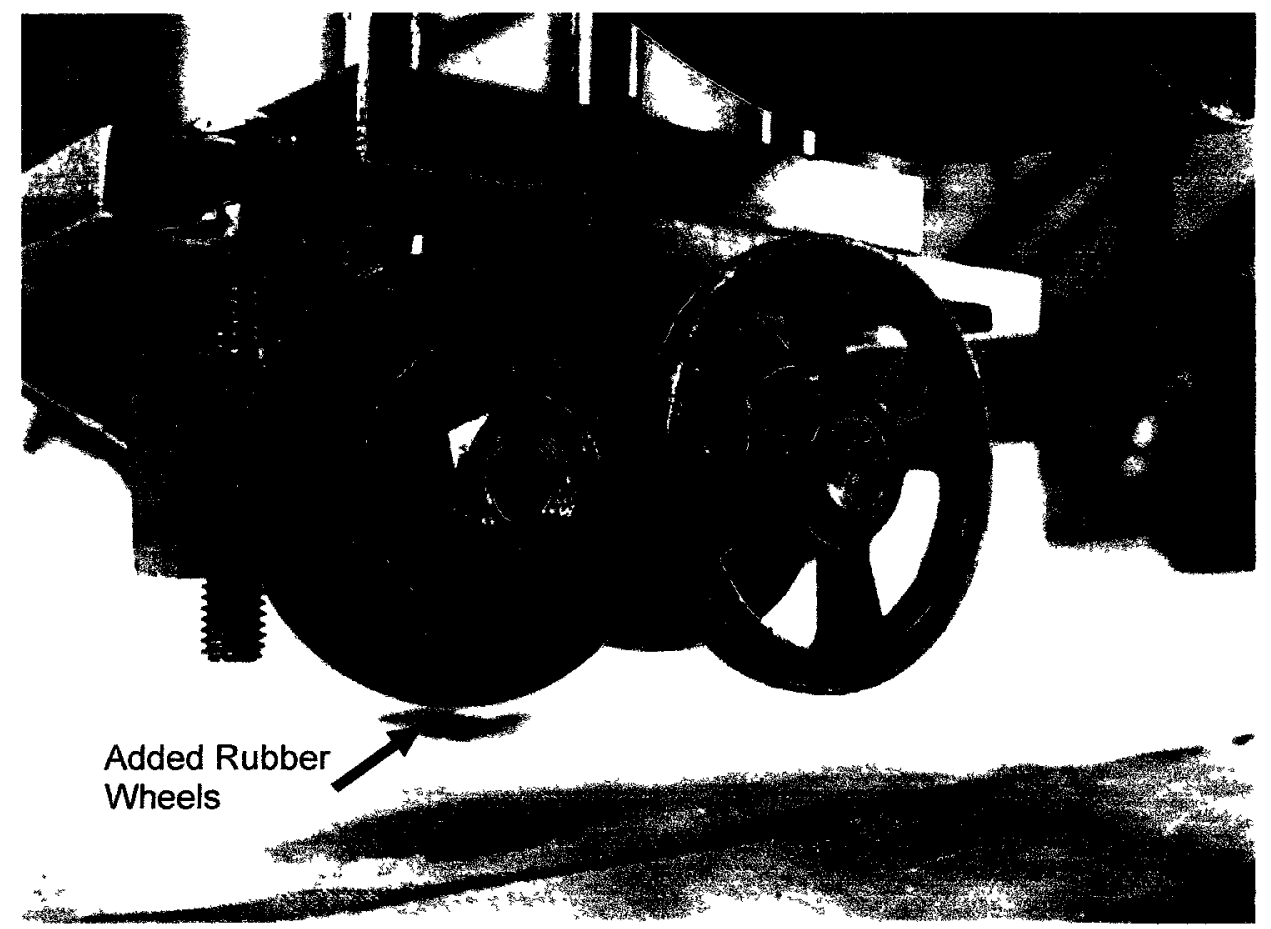

Figure 2.7 - Addition of a rubber wheel to distribute the force from the pneumatics over a larger area to prevent the copper tracks from bending. 


\section{Chapter 3}

\section{Process Modeling and Validation}

\subsection{Modeling Overview}

The purpose of modeling a dynamic process is to understand its behaviour as well as identify some of the key parameters involved in it. One of the most important variables in thermoplastic resistance welding is the temperature at the weld interface. With the weld interface encapsulated inside the thermoplastic laminates, it becomes difficult to get a sense of the weld zone temperature. Thermocouples are one option to measure the temperature. However, they become permanently embedded in the weld stack after welding, requiring cutting and re-twisting after every weld. They also must be electrically insulated to prevent the electrical current from affecting the data. Lastly, the setup of the copper tracks makes it difficult to insert multiple thermocouples along the weld line. The end result is a costly and time-consuming option.

Modeling the process in an FEM model can help in two ways: first it is possible to study the dynamics of temperature at the weld interface, and second, it is possible to see the temperature profile along the workpiece. It provides a visualization of some parameters that are difficult to determine experimentally. An example of this would be the distribution of the current along the length of the weld, and the weld zone

temperature. Model verification would require experiments, but the amount of experiments required to match a model are significantly less than solely performing 
experiments to understand the process dynamics. Under this reasoning, a threedimensional model was created to observe the process dynamics, and validated with experiments.

\subsection{3-D Process Modeling}

COMSOL Multiphysics software is a FEM solver program in which multiple physics can be modeled simultaneously. Two types of physics, "Conductive Media DC" and "General Heat Transfer", were used to model the process. The first was used to define the input voltage to the welding process, while the latter computed the resulting temperatures due to the resistive heating of the stainless steel mesh.

\subsubsection{Model Geometry}

The three-dimensional geometry in Fig. 3.1 has an overall length of $76.2 \mathrm{~mm}$, and a width of $50.8 \mathrm{~mm}$. The heating element, with same overall dimensions, is a 304 stainless steel mesh with a plain weave of $200 \times 200$ wires per square inch and a wire diameter of 0.0021 in supplied by Belleville Wire Cloth. It is sandwiched between two polypropylene strips $76.2 \mathrm{~mm}$ long, $31.75 \mathrm{~mm}$ wide and $0.16 \mathrm{~mm}$ thick. On top of these are two pieces of glass-fibre/polypropylene (PP) composite $2.25 \mathrm{~mm}$ thick, with a fibre volume fraction of $34 \%$. The copper blocks are each 0.48 inches wide with a 0.02 inch gap between each block. They are offset from the composite laminate by $1.0 \mathrm{~mm}$. The grey component in the figure is the 0.375 in thick table that was used to weld the coupon on during experiments. The weld stack is shown in Fig. 3.2. The mesh in Fig. 3.3 used to solve the model was auto-generated in COMSOL. COMSOL does feature an automatic mesh generator, but it created a mesh that did not allow for convergence when solving. Instead the auto mesh feature was used to give an initial mesh and then manually modified and run. This was accomplished several times until the solver converged when solving. The mesh consisted of 44471 tetrahedral elements, with 17010 of those elements contained in the heating element. The heating element is the source of the heat 
generation in the model, and was thus given a much finer mesh to ensure a smooth solution.

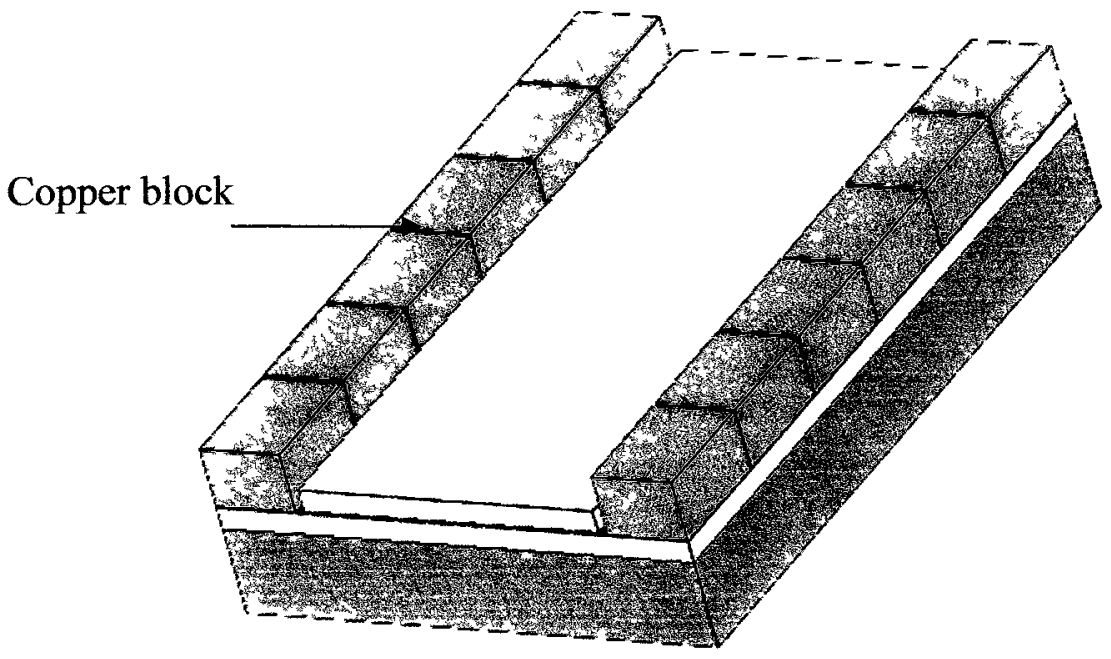

Figure 3.1 - Three dimensional geometry used in FEM modeling of the weld process.

Glass/Polypropylene

Polypropylene

Heating Element

Figure 3.2 - Cross sectional view of the weld stack showing all materials. 


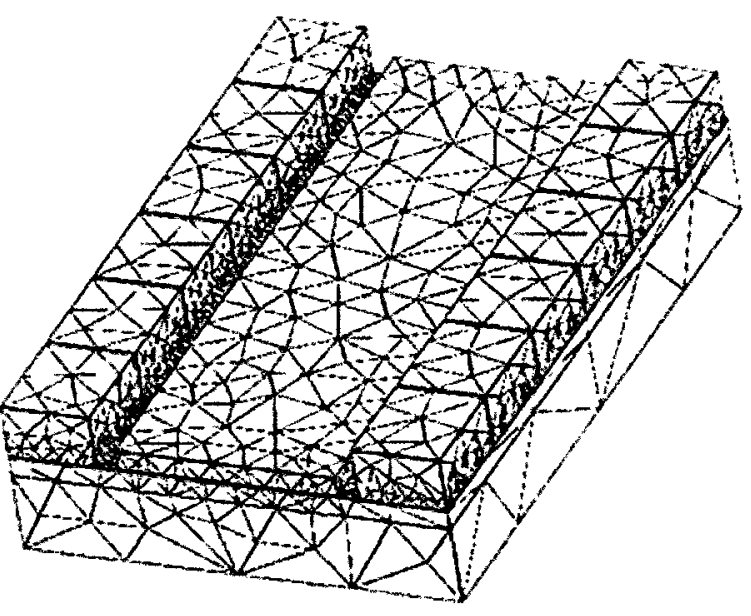

(a)

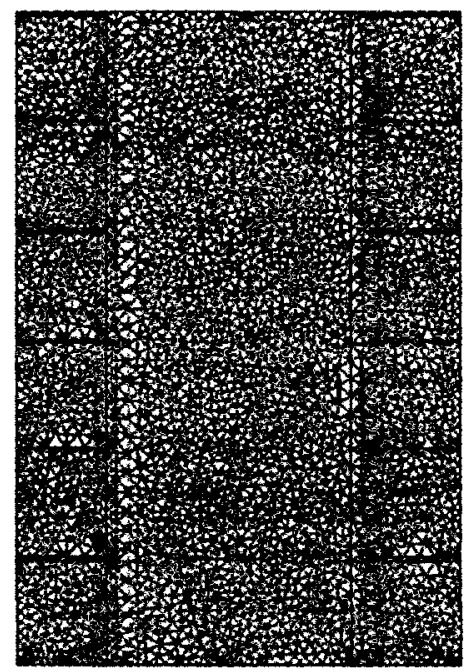

(b)

Figure 3.3 - (a) Triangular mesh of all components (b) Triangular mesh on heating element.

\subsubsection{Electrostatic Modeling}

Ohm's law describes the relationship between the current density at a certain spatial point and the electric field at that point [19]. The differential form of this equation for an isotropic material is

$$
\vec{\nabla}(\sigma \vec{\nabla} V)=0
$$

where $\sigma$ is the electrical conductivity of the material, and $V$ the voltage. The partial differential equation is a function of spatial location only, and not time.

\section{Electrical Conductivity of the Heating Element}

To determine the electrical conductivity of the heating element, experiments were arranged and performed where voltages ranging from $2 \mathrm{~V}$ to $4 \mathrm{~V}$ in $0.5 \mathrm{~V}$ increments were applied to a heating element 0.5 inches wide and one inch long. At two volts, the current was approximately 6.8A, as shown in Fig. 3.4. The electrical conductivity was then calculated using eq. (3.2) [20], where $\sigma$ is electrical conductivity, $l$ is length, $R$ is 
resistance and $A$ is cross-sectional area. Table 3.1 shows the results of the experiments. The average electrical conductivity was 54183 Siemens $/ \mathrm{m}$, and was used as the electrical conductivity of the heating element in the FEM model.

$$
\sigma=\frac{l}{R \cdot A}
$$

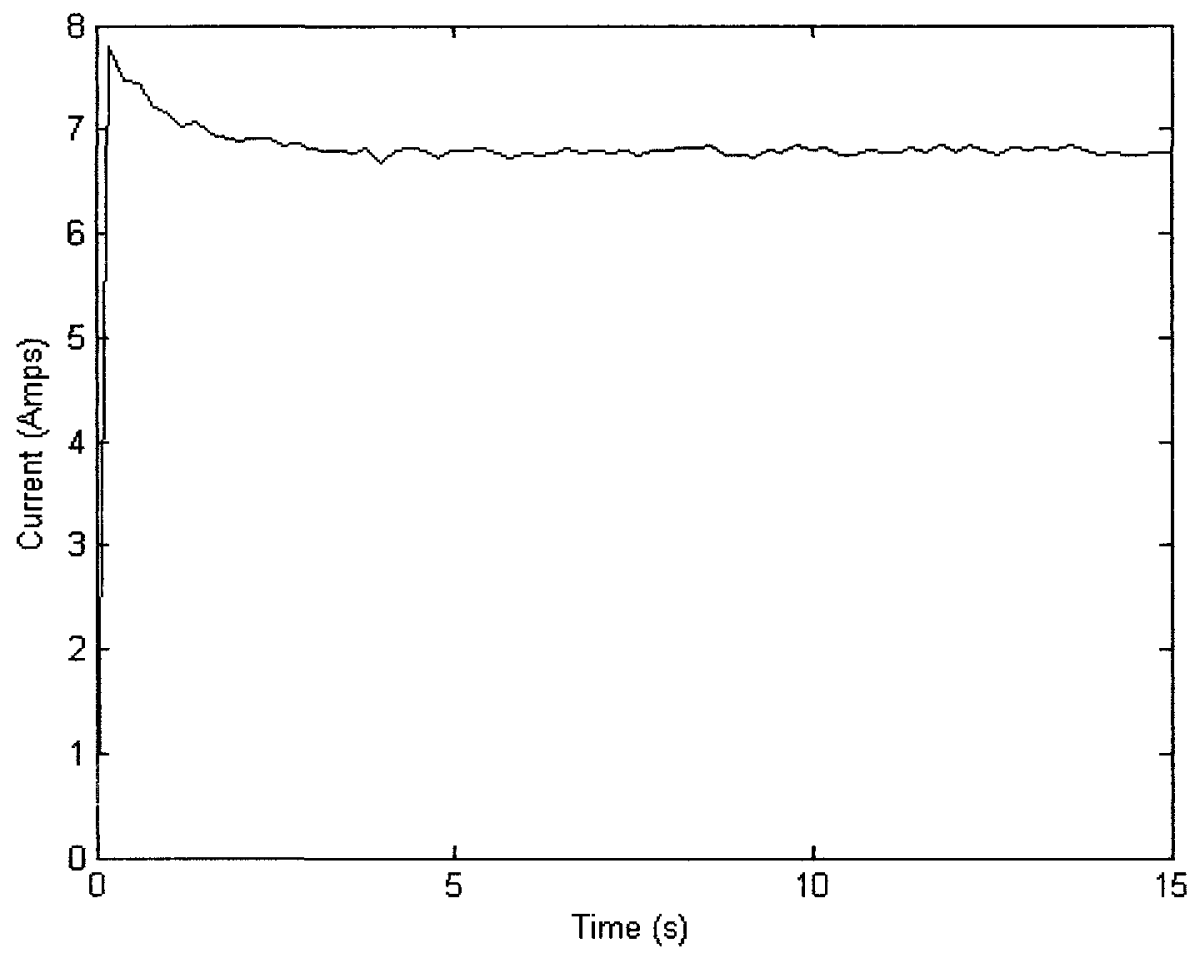

Figure 3.4 - Current measured at $2 \mathrm{~V}$ on heating element 0.5 in by 1 in by 0.0042 in.

\begin{tabular}{|c|c|c|}
\hline Voltage (Volts) & Current (Amps) & $\begin{array}{c}\text { Electrical } \\
\text { Conductivity (S/m) }\end{array}$ \\
\hline 2.0 & 6.8 & 55616 \\
\hline 2.5 & 8.2 & 54388 \\
\hline 3.0 & 9.3 & 52827 \\
\hline 3.5 & 10.7 & 54203 \\
\hline 4.0 & 12.2 & 53882 \\
\hline
\end{tabular}

Table 3.1 - Electrical Conductivity calculated using eq. (3.2) at different voltages. 
The electrical conductivity for all other materials was set to zero, because they are all electrically insulated plastics.

\section{Electrostatic Boundary Conditions}

All boundaries, except for the ones discussed below were set to be electrically insulated, that is no current in or out of the boundary.

Performing a weld requires the movement of the electrodes across the copper blocks. In the model, that translates to shifting the voltage from one pair of copper blocks to the next. To accomplish this, a modified step function that is $\mathrm{C}^{2}$ continuous was used to apply the voltage, and then remove it. Shown in Fig. 3.5 is this function with a step time of one second and a transition step of 0.25 seconds. To achieve a particular voltage, this step function is then scaled by the desired voltage. For a more detailed list of equations used to transition the voltage refer to Appendix A.

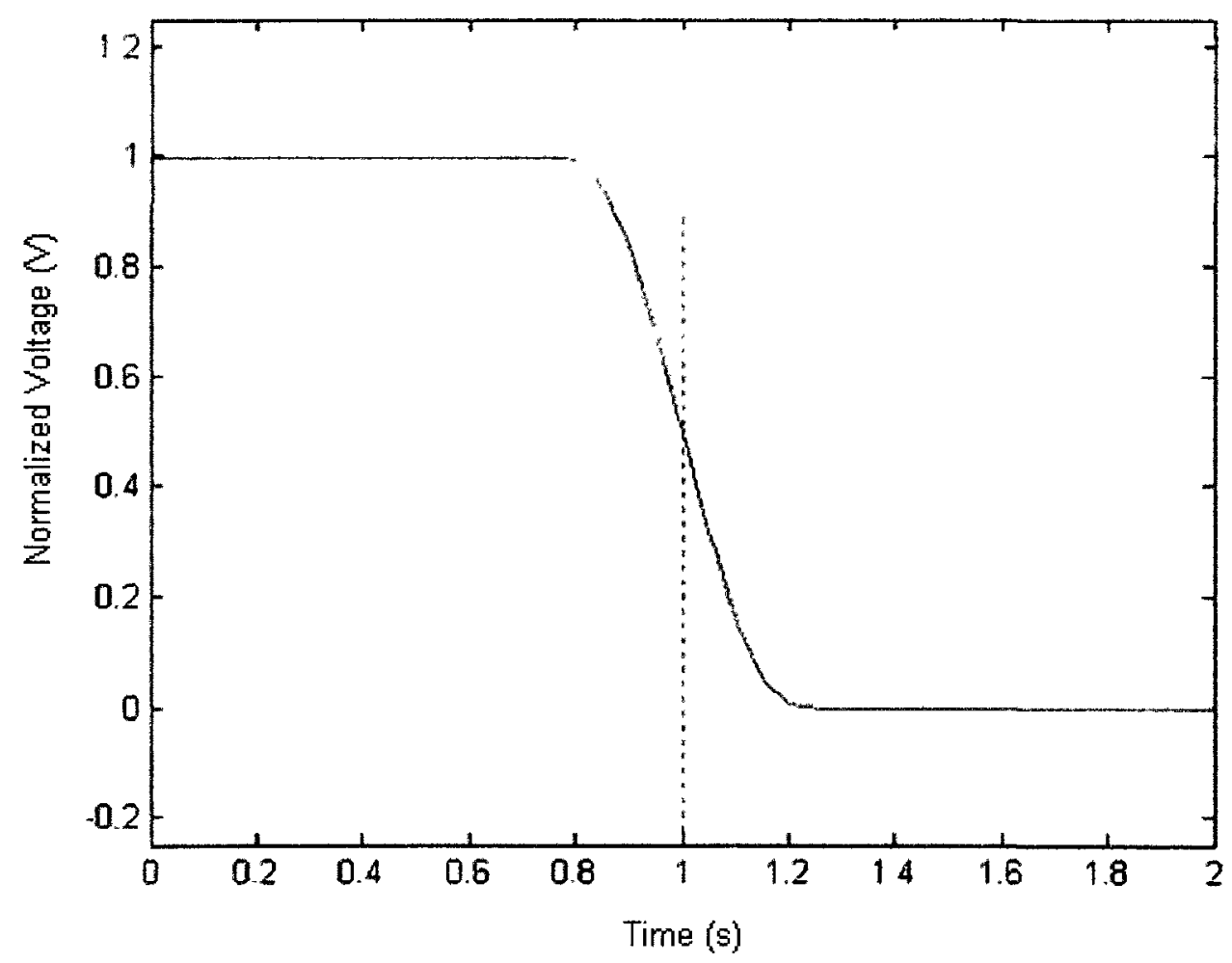

Figure 3.5 $-\mathrm{C}^{2}$ continuous step function used to transition the voltage from on to off. 
The voltage was applied at the interface between the copper block and the heating element rather than atop the copper blocks to ensure that the current flowed across the width of the heating element instead across adjacent copper blocks. The boundary conditions are shown in Fig. 3.6, where each voltage (V) has a corresponding ground (G).

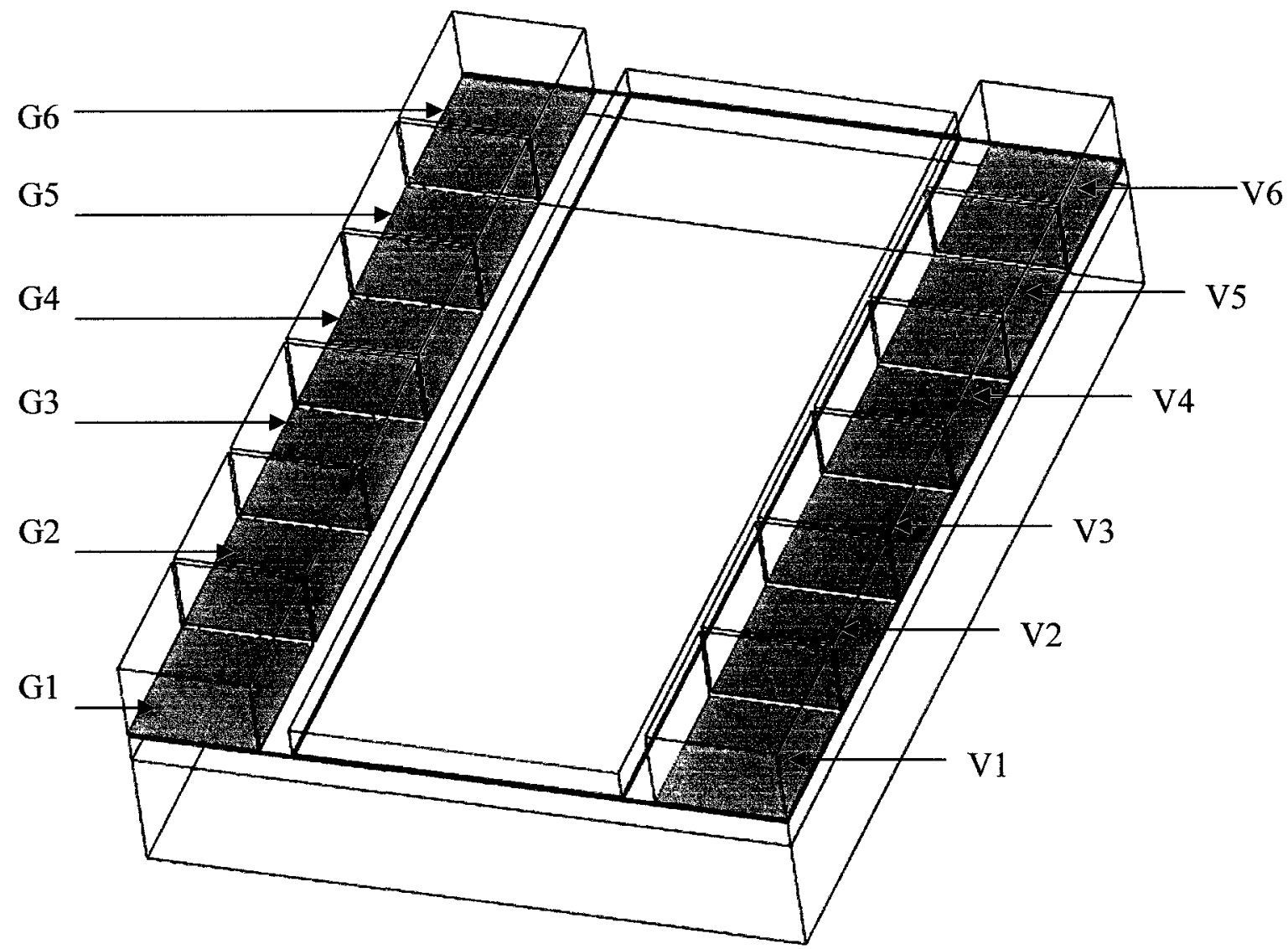

Figure 3.6 - Location of voltage applications in the FEM model. Each voltage (V) has a corresponding ground $(\mathrm{G})$.

A problem was discovered using this technique. For example, if the desired voltage was 4 volts, boundary V1 would be set to 4 volts by multiplying its step function by 4 . However, boundaries V2-V6 have no voltage applied on them yet, so their step function outputs a value of zero volts. This creates multiple grounds in the model, shown in Fig. 3.7. During a weld the ground and voltage source are always located on copper blocks across from each other. The problem with the multiple grounds is that the current 
will divert to the ground adjacent to the voltage source rather than the ground across from it. Therefore, the model exhibits an unreal leakage of current not seen in the process. To correct this issue, the voltage solution option inside COMSOL was used. When solving the model, COMSOL stores the voltage at each node in the mesh as a variable "V". To fix the problem of multiple grounds, each step function, when not active, was set to the solution variable "V", so as to create a continuous voltage field on the mesh shown in Fig. 3.8. For an entire weld, the result is shown in Fig. 3.9.
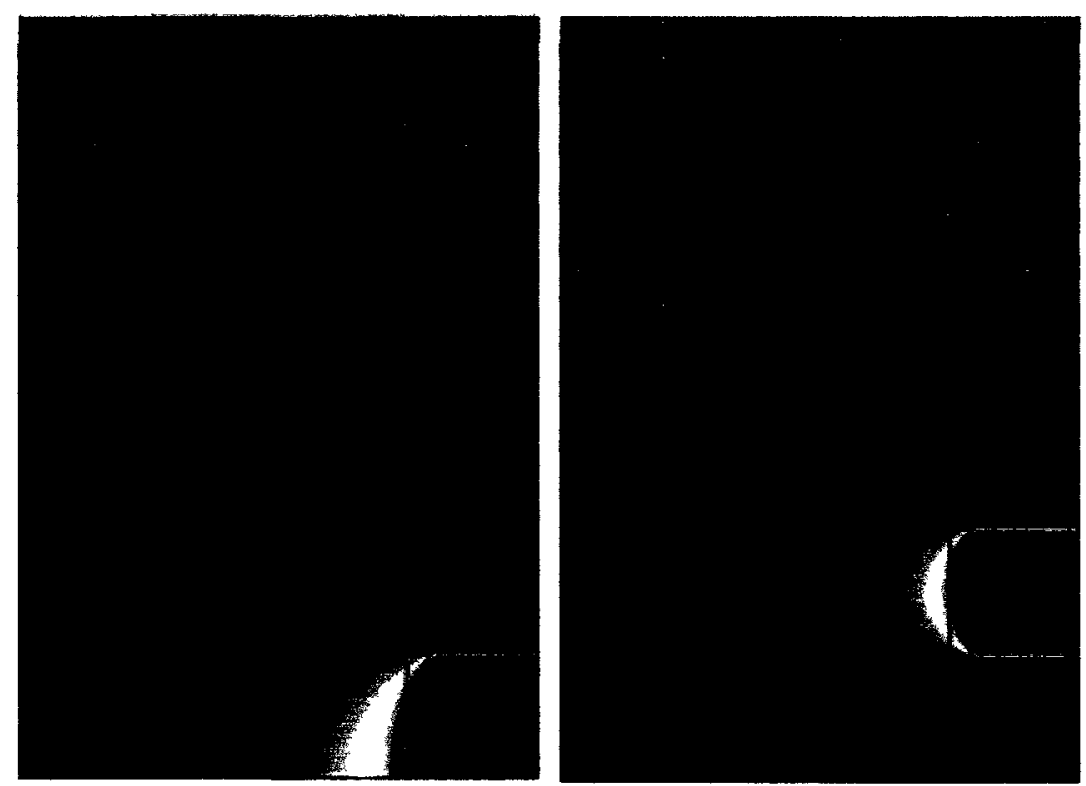

Volts
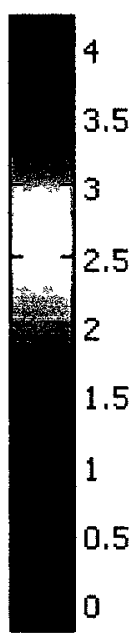

Figure 3.7 - Multiple grounds as a result of using step functions with zero initial output. 


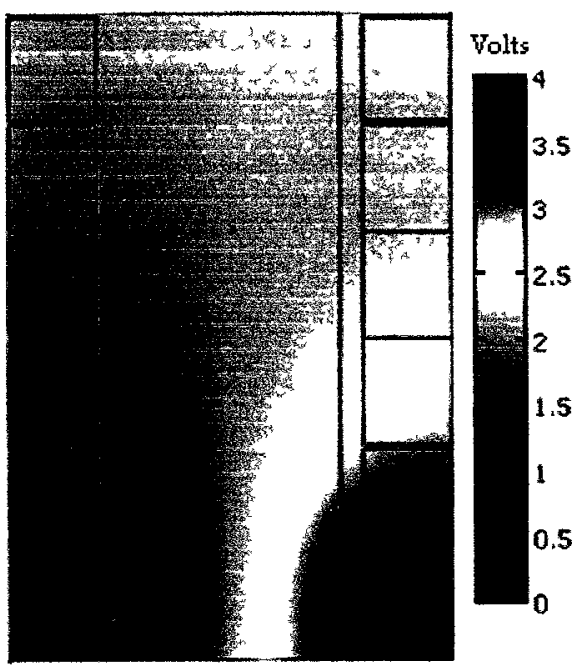

Figure 3.8 - All voltage boundaries set to solution variable "V" when voltage is not directly applied on it.

Figure 3.9 - A weld showing the change in location of voltage over time (last two sections omitted).

\section{Electrostatic Model Simulation Results and Experimental Validation}

During the weld process there exists large and short periodic increases in total current as shown in Fig. 3.12. Each flat portion in Fig. 3.12 represents the electrodes directly on top of the copper block, hence the six flat sections on the figure. As the voltage source transitions from one copper block to the next, there is an increase in the current. If the assumption is made that the resistance is the same across each weld section, shown in Fig. 3.10, then as the electrode passes over two weld sections, the effective resistance is half of the original resistance, $\mathrm{R}$. This lower effective resistance causes the rise in current. 


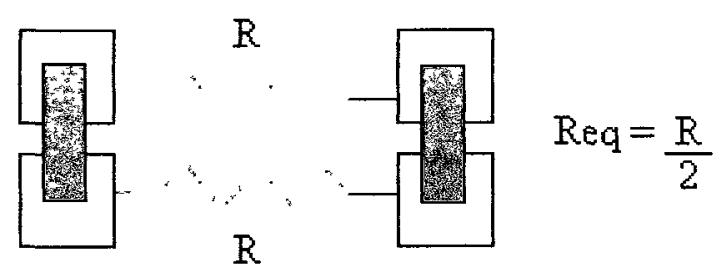

Figure 3.10 - Electrodes transitioning between two copper blocks causing a lower equivalent resistance.

To ensure that the results from the COMSOL model are accurate, a set of validation experiments were performed to compare results. To validate the model, experiments were run using a KUKA 210 robot with the end-effector attached to perform the weld. A Xantec $12 \mathrm{~kW}$ power supply was operated in voltage control mode and with constant voltages set in the robot program as an output. The voltage and current signals were measured using RT-Lab ${ }^{\mathrm{TM}}$, a QNX node that was configured for data acquisition. Figure 3.11 shows the block diagram for the experimental setup. Shown in Figures 3.12 to 3.16 are the comparison between the model and experimental results at five separate voltages ranging from $4 \mathrm{~V}$ to $6 \mathrm{~V}$. The 11 key points on Figures 3.12 to 3.16 are locations in which a change in the current occurred in the model. The current generated during the welding process is a cyclic pattern involving a stable current followed by a brief spike. Table 3.2 displays the percentage error between the model and experimental measurements for these 11 key points shown on Figures 3.12 to 3.16. The error between the model and experiments for each key point is typically below $5 \%$ with the exception of point six. Point 6 on Figures 3.12 to 3.16 depicts the spike in current that occurs during the transition from the third to fourth sections. The average error across all voltages was $10.42 \%$, which is significantly higher than the other points. Also at point 6 , the current spike in the experimental value lags that of the model. This was due to a manufacturing defect in the copper blocks. The third copper block was shorter than the rest, and the fourth one was slightly longer. The result was a slight delay during the transition from third to fourth block that fixed itself by the end of the fourth block. In the model, the electrical conductivity of the heating element was not temperature dependent. The higher 
error could have been attributed to the fact that the resistance did increase slightly as the heating element became hotter.

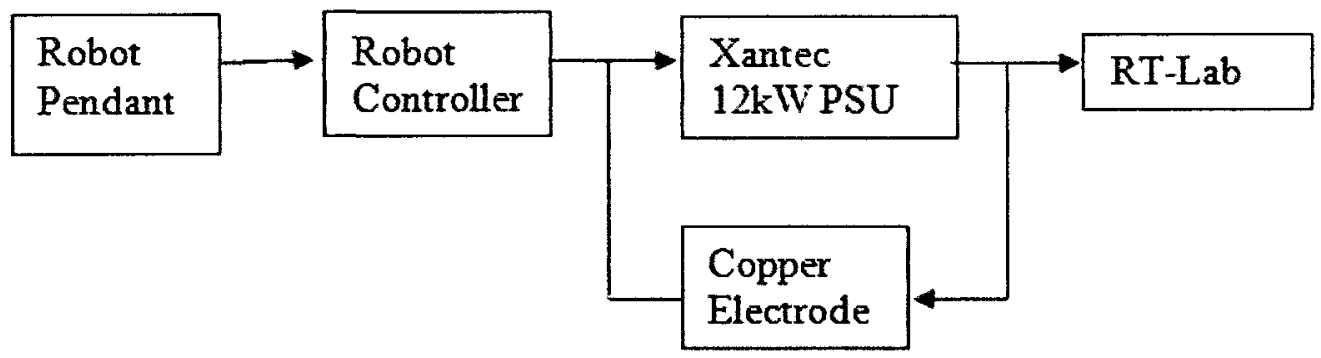

Figure 3.11 - Block diagram of hardware used in the experimental setup.

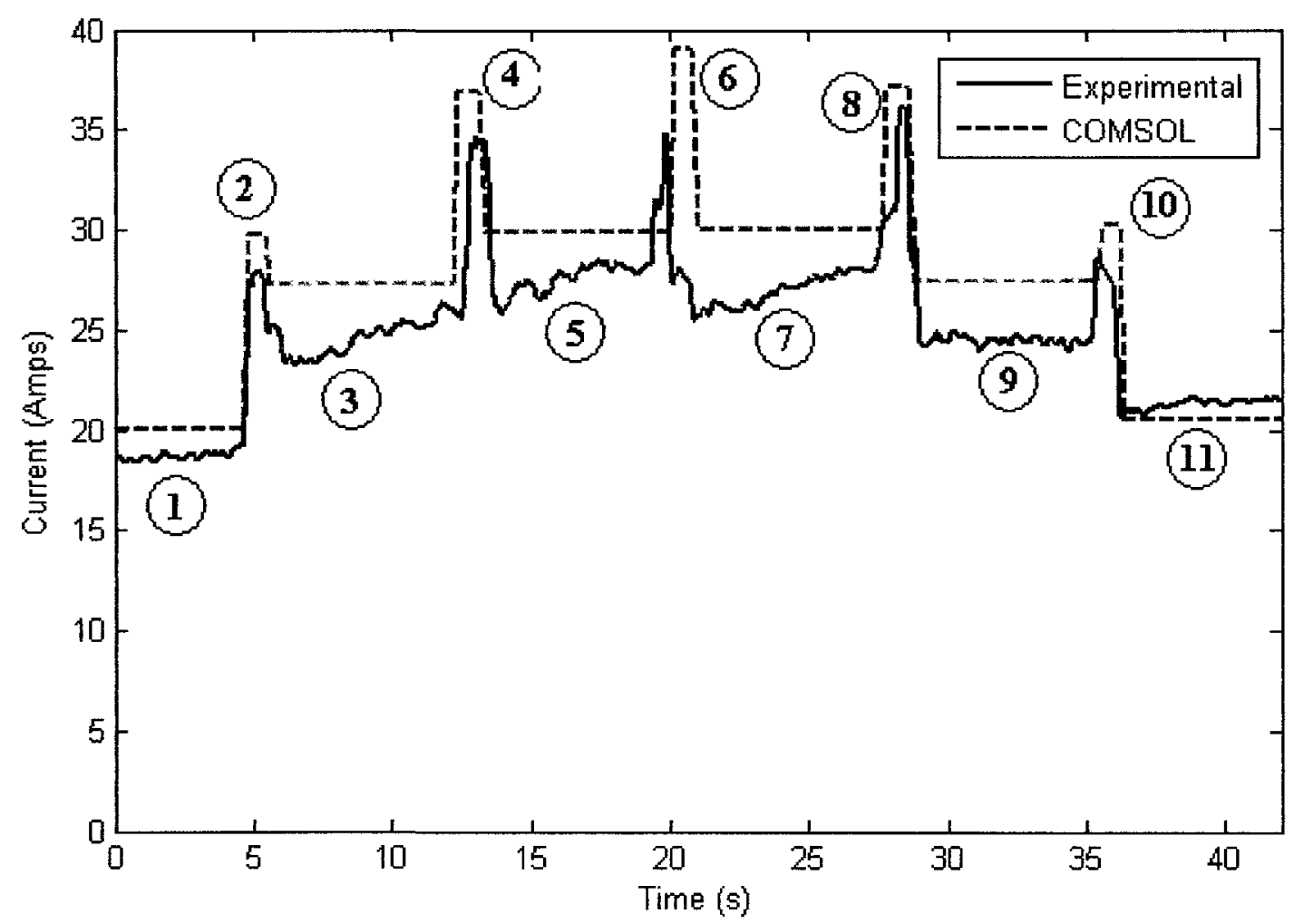

Figure 3.12 - Current comparison between $\mathrm{COMSOL}$ and experiments at $4 \mathrm{~V}$. 


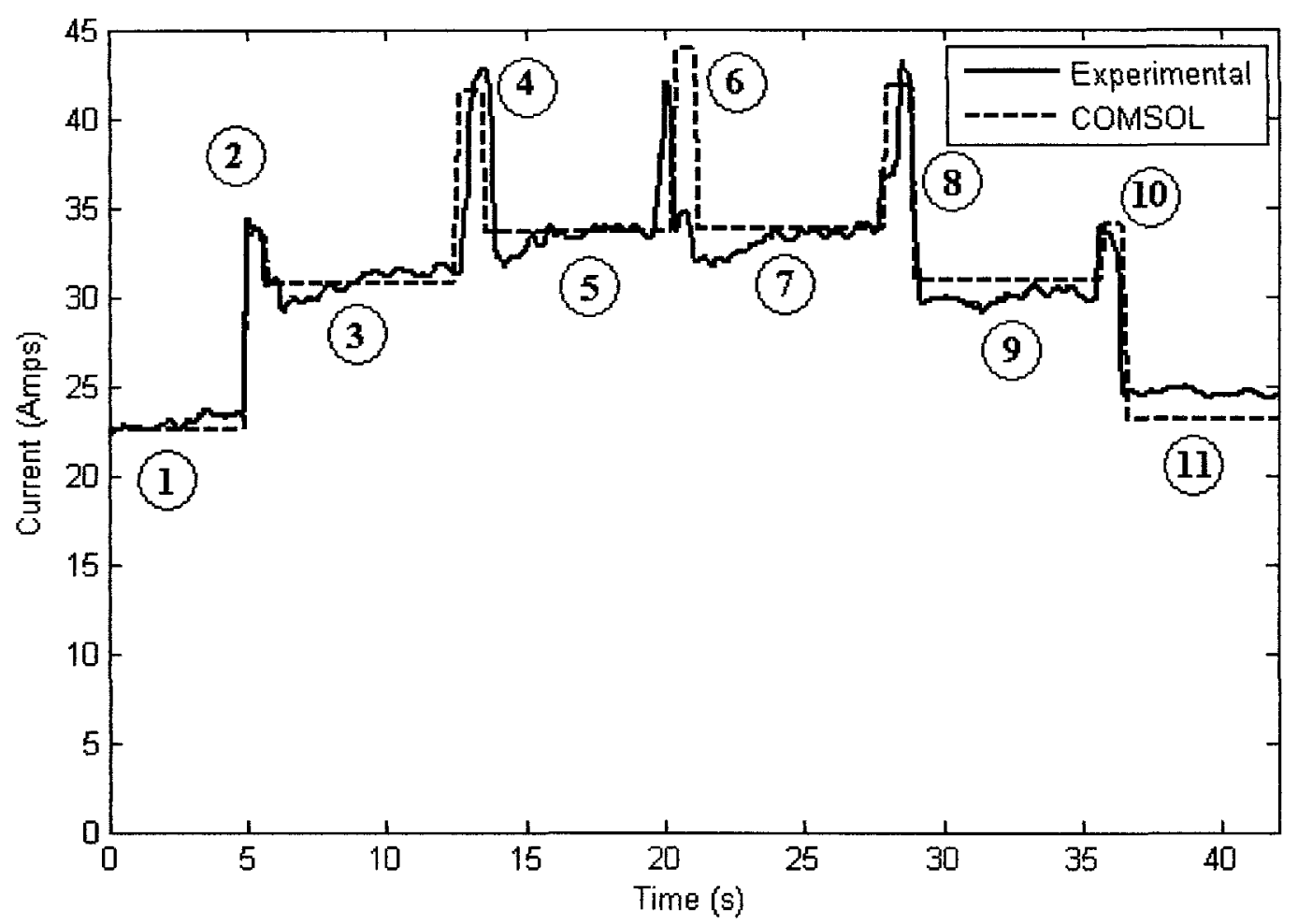

Figure 3.13 - Current comparison between COMSOL and experiments at 4.5V.

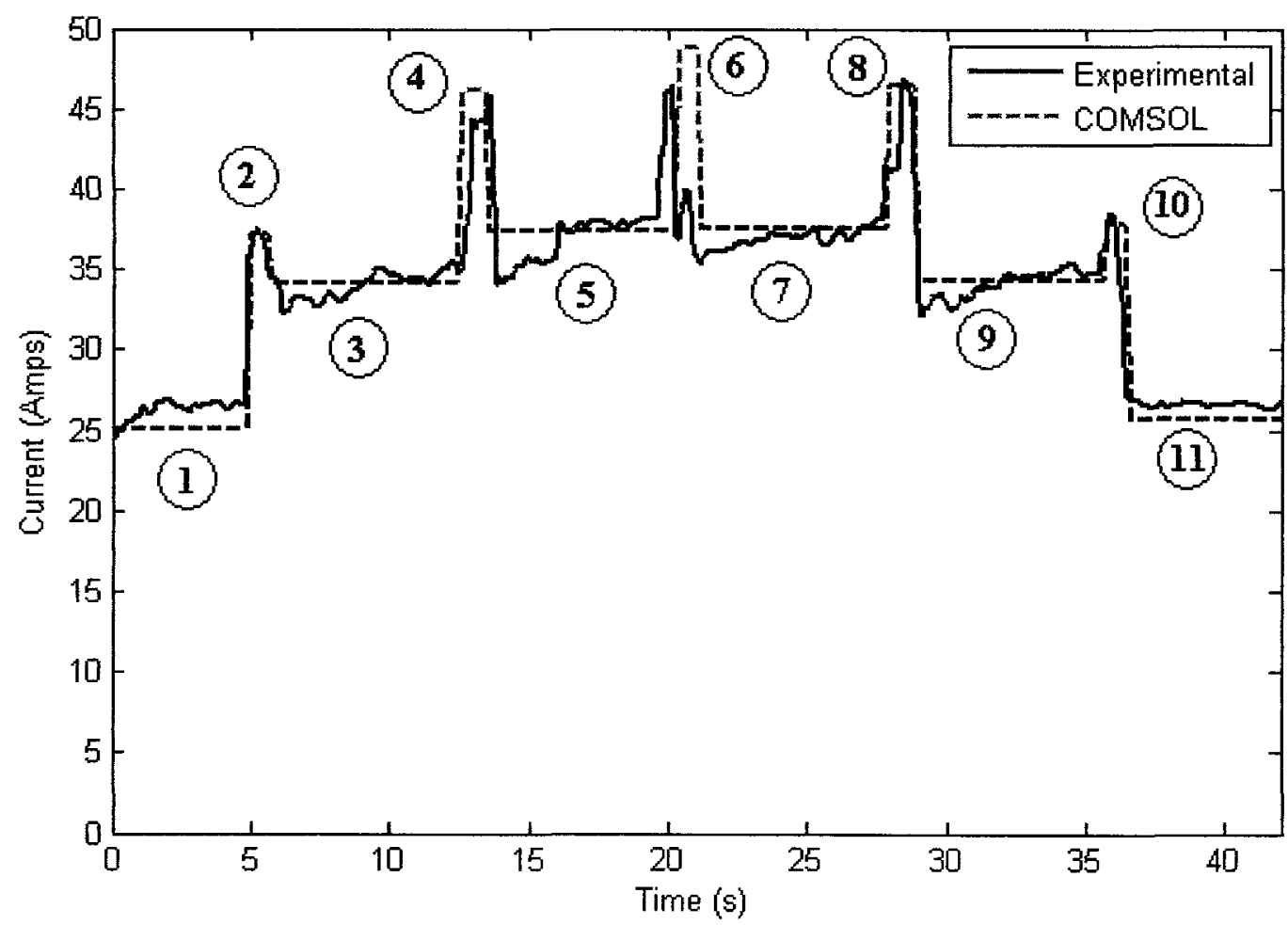

Figure 3.14 - Current comparison between COMSOL and experiments at 5V. 


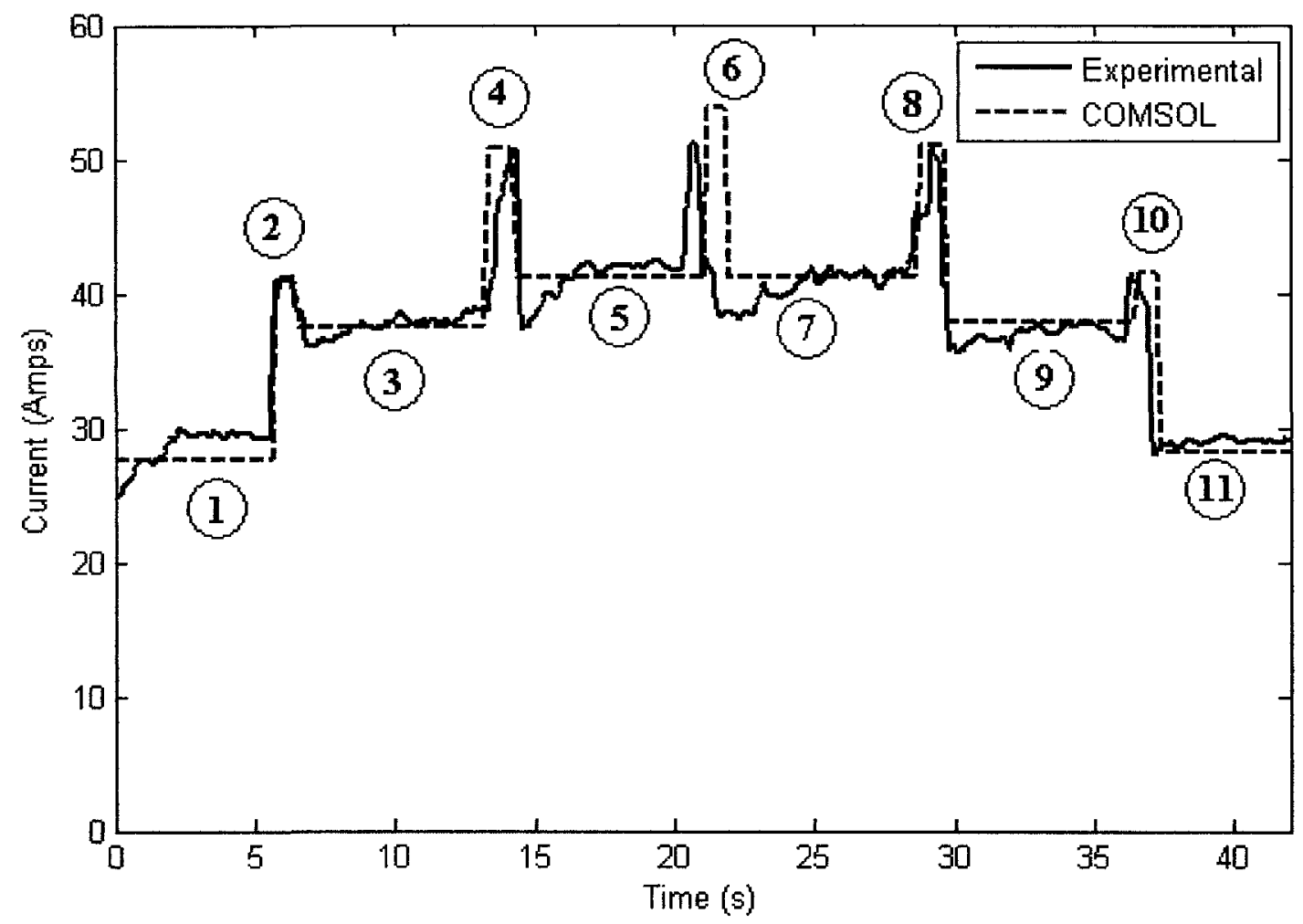

Figure 3.15 - Current comparison between COMSOL and experiments at 5.5V.

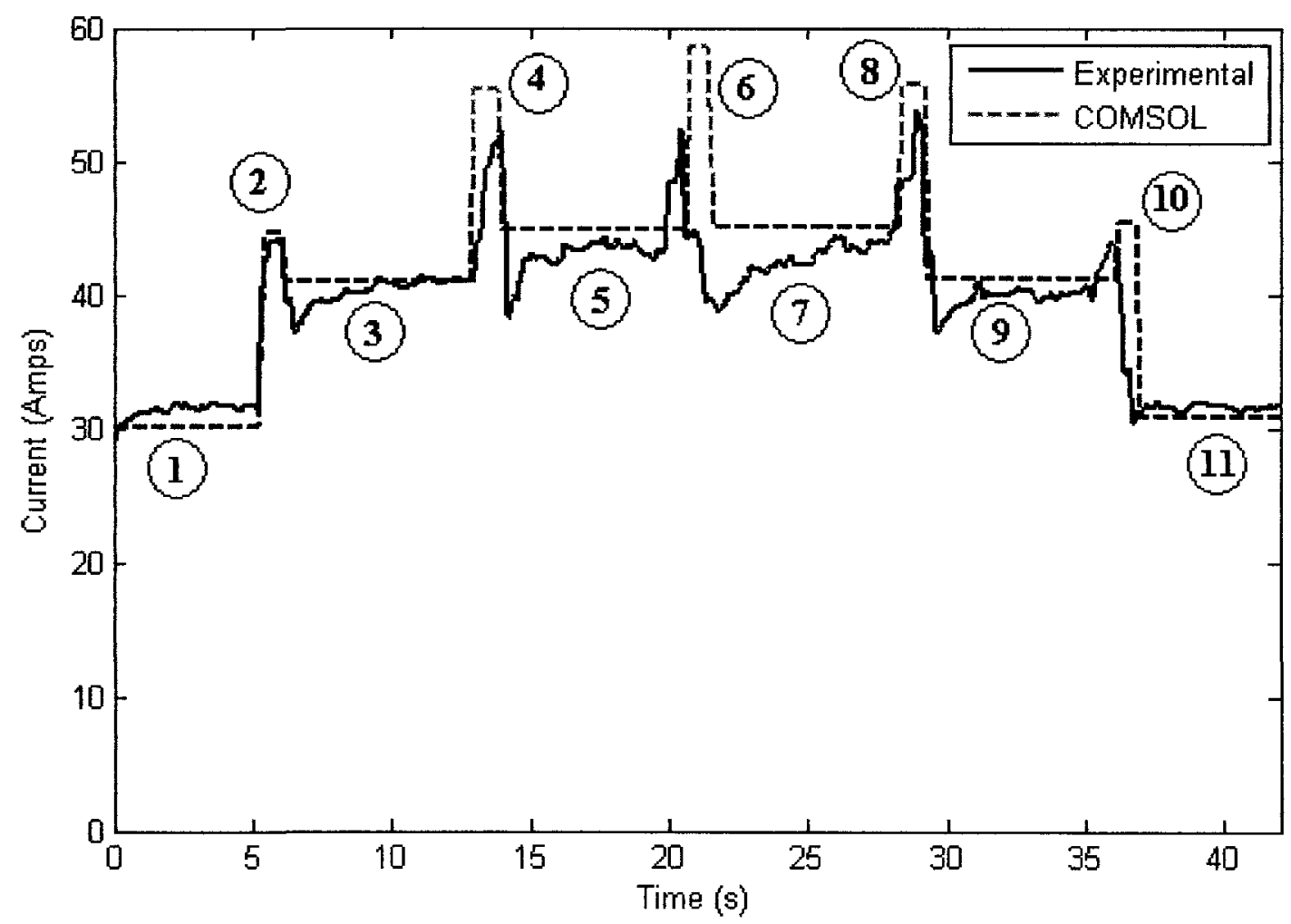

Figure 3.16 - Current comparison between COMSOL and experiments at 6V. 


\begin{tabular}{|c|c|c|c|c|c|c|}
\hline \multirow{2}{*}{ Location } & \multicolumn{5}{|c|}{ Percent Error } & \multirow[b]{2}{*}{ AVERAGE } \\
\hline & $4.0 \mathrm{~V}$ & $4.5 \mathrm{~V}$ & $5.0 \mathrm{~V}$ & $5.5 \mathrm{~V}$ & $6.0 \mathrm{~V}$ & \\
\hline 1 & 7.31 & 1.74 & 4.34 & 3.42 & 3.88 & 4.14 \\
\hline 2 & 8.00 & 0.72 & 0.53 & 1.90 & 3.38 & 2.90 \\
\hline 3 & 10.66 & 1.44 & 0.16 & 0.66 & 1.60 & 2.90 \\
\hline 4 & 7.50 & 1.26 & 4.82 & 4.97 & 10.19 & 5.75 \\
\hline 5 & 7.55 & 0.17 & 0.18 & 1.03 & 3.70 & 2.53 \\
\hline 6 & 15.19 & 6.31 & 8.56 & 10.10 & 11.93 & 10.42 \\
\hline 7 & 9.95 & 1.05 & 1.22 & 1.81 & 5.39 & 3.88 \\
\hline 8 & 4.31 & 1.02 & 1.42 & 3.57 & 4.15 & 2.89 \\
\hline 9 & 12.39 & 2.73 & 0.38 & 1.71 & 2.80 & 4.00 \\
\hline 10 & 8.08 & 2.04 & 2.08 & 3.32 & 4.81 & 4.07 \\
\hline 11 & 4.37 & 5.91 & 3.57 & 2.27 & 2.34 & 3.69 \\
\hline
\end{tabular}

Table 3.2 - The percent error between experimental current measurements and the COMSOL model at 5 different voltages corresponding to locations shown in Figures 3.12 to 3.16 .

The total stable current increases from the first weld section to the next until it reaches a maximum at the third weld section, or the middle of the weld coupon. This is due to the distribution of the current along the length of the coupon as each section is welded. Figure 3.17 shows the flow of the current, predicted by the model, when welding the first section. Figures 3.18 and 3.19 show the current flow for weld sections two and three. During the first weld section, Fig. 3.17, the voltage is applied across the first set of copper blocks. The applied voltage creates an electric field which causes current to flow and distribute along the length of the weld coupon. The total current is lower in the first weld section because it is bounded by the edge of the coupon, and thus an electric field is created on one side of the heating element. However, as the electrodes move closer to the middle of the weld, Figures 3.18 and 3.19, an electric field is created on the heating element on both sides of the source voltage. This then creates a distribution of current on either side of the source voltage, resulting in a larger total current. 


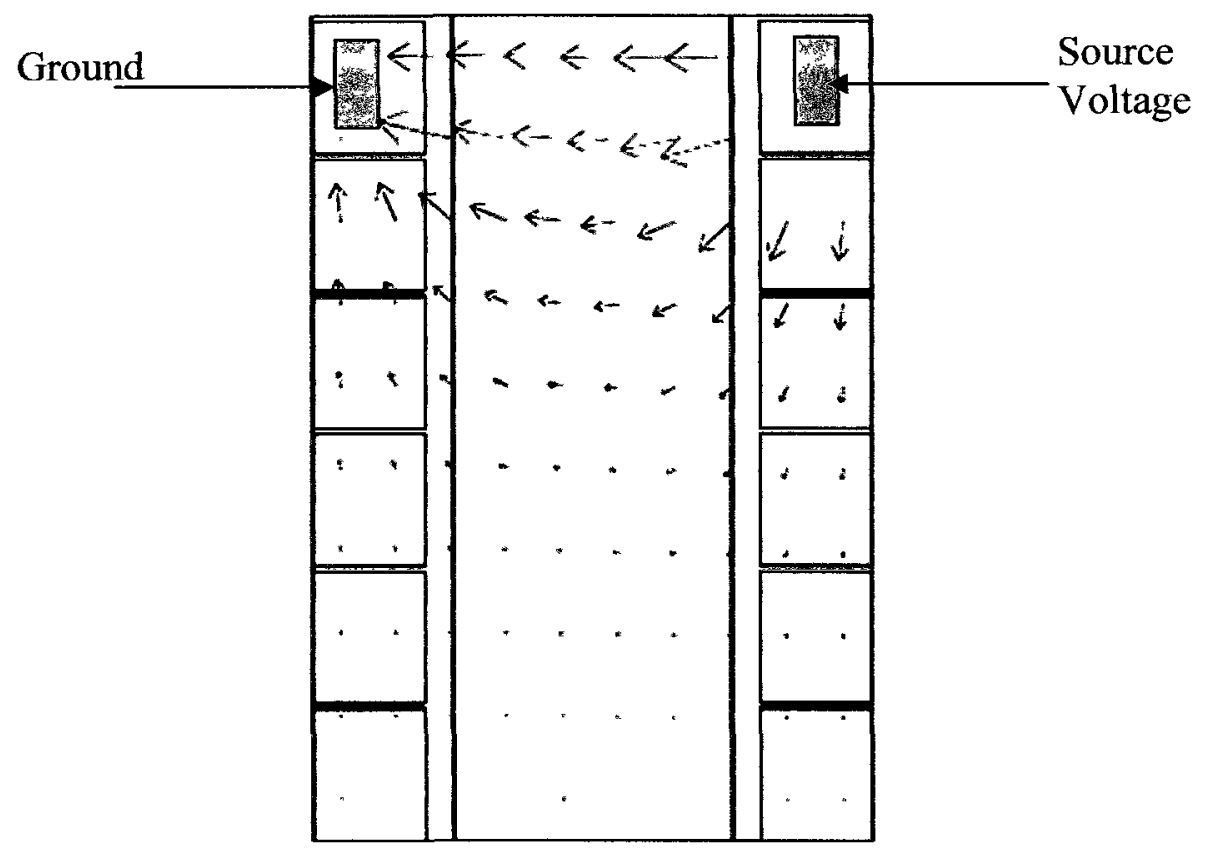

Figure 3.17 - COMSOL model with arrows depicting the direction of the current for the first weld section.

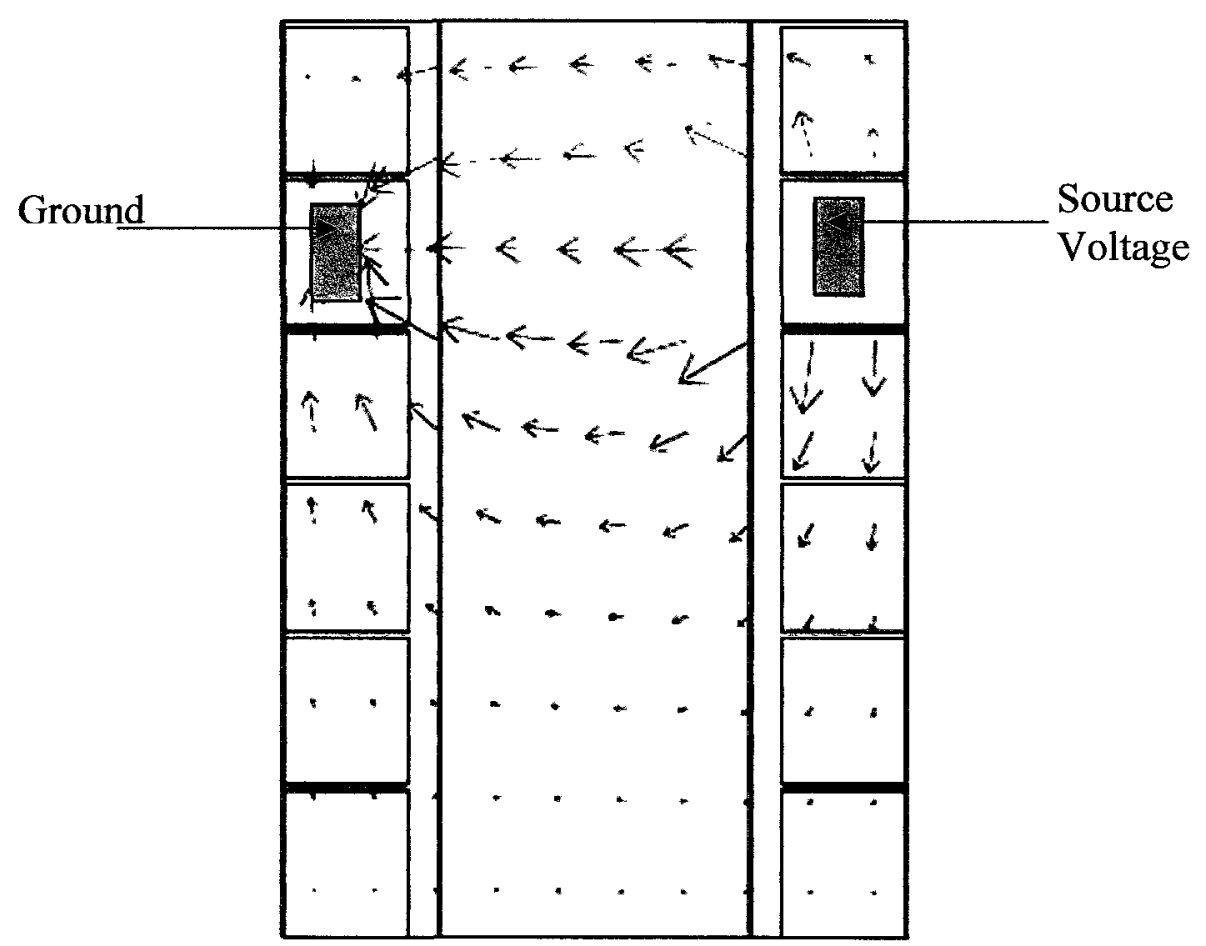

Figure 3.18 - COMSOL model with arrows depict the direction of the current for the second weld section. 


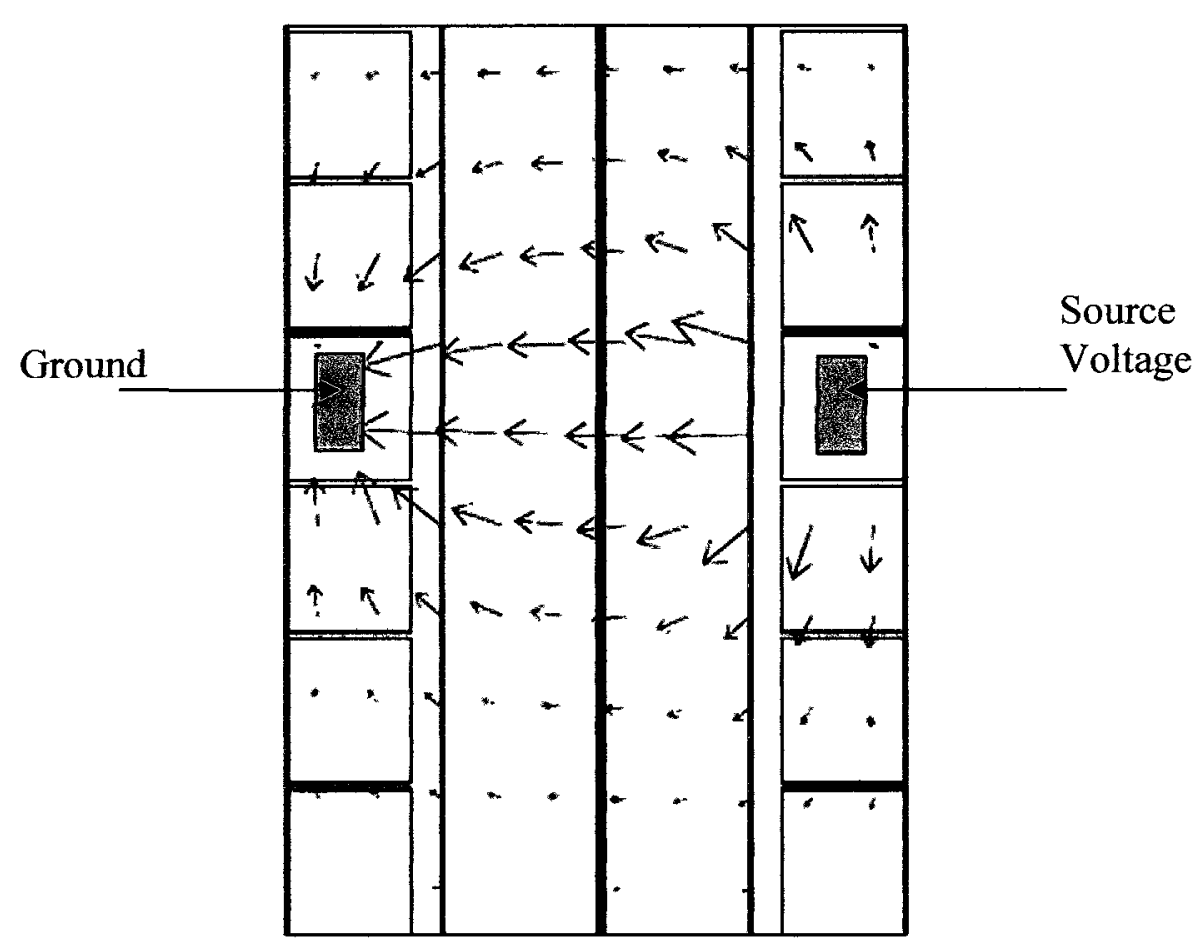

Figure 3.19 - COMSOL model with arrows depict the direction of the current for the third weld section.

Figure 3.20 depicts the model's prediction of the distribution of resistive heating along the vertical line in Fig. 3.19 while welding from the third to the fourth copper block section at 6V. The vertical lines in Fig. 3.20 denote the width and location of the third and fourth copper block. The power supplied to the heating element predicted by the model while welding either the third or fourth weld section is $247.0 \mathrm{~W}$. For the third weld section, from Fig. $3.20,34.3 \%$ of the total power is contained within the boundaries of its copper blocks. At $6 \mathrm{~V}$, the current passing through the third copper block section is therefore approximately $14.1 \mathrm{~A}$. While the electrodes are transitioning between the third and fourth blocks, the total power supplied to the entire heating element is $321.8 \mathrm{~W}$, as predicted by the model. Of this, $54.4 \%$ of the total power is contained between the third and fourth blocks. The resulting current passing through the two copper block sections simultaneously is then $29.1 \mathrm{~A}$. Figure 3.20 shows that the distribution of the power is symmetric across the two copper blocks while transitioning between blocks. This results in an individual current of approximately $14.55 \mathrm{~A}$ across each copper section. This result 
then shows that although the power does dramatically increase while transitioning between two copper blocks, the actual current passing through each block does not change.

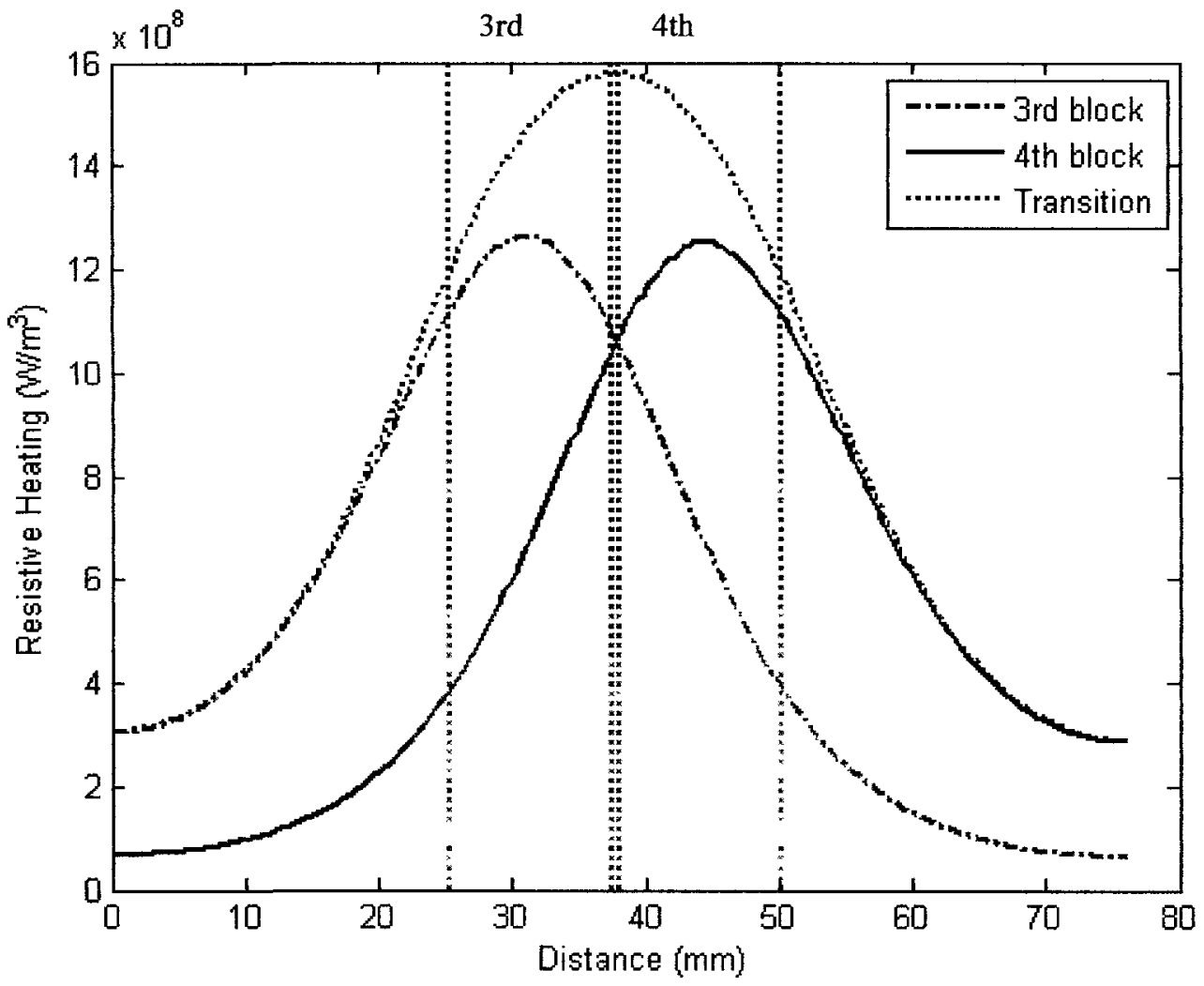

Figure 3.20 - Resistive heating along the vertical line in Fig. 3.19 that occurs when welding the $3^{\text {rd }}$ and $4^{\text {th }}$ copper block sections as well as while transitioning between them. The vertical lines show the beginning and the end of each copper block.

\subsubsection{Heat Transfer Modeling}

\section{$\underline{\text { Heat Transfer Equations }}$}

Fourier's law of conduction states that the heat flux and temperature gradient are directly proportional to each other [21]. In differential form the three-dimensional conduction equation becomes 


$$
\rho C_{p} \frac{\partial T}{\partial t}-k\left(\frac{\partial^{2} T}{\partial x^{2}}+\frac{\partial^{2} T}{\partial y^{2}}+\frac{\partial^{2} T}{\partial z^{2}}\right)=Q
$$

where $\rho$ is the material density, $C_{p}$ is the specific heat capacity at constant pressure, $k$ is the thermal conductivity, $T$ is absolute temperature and $Q$ is the rate of heat generation.

Both convective and radiation heat transfer boundary conditions are incorporated in the model. The steady-state form of Newton's Law of Cooling describes a body's loss of heat transfer occurring between a body and its surrounding ambient fluid [21]. Natural convection is then described as

$$
Q_{c}=\bar{h}\left(T_{b}-T_{\infty}\right)
$$

where $Q_{c}$ is the convective heat transfer rate, $h$ is the overall heat transfer coefficient, $T_{b}$ is the body temperature, and $T_{\infty}$ is the ambient temperature. Radiation heat transfer was defined using the Stefan-Boltzmann law for non-black body [21]. Radiation between a body and the atmosphere is described as,

$$
Q_{r}=\varepsilon \sigma_{s}\left(T_{b}^{4}-T_{\infty}^{4}\right)
$$

where $Q_{r}$ is the radiation heat transfer, $\varepsilon$ is the emissivity, $\sigma_{s}$ is the Stefan-Boltzmann constant defined as $5.67 \times 10^{-8} \mathrm{~W} /\left(\mathrm{m}^{2} \cdot \mathrm{K}^{4}\right)$, and $\mathrm{T}_{\infty}$ is the ambient temperature.

\section{Material Properties}

The physical properties are required for use in COMSOL to solve the differential equations. Without proper values for the physical properties, the model would not yield accurate results. Table 3.3 presents the thermal conductivity and density for the 304 stainless steel heating element, polypropylene resin film, and the glass/PP laminate. The glass/PP was assumed anisotropic for thermal conductivity, where $k_{x x}, k_{y y}$, and $k_{z z}$ are the thermal conductivity in the $\mathrm{x}, \mathrm{y}$, and $\mathrm{z}$ directions. 


\begin{tabular}{|l|c|c|c|}
\hline Material & $\begin{array}{l}\text { Thermal } \\
\text { Conductivity } \\
(\mathbf{W} /(\mathbf{m} \cdot \mathbf{K}))\end{array}$ & $\begin{array}{l}\text { Density } \\
\left(\mathbf{k g} / \mathbf{m}^{3}\right)\end{array}$ & $\begin{array}{l}\text { Specific } \\
\text { Heat } \\
\text { Capacity } \\
(\mathbf{J} / \mathbf{( k g} \cdot \mathbf{K}))\end{array}$ \\
\hline 304 Stainless Steel [22] & 16.3 & 8000 & 502 \\
\hline Polypropylene [24] & 0.16 & 950 & $*$ \\
\hline Glass/PP [24] & $\begin{array}{l}\mathrm{k}_{\mathrm{xx}}=0.355 \\
\mathrm{k}_{\mathrm{yy}}=0.355 \\
\mathrm{k}_{\mathrm{zz}}=0.292\end{array}$ & 1350 & $*$ \\
\hline
\end{tabular}

Table 3.3 - Material properties of heating element, polypropylene resin film and the Glass/PP Laminate. (* indicates temperature dependent property in table below)

Table 3.4 presents the specific heat capacity of the polypropylene resin film as a function of temperature. As was observed by Jun'ichi and Tomohiro [25], at the approximate melting point of $160^{\circ} \mathrm{C}$ of the polypropylene film, the heat capacity is increased approximately four times its room temperature value to $8100 \mathrm{~J} /(\mathrm{kg} \cdot \mathrm{K})$. After $175^{\circ} \mathrm{C}$, the specific heat capacity was set to be constant at $4000 \mathrm{~J} /(\mathrm{kg} \cdot \mathrm{K})$ [25]. Table 3.5 also shows the temperature dependency of the specific heat capacity for glass/PP. 


\begin{tabular}{|c|c|}
\hline $\begin{array}{c}\text { Temperature } \\
\left({ }^{\mathbf{C}} \mathbf{C}\right)\end{array}$ & $\begin{array}{r}\text { Specific Heat } \\
\text { Capacity } \\
(\mathbf{J} /(\mathbf{k g} \cdot \mathbf{K}))\end{array}$ \\
\hline 25 & 1900 \\
\hline 80 & 2100 \\
\hline 130 & 3000 \\
\hline 150 & 4000 \\
\hline 155 & 5000 \\
\hline 160 & 7000 \\
\hline 165 & 8100 \\
\hline 170 & 7000 \\
\hline 175 & 4000 \\
\hline & \\
\hline
\end{tabular}

Table 3.4 - Specific heat capacity of polypropylene at constant pressure as a function of temperature [25]. (Approximate melting point in bold).

\begin{tabular}{|c|c|}
\hline $\begin{array}{c}\text { Temperature } \\
\left({ }^{\mathbf{0}} \mathbf{C}\right)\end{array}$ & $\begin{array}{c}\text { Specific Heat } \\
\text { Capacity } \\
(\mathbf{J} /(\mathbf{k g} \cdot \mathbf{K}))\end{array}$ \\
\hline 20 & 2206 \\
\hline 100 & 2466 \\
\hline 200 & 2800 \\
\hline 300 & 3130 \\
\hline
\end{tabular}

Table 3.5 - Specific heat capacity for the $34 \%$ Glass-fibre, $66 \%$ polypropylene laminate at constant pressure as a function of temperature [26]. 


\section{Heat Transfer Boundary Conditions}

When solving eq. (3.1), COMSOL also calculates the resistive heating that results from calculated current. This resistive heating term is the term $Q$ in eq. (3.3) when solving the heat equation. This approach establishes a link between the electrostatics and the heat transfer, essentially coupling the two physics together. The result is a heat source that is non-uniformly spread throughout the heating element.

With the exception of the bottom surface in Fig. 3.1, which was set to have a constant temperature of $25^{\circ} \mathrm{C}$, all boundaries were set to have both convection and radiation conditions. The heat transfer coefficient, $\bar{h}$, was selected to be $5 \mathrm{~W} /\left(\mathrm{m}^{2} \cdot \mathrm{K}\right)$, which was the common value used in several published works on the static welding process [27]-[31]. All boundaries were also assumed grey bodies radiating with the atmosphere with an emissivity of 0.95 , which is also consistent with [27]-[31]. The atmospheric temperature was set to $25^{\circ} \mathrm{C}$. The initial temperature for all boundaries was set according to the pre-weld thermocouple readings during experiments for each particular voltage.

\section{$\underline{\text { Heat Transfer Simulation Results and Experimental Validation }}$}

When welding, the composite melts from the exterior to the middle of the coupon. This is shown in Fig. 3.21 after simulating for 7.2 seconds at $6 \mathrm{~V}$. This means that the last portion of the laminate to melt will always be along the centerline of the work-piece. 


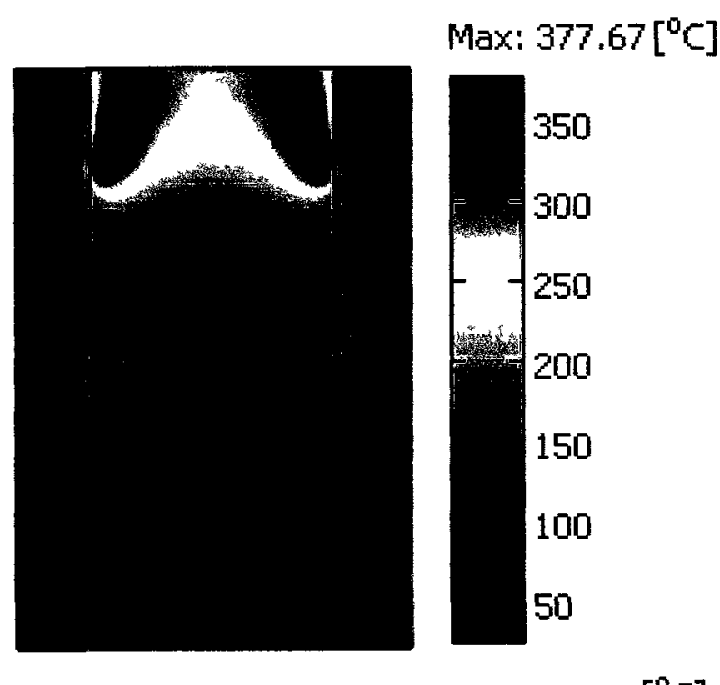

Min: $25.863\left[^{\circ} \mathrm{C}\right]$

Figure 3.21 - Temperature distribution along the heating element after 7.2 seconds at $6 \mathrm{~V}$.

To validate the results from the COMSOL model a series of experiments were conducted to compare the temperatures in the model to experimental measurements. Shown in Fig. 3.22 is a top view of the experimental setup. The three circles indicate the locations that the temperature was measured for comparison with the model. To measure the temperature a National Instruments (NI) SC-2345 K-type (Al-Cr) thermocouple acquisition system was used to measure the temperatures at those three locations that occur on the heating element at $4 \mathrm{~V}, 5 \mathrm{~V}$, and $6 \mathrm{~V}$. The NI system uses LabVIEW, running on a Windows XP Platform, to acquire all the thermocouple data and store it in an Excel® spreadsheet. All experiments were run at a weld speed of four inches per minute. The pneumatic system in Fig. 2.2 was used to apply a pressure of $1.5 \mathrm{MPa}$ on the copper blocks to ensure a strong contact. The thermocouples were insulated with Kapton ${ }^{\circledR}$ polyimide film [32] to prevent the electrical weld current from corrupting the temperature readings as was used by [28]. The Kapton ${ }^{\circledR}$ was $0.12 \mathrm{~mm}$ thick, which is a significant inclusion in the weld stack considering that the polypropylene film is $0.16 \mathrm{~mm}$ thick. To account for this inclusion all temperature data extracted from the model was taken 0.12 $\mathrm{mm}$ above the heating element. 


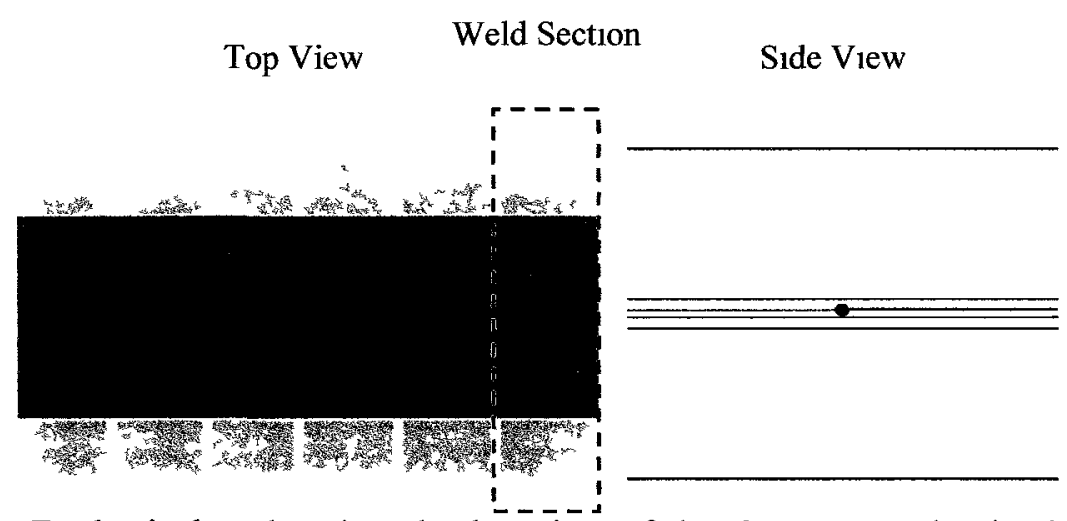

Figure 3.22 - Dark circles showing the location of the thermocouples in the weld stack, placed directly atop the heating element.

Shown in Figures 3.23 to 3.31 , are the comparison of the model with the experimental measurements. Each weld with fixed parameter set was completed four times, with the data shown representing the median curve of each parameter set. In Figures $3.23,3.26$, and 3.29 the temperature profiles for the first weld section are presented with each figure signifying the temperature at a particular voltage. Each weld is broken up into several weld sections. A weld section, as shown in Fig. 3.22, is defined as the area of the workpieces bounded by the edges of two opposite copper blocks where the voltage is applied. The time the electrodes are supplying power to an individual weld section at four inches per minute is 7.2 seconds. During this time the temperature inside that particular weld section is continuously increasing. Once the electrodes begin to reach the edge of the weld section, they transition to the next weld section. The temperature profiles for the second weld section are shown in Figures 3.24, 3.27, and 3.30. Although the electrodes have moved to the next section, there is still some residual heating effect that occurs on the first weld section. This can be seen in Figures 3.23, 3.26, and 3.29 from 7.7 seconds to 14.4 seconds. This occurs because of two reasons. Firstly, the electrical field resulting from the applied voltage causes current to flow in those adjacent sections, as was discussed in section 3.2.2. Secondly, when the temperature rises in the second section, heat is transferred to the adjacent section.

This same phenomenon causes a noticeable increase in the temperature of the section ahead of the one being welded. Since the weld section has yet to be welded, this 
is referred to as "pre-heating". The pre-heat temperature is then defined as the temperature in the weld section at the instant the voltage is transitioned from one weld section to the next. Each temperature plot is labeled with numbers indicating the key points that were used to compare with the COMSOL model. For example, in Fig. 3.31 there are three key points indicating two pre-heat temperatures and one weld temperature. At $4 \mathrm{~V}$, the pre-heat temperature on the second section, shown in Fig. 3.24, is approximately $74^{\circ} \mathrm{C}$, which is $43 \%$ of the maximum value reached when that section was welded. At $5 \mathrm{~V}$ in Fig. 3.27, the pre-heat temperature for the second section is approximately $98^{\circ} \mathrm{C}, 53 \%$ of its maximum. At $6 \mathrm{~V}$ in Fig. 3.30 , the preheat temperature is approximately $120^{\circ} \mathrm{C}$, also $53 \%$ of its maximum.

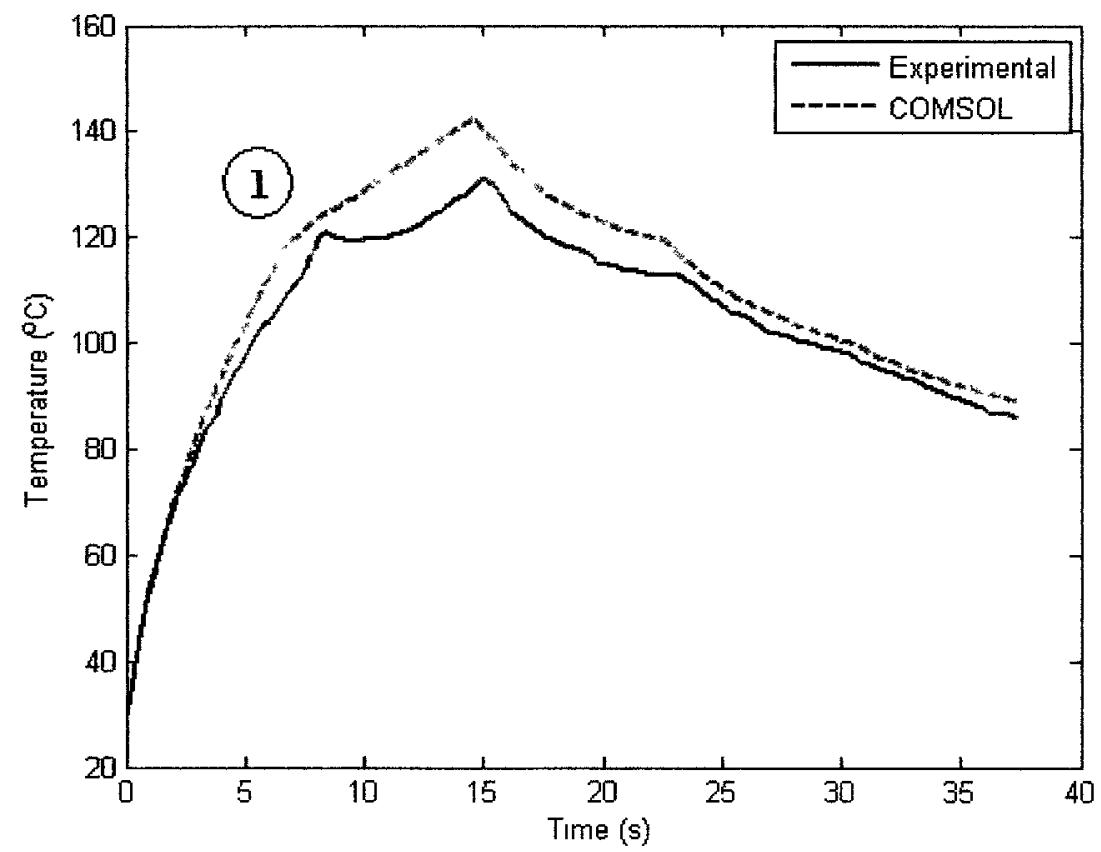

Figure 3.23 - Temperature comparison between simulation and experiments at $4 \mathrm{~V}$ and 4 inches per minute for the first weld section. 


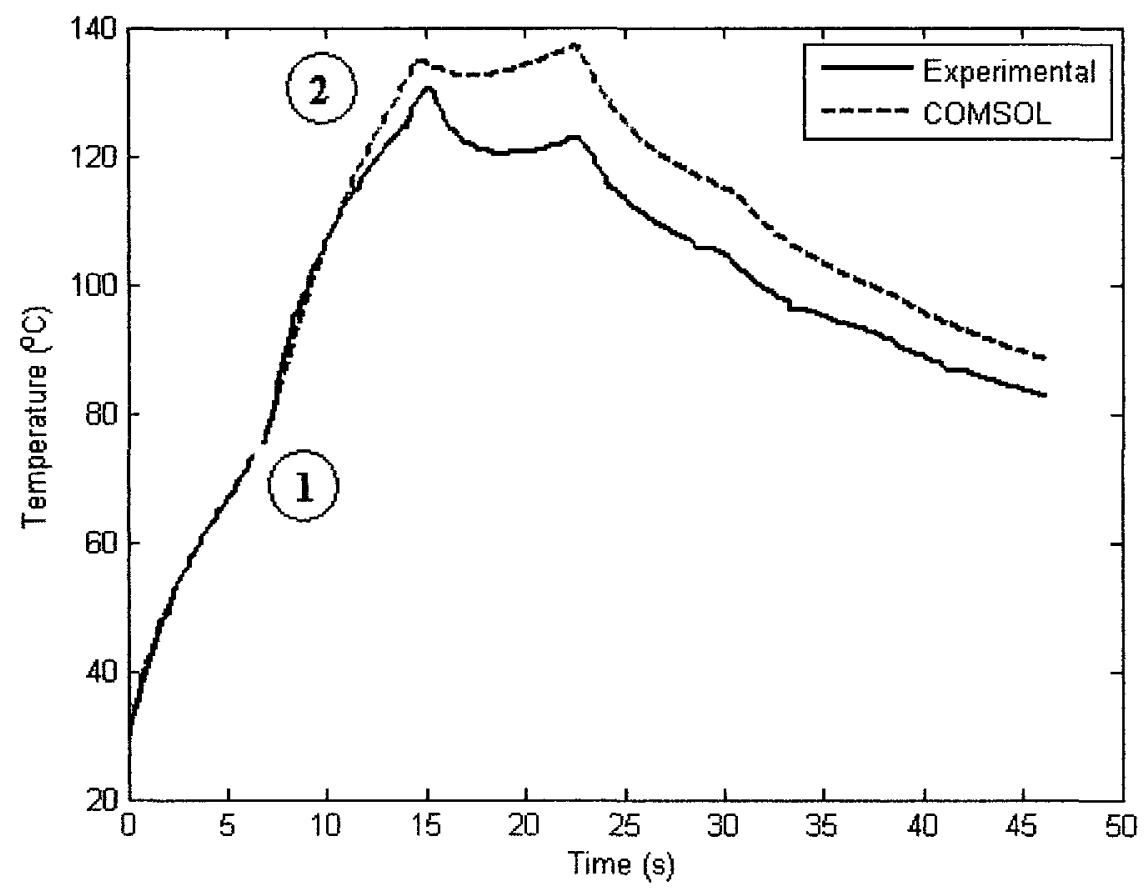

Figure 3.24 - Temperature comparison between simulation and experiments at $4 \mathrm{~V}$ and 4 inches per minute for the second weld section.

The secondary heating that occurs in the first weld section is more prominent then for the subsequent weld sections. At $6 \mathrm{~V}$, the secondary heating in the first weld section of the experimental data shown in Fig. 3.29 , causes the temperature to rise to $269^{\circ} \mathrm{C}$, an increase of $25.6 \%$ over the maximum temperature reached when the voltage was applied on that section. However, the secondary heating in the second weld section causes an increase of only $7.4 \%$. This is mainly due to the fact that the first weld section is limited by the poor convective boundary condition, effectively trapping the heat inside the weld section prohibiting it from dispersing. On the other hand, the second weld section has stainless steel mesh on either side of it allowing the heat to disperse along the mesh adjacent to both sides of the weld section. It is worth noting that at $4 \mathrm{~V}$ secondary heating only occurs significantly in the first weld section. 


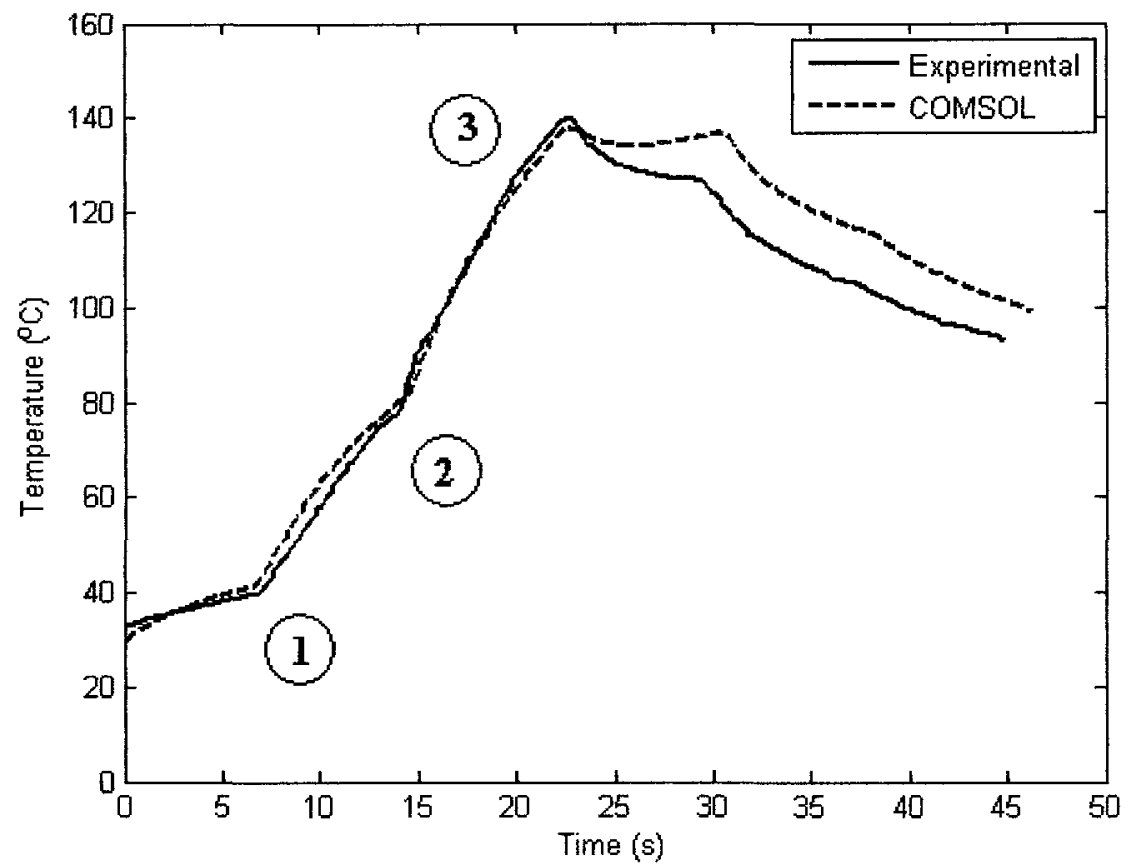

Figure 3.25 - Temperature comparison between simulation and experiments at $4 \mathrm{~V}$ and 4 inches per minute for the third weld section.

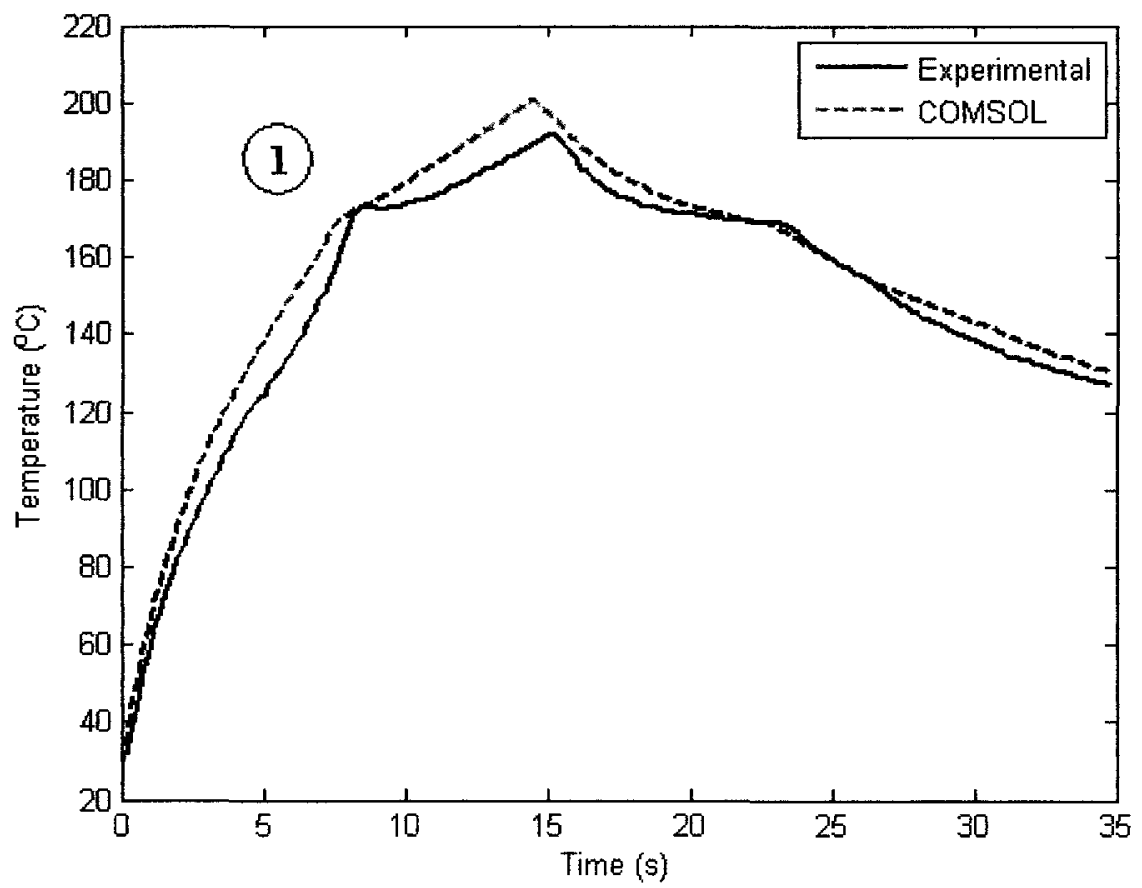

Figure 3.26 - Temperature comparison between simulation and experiments at $5 \mathrm{~V}$ and 4 inches per minute for the first weld section. 


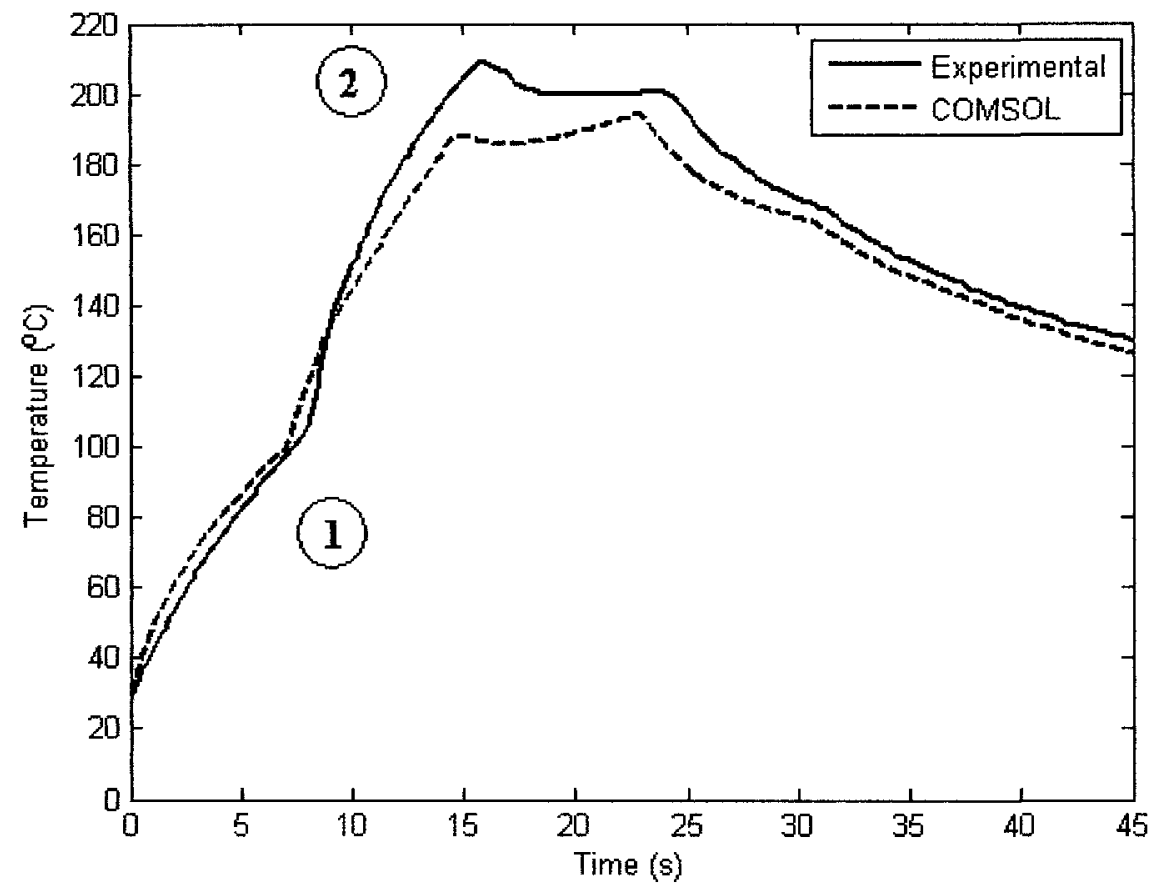

Figure 3.27 - Temperature comparison between simulation and experiments at $5 \mathrm{~V}$ and 4 inches per minute for the second weld section.

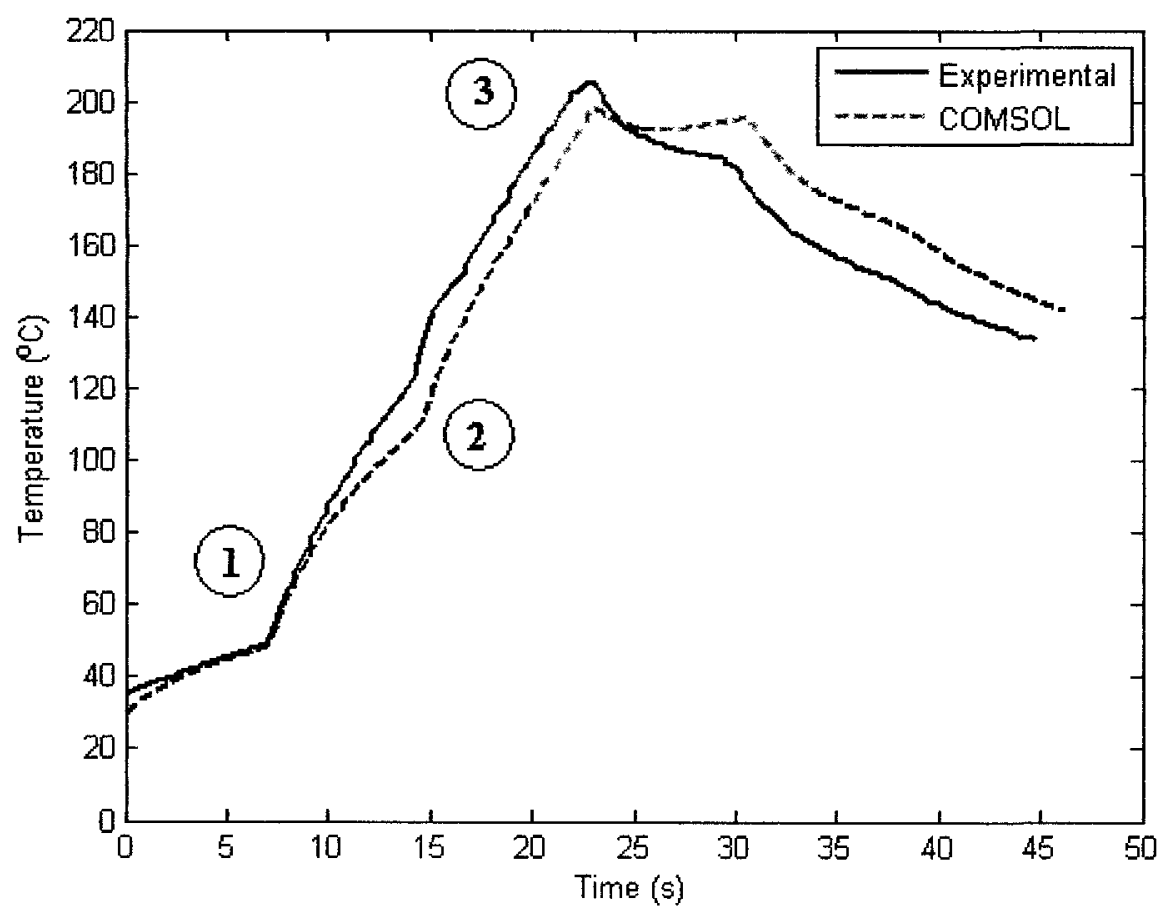

Figure 3.28 -Temperature comparison between simulation and experiments at $5 \mathrm{~V}$ and 4 inches per minute for the third weld section. 


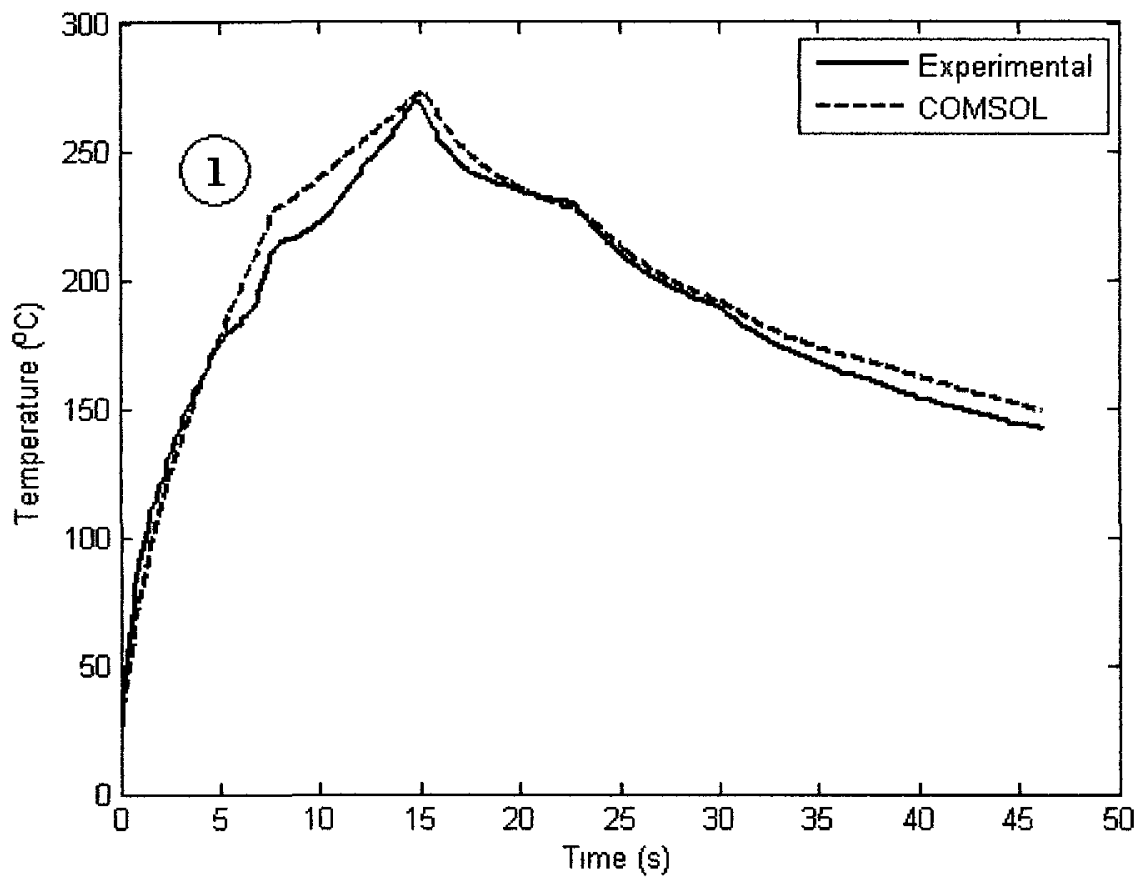

Figure 3.29 - Temperature comparison between simulation and experiments at $6 \mathrm{~V}$ and 4 inches per minute for the first weld section.

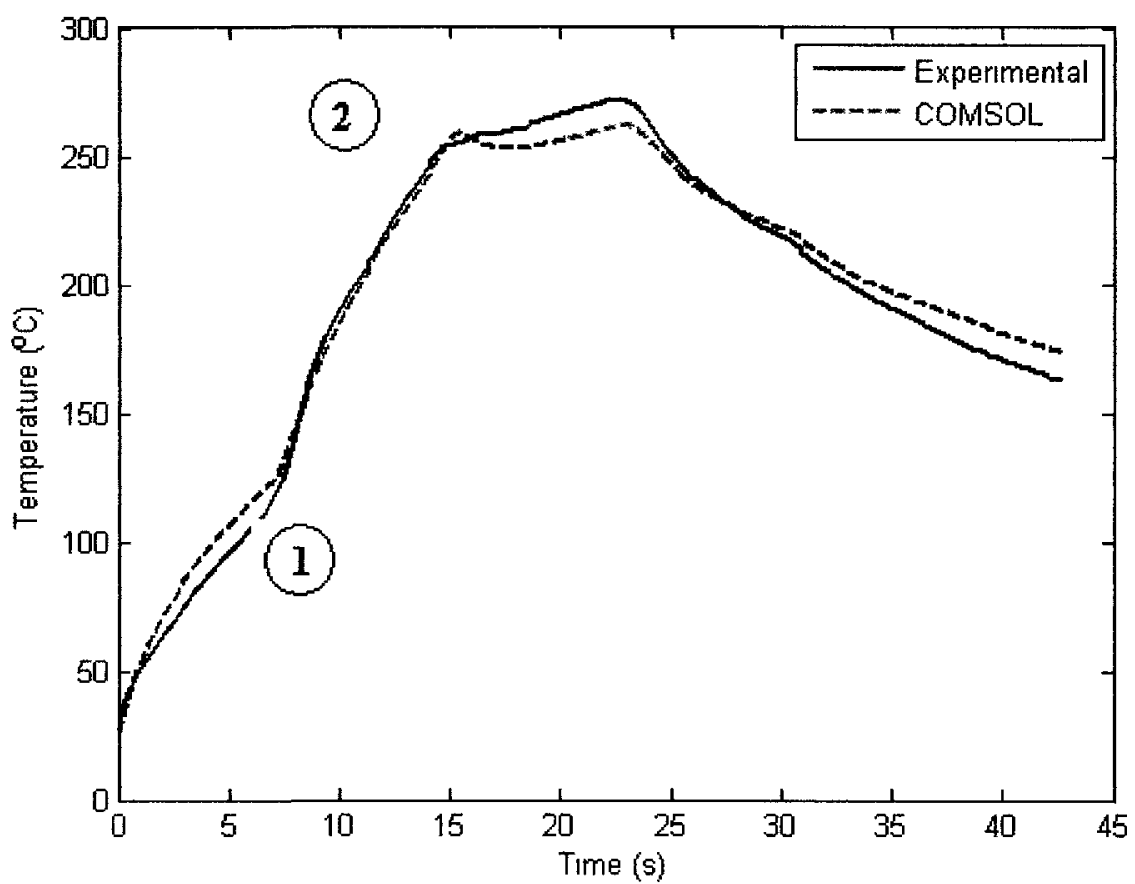

Figure 3.30 - Temperature comparison between simulation and experiments at $6 \mathrm{~V}$ and 4 inches per minute for the second weld section. 


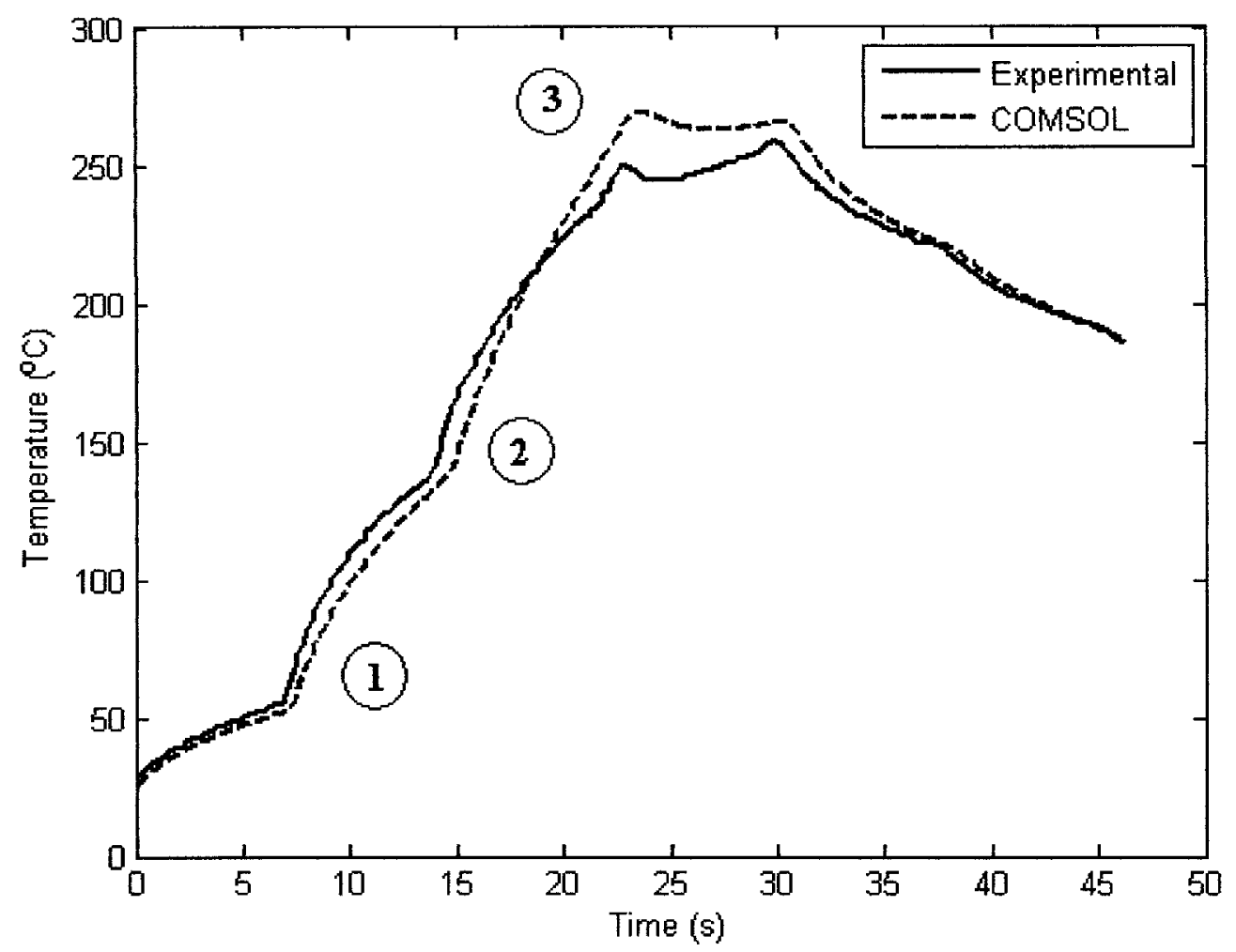

Figure 3.31 - Temperature comparison between simulation and experiments at $6 \mathrm{~V}$ and 4 inches per minute for the third weld section.

\begin{tabular}{|c|c|c|c|}
\hline \multirow{2}{*}{$\begin{array}{c}\text { Transition } \\
\text { Point }\end{array}$} & \multicolumn{3}{|c|}{ 1st Section } \\
\cline { 2 - 4 } & TC & Model & \% Error \\
\hline \multirow{2}{*}{ 1st } & 120.5 & 124.2 & 3.07 \\
\hline 1st & 79.3 & 79.5 & 0.25 \\
\hline 2nd & 130.8 & 134.9 & 3.04 \\
\hline & \multicolumn{3}{|c|}{ 3rd Section } \\
\hline 1st & 39.3 & 42.8 & 8.91 \\
\hline 2nd & 77.1 & 82.1 & 6.49 \\
\hline 3rd & 139.8 & 138 & 1.29 \\
\hline
\end{tabular}

Table 3.6 - Percentage error between the COMSOL model and thermocouple measurements (TC) for each weld section at $4 \mathrm{~V}$ from Figures 3.23, 3.24, and 3.25. The transition points are defined on each corresponding figure. 


\begin{tabular}{|c|c|c|c|}
\hline \multirow{2}{*}{$\begin{array}{c}\text { Transition } \\
\text { Point }\end{array}$} & \multicolumn{3}{|c|}{ 1st Section } \\
\hline & $\begin{array}{l}\text { TC } \\
\left({ }^{\circ} \mathrm{C}\right)\end{array}$ & $\begin{array}{l}\text { Model } \\
\left({ }^{\circ} \mathrm{C}\right)\end{array}$ & \% Error \\
\hline \multirow[t]{2}{*}{ 1st } & 172.8 & 170.0 & 1.62 \\
\hline & \multicolumn{3}{|c|}{ 2nd Section } \\
\hline 1st & 103.6 & 99.5 & 4.12 \\
\hline \multirow[t]{2}{*}{ 2nd } & 209.2 & 187.3 & 11.69 \\
\hline & \multicolumn{3}{|c|}{ 3rd Section } \\
\hline 1st & 48.9 & 48.3 & 1.23 \\
\hline 2nd & 127.0 & 109.2 & 14.06 \\
\hline 3rd & 205.3 & 197.7 & 3.69 \\
\hline
\end{tabular}

Table 3.7 - Percentage error between the COMSOL model and thermocouple (TC) measurements for each weld section at $5 \mathrm{~V}$ from Figures $3.26,3.27$, and 3.28. The transition points are defined on each corresponding figure.

\begin{tabular}{|c|c|c|c|}
\hline \multirow{2}{*}{$\begin{array}{c}\text { Transition } \\
\text { Point }\end{array}$} & \multicolumn{3}{|c|}{ 1st Section } \\
\cline { 2 - 4 } & TC & $\begin{array}{c}\text { Model } \\
\left.\text { ( }{ }^{\circ} \mathrm{C}\right)\end{array}$ & \% Error \\
\hline 1st & 214.1 & 228.7 & 6.80 \\
\hline & \multicolumn{3}{|c|}{ 2nd Section } \\
\hline 1st & 120.4 & 128.8 & 6.55 \\
\hline 2nd & 253.0 & 259.2 & 2.37 \\
\hline & \multicolumn{3}{|c|}{ 3rd Section } \\
\hline 1st & 55.7 & 52.4 & 5.92 \\
\hline 2nd & 141.8 & 134.4 & 5.21 \\
\hline 3rd & 249.8 & 269.1 & 7.76 \\
\hline
\end{tabular}

Table 3.8 - Percentage error between the COMSOL model and thermocouple (TC) measurements for each weld section at $6 \mathrm{~V}$ from Figures 3.29, 3.30, and 3.31. The transition points are defined on each corresponding figure. 
Tables 3.6, 3.7, and 3.8 present the error percentages of the transition points that are labeled on Figures 3.23 to 3.31 for all three voltage settings. The errors are typically below $8 \%$, and all are less than $15 \%$. There is some slight uncertainty that exists due to the possible motion of the thermocouple. Once the weld interface becomes completely molten, it is much easier for the thermocouple to shift slightly. Here, we have done a simple sensitivity test. Using the COMSOL model, the temperature is measured at $2 \mathrm{~mm}$ ahead of the experiments. The location is shown in Fig. 3.32 (b). With $4 \mathrm{~V}$ applied to the first section, Fig. 3.32 (a) shows the preheat temperature directly on the heating element at the second weld section along the lines shown in Fig. 3.32 (b). The temperature difference at the midpoint of section two and $2 \mathrm{~mm}$ ahead of section 2 is $11 \%$. Fig. 3.33 shows the first section with $4 \mathrm{~V}$ applied to it. The variation in temperature from the midpoint to $2 \mathrm{~mm}$ ahead of it is only $4.5 \%$. In this case, the section has a voltage applied directly to it, and so the application of power causes less variation in temperature in the area close to the midpoint. For the pre-heat case, the heating is a residual effect, and so the further away from the heat source the thermocouple gets, the more significant the variations.

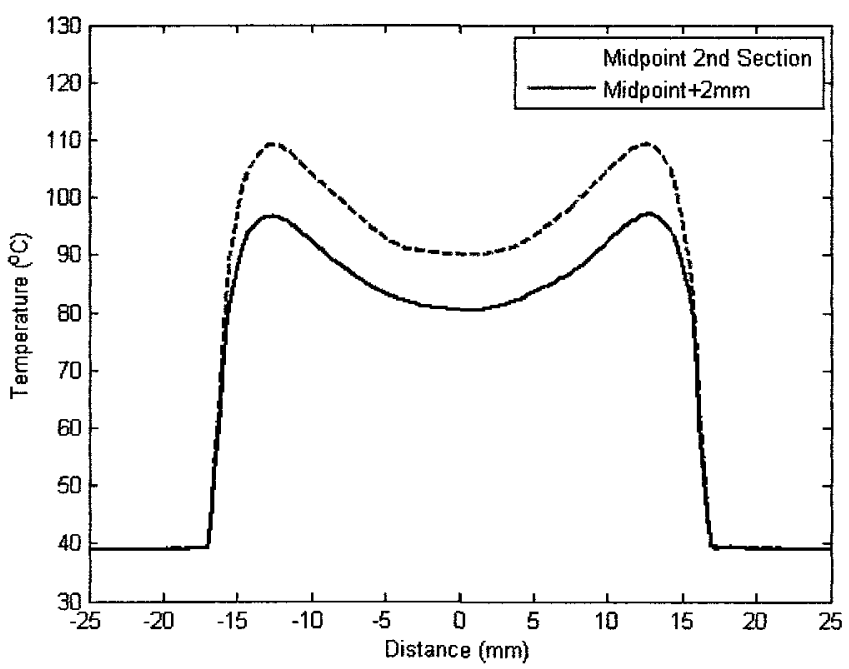

(a)

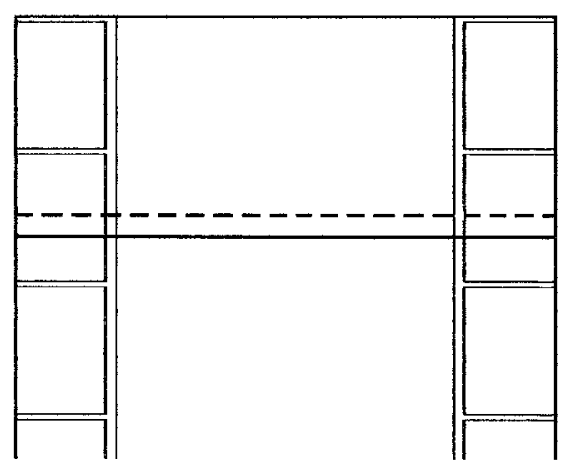

(b)

Figure 3.32 - (a) Temperature of the heating element across the $2^{\text {nd }}$ weld section while the first section has $4 \mathrm{~V}$ applied to it. (b) Shows the horizontal location of each measurement. 


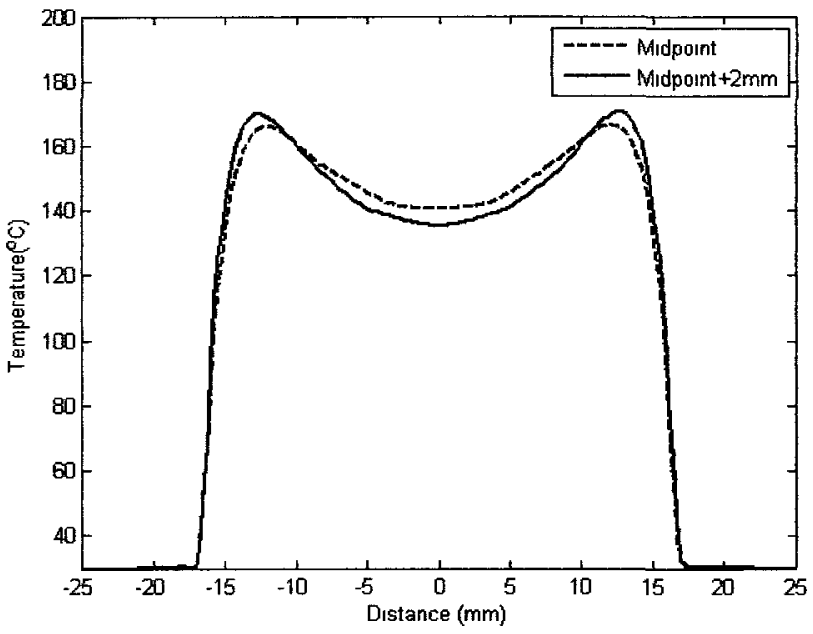

(a)

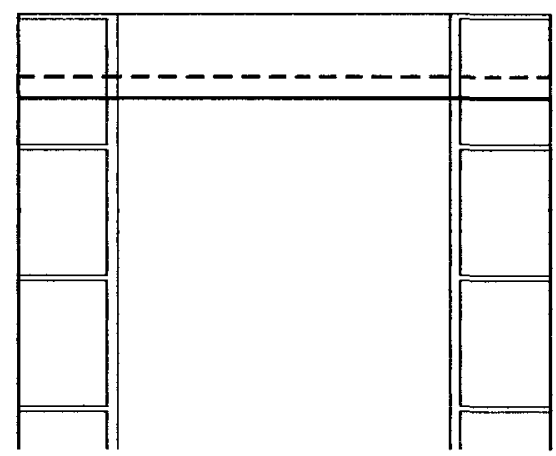

(b)

Figure 3.33 - (a) Temperature of the heating element across the 1st weld section while $4 \mathrm{~V}$ is applied to it. (b) Shows the horizontal location of each measurement.

In summary, a 3-D heat transfer model was created to model the current and temperature profiles of the continuous resistance welding process. The electrostatics model correlated with experimental measurements with less than $5 \%$ error. The trend in the current while welding was reproduced accurately with the model showing peaks in current that existed in the experiments. On the heat transfer side of the model, the key points that were compared had typically less than $10 \%$ error between the model and the experiments. The model also reproduced the pre-heating phenomenon that was observed experimentally.

To implement this process in a full-scale manufacturing scenario, it is not feasible to measure the weld temperature using thermocouples each time. Instead, the model could be used online to determine the weld temperature. The model could be used to generate a temperature feedback signal that could be used to control the welding process in a closed-loop manner. 


\section{Chapter 4}

\section{Process Control}

\subsection{Control Objectives}

The resistance welding process for thermoplastics is a discrete welding process. Although the electrodes that supply power to the heating element move continuously, the inclusion of the copper block tracks causes the welding to occur section by section. The controller is required to control the temperature along the centerline of the heating element. However, this is extremely challenging due to the fact that the electrodes move along a weld section whose heat generation does not follow the electrodes. Consider a single weld section. The electrodes move from the beginning to the end of the copper block pair for that weld section. Whether the electrode is at the beginning of the copper block or at the end of it, the heat generation inside that weld section remains the same. This indicates that the heat profile in the weld section would be the same if the electrodes were fixed atop the copper blocks for that section. Furthermore, when the electrodes move to the next weld section, discontinuity in the heat flow exists because the workpieces are being welded one section at a time. This discontinuity in the heat from weld section to weld section makes following the temperature along the centerline with the electrodes difficult because there will be sudden drops in temperature when transitioning from weld section to weld section. Instead of controlling the entire 
centerline temperature of the weld as the electrode moves, the controller is required to control the temperature at the midpoint of each weld section.

There are two main variables available in the resistance welding process that can be used to control the weld temperature; voltage and weld speed. The voltage directly controls the power input to the heating element, and thus controls the heat generation inside the heating element. The weld speed dictates the amount of time a weld section will be welded. Both variables are required to be controlled at the same time to be able to achieve proper weld performance. For example, the voltage must be reduced when approaching the reference temperature to prevent overshoot. An overshoot on the temperature is not acceptable as there are no direct means of reducing the temperature other than lowering the voltage to extremely small values. At the same time, as the temperature approaches its reference value, the weld speed should increase to reduce the total weld duration. Having two input variables that affect the weld quality provides more flexibility for control, but on the other hand there is more complexity in selecting the two input levels to achieve a reasonable weld quality. Fuzzy Logic provides a convenient framework to combine multiple inputs with a "human-like" control approach. With the fuzzy logic controller, it is possible to specifically design the behavior of each control variable. By doing this, both the voltage and weld speed can be defined to change together by means of simple if-then statements that encompass both the weld speed and voltage. One of the major problems in performing feedback control of this resistance welding process is the temperature feedback itself. It is extremely difficult to measure the weld temperature online because the heating element is sandwiched between the work pieces. Without the temperature measurement, there is effectively no feedback. To address this issue, it is proposed to create a linear model that is capable of estimating the temperature online. The current can be used as the input to the linear model, with the output being the estimated temperature at the midpoint of the weld section. Using this technique, the estimated temperature can be used as the feedback for the fuzzy logic control loop. 


\subsection{Fuzzy Logic}

Fuzzy logic is a control approach that can be used to mimic human reasoning [33]. The best way to describe fuzzy logic is through an example, such as water level control [33]. Consider that in a cement plant there exists a water tank, with a valve and two sensors, low $(\mathrm{L})$ and high $(\mathrm{H})$ water level sensors as shown in Fig. 4.1. If the water dipped below $L$, then the valve would open causing the tank to fill with water until the water reached level $\mathrm{H}$. At this point the valve would close. In this case the valve has only two conditions, high and low, i.e., the valve is either fully open or fully closed. Fuzzy logic essentially creates an interval between the high and low cases so that the valve can open partially and operate with a range of different flow rates. The range of the valve positions from low to high is what is known as the universe of discourse [33]. In this example it would be the range between the minimum volumetric flow rate of zero (valve fully closed), and the maximum volumetric flow rate (valve fully open). This range is then split into several functions, known as membership functions [33], where each function has a qualitative value associated with it. For this example, the input, or the height of the water in Fig. 4.2 is defined to have three membership functions; LOW, MED and HIGH from a range of $0 \mathrm{~m}$ to $1 \mathrm{~m}$, the length between $\mathrm{L}$ and $\mathrm{H}$. For example if the height of the water is $0.2 \mathrm{~m}$, that height is not said to be "LOW" or "MED", but rather its membership to LOW is 0.5 , its membership to MED is 0.25 , and its membership to HIGH is zero. This is shown in Fig. 4.2. The output, or volume flow rate, is also defined to have three membership functions; SLOW, MED, and FAST from a range of $0 \mathrm{~L} / \mathrm{min}$ (valve fully closed) to $5 \mathrm{~L} / \mathrm{min}$ (valve fully open) as shown in Fig 4.3. These membership functions map the input to a set of membership functions in the universe of discourse. 


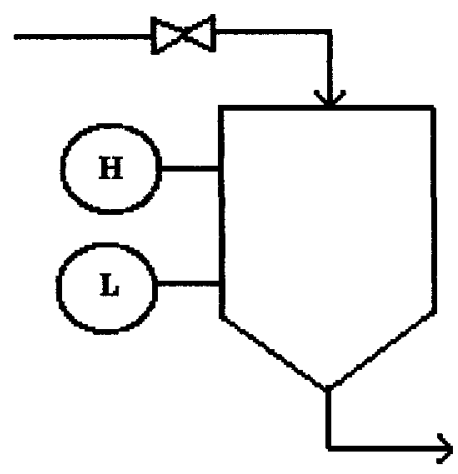

Figure 4.1 - Water tank with a low level (L) sensor, a high level $(\mathrm{H})$ sensor and a valve [33].

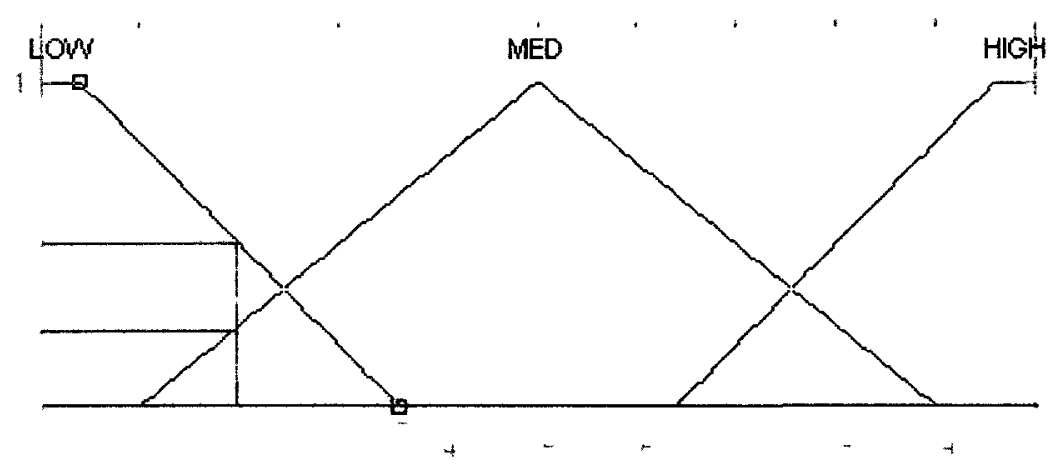

Height (m)

Figure 4.2 - Membership functions for the height of the water in the tank from $L$ to $H$.

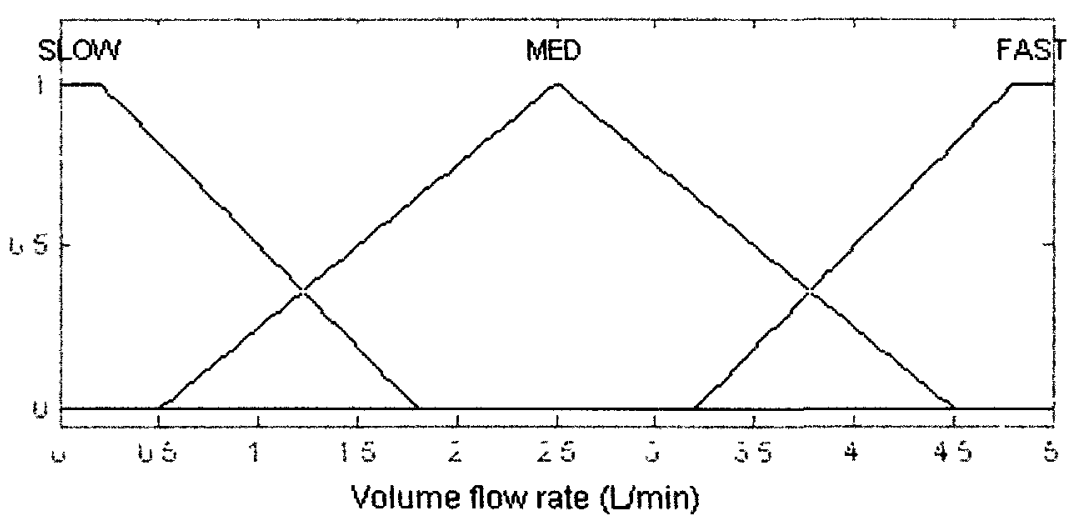

Figure 4.3 - Membership functions for the volume flow rate ranging from $0 \mathrm{~L} / \mathrm{min}$ (valve closed) to $5 \mathrm{~L} / \mathrm{min}$ (valve fully open). 
The process of mapping the input to membership functions between 0 and 1 is known as fuzzification [34]. These numbers can be interpreted as the degree of membership [33]. The link between the volume flow rate and the height of the water in the tank is determined by what is known as the rule base [34]. The rule base is a set of ifthen rules that specify the output membership function according to the input membership function. For example two rules could be,

\section{RULE 1: If (height of water) is LOW then, (volume flow rate) is FAST}

RULE 2: $\quad$ If (height of water) is $M E D$ then, (volume flow rate) is MED

A set of rules similar to these is required to evaluate all possible conditions. If for example, the height of water in the tank is $0.2 \mathrm{~m}$, then both rules above are true. Figure 4.4 shows that this height belongs to LOW with a degree of 0.5 and to MED with a degree of 0.25 . The results are then transferred to output, or volumetric flow rate, using the rule base as shown in Fig. 4.5. Now the question is to decide what volumetric flow rate to use if different rules give different outputs. To do this a method known as aggregation is used to combine the result of all rules. Aggregation is the union of all the output membership functions. In fuzzy logic, the union between two variables is defined to be the maximum of the two [33]. The result of the aggregation is shown in Fig. 4.6.

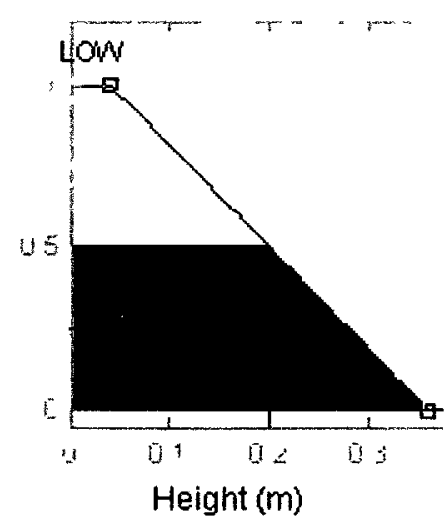

(a)

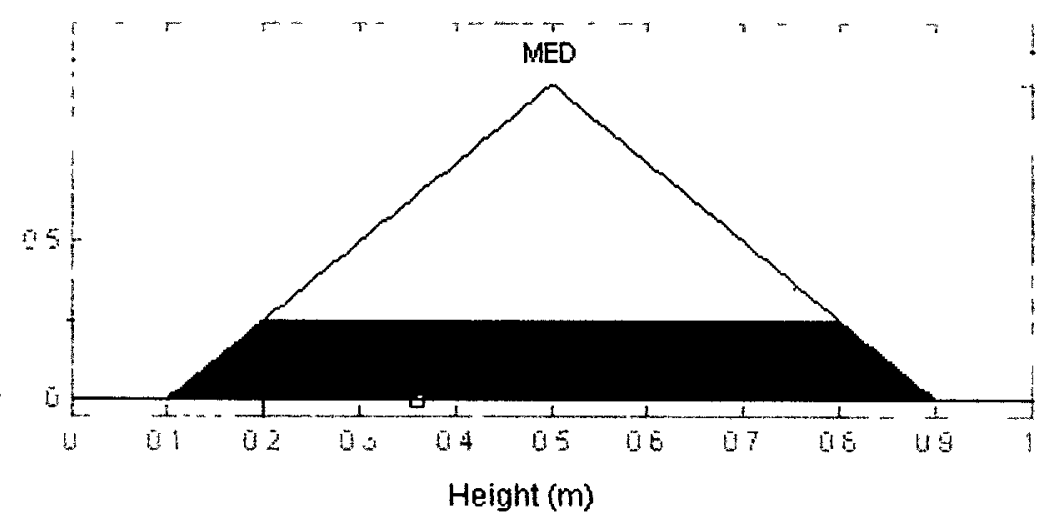

(b)

Figure 4.4 - Degree of membership for water height for (a) RULE 1 and (b) RULE 2 when the height of the water is $0.2 \mathrm{~m}$ from $\mathrm{L}$. 


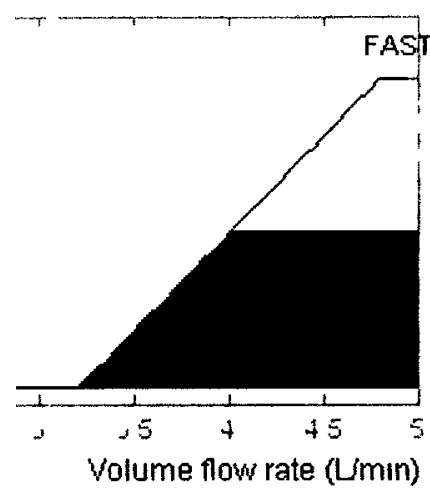

(a)

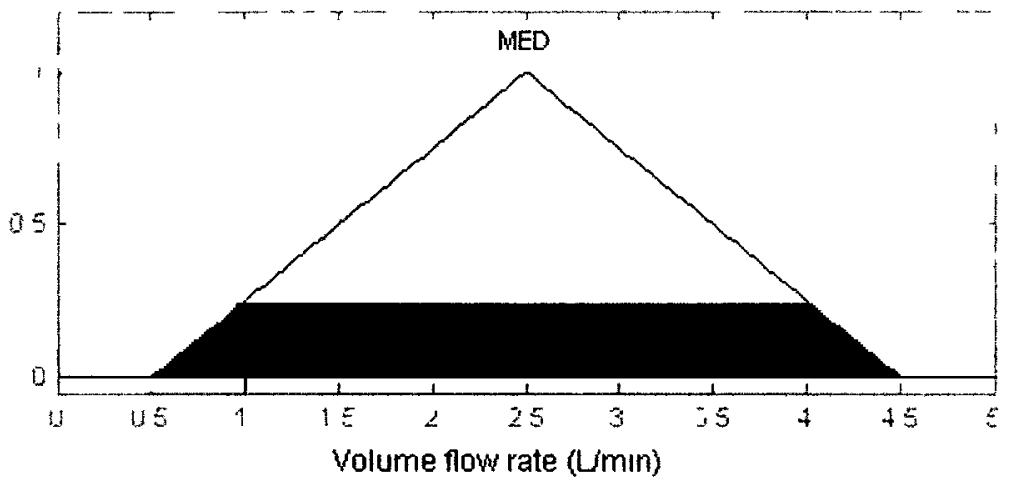

(b)

Figure 4.5 - Degree of membership on the volume flow rate for (a) RULE 1 and (b) RULE 2 when the height of water is $0.2 \mathrm{~m}$ from $\mathrm{L}$.

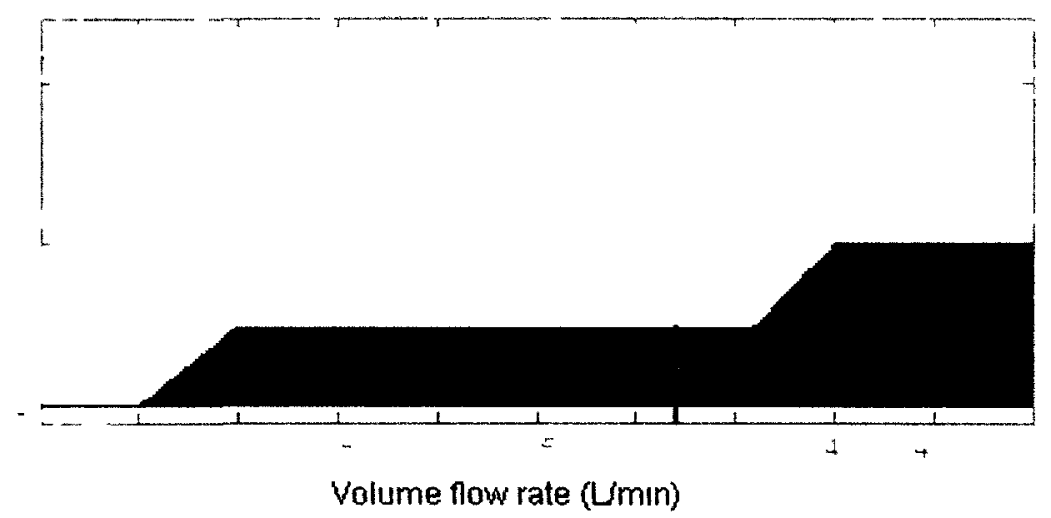

Figure 4.6 - Aggregation using the maximum of the outputs from Rules 1 and 2 that were generated from Figures 4.4 and 4.5 .

The final step, known as deffuzification, is to determine the numerical value of the output defined by the center of area of the aggregated output [34]

$$
y=\frac{\sum_{\mathrm{i}} \mu\left(x_{i}\right) x_{i}}{\sum_{i} \mu\left(x_{i}\right)},
$$

where $\mu\left(x_{1}\right)$ is the degree of membership at point $x_{l}$. In this example, with the height of the water being $0.2 \mathrm{~m}$, the output volume flow rate would be $3.22 \mathrm{~L} / \mathrm{min}$, as shown as the vertical line in Fig. 4.6. 


\subsection{Online Temperature Estimation}

In the case of thermoplastic resistance welding, the parameter to be controlled is the temperature at the midpoint of the section being welded. However, this temperature is not easily measureable online. To address this issue, and with the accurate results obtained with the $3 \mathrm{D}$ model, it is proposed to estimate the temperature online using a linear model from the 3D process model described in section 3.2. There are two possible variables that can be used to estimate the temperature in the resistance welding process; the voltage and the current. Obviously the current is selected due to its direct relation to the heat power generated. The voltage, is not an appropriate variable to be used; if during a weld the heating element is broken or current is interrupted, no current can flow across the heating element while the full voltage is still applied across the material. Therefore, the current was chosen to be the input to a linear model, while the output was chosen to be the estimated midpoint temperature. The control set-point was set at $200^{\circ} \mathrm{C}, 40^{\circ} \mathrm{C}$ above the approximate melting point of $160^{\circ} \mathrm{C}$ for the glass/PP laminate.

The temperature to be estimated is always the midpoint on the heating element between a pair of copper blocks. The electrodes move continuously over the copper block tracks, and as they transition from one pair of copper blocks to the next, the position at which the temperature is being estimated changes to the midpoint between the next pair of copper blocks. To address this discrete movement of the control point, the linear temperature model has to be reset to its initial conditions for each weld section. However, even without the input voltage on an upcoming block, there is still a temperature rise, which means the linear model of that block has a different initial condition when the voltage is applied to it. It is therefore required to not only reset the linear temperature model, but to set its initial temperature output to the preheat temperature. 


\subsubsection{Pre-Heat Temperature Approximation}

In reality, there is significant pre-heating of the adjacent blocks, as was shown in Figures 3.23 to 3.31 . It is therefore required to set the initial conditions on the linear model to be an estimate of this pre-heat temperature. To recall, the open loop experimental results in Figures 3.12 to 3.16 showed that as the electrodes traverse away from the boundary of the coupon, the steady portion of the weld current increases from weld section to weld section. However, to represent the pre-heat temperature accurately, the weld current must be the same across subsequent sections. To achieve this, the 3D COMSOL model length was increased to $139.7 \mathrm{~mm}$ to increase the size of the heating element to a point where the steady-current remains constant from weld section to weld section, away from the coupon boundaries. The new geometry encompasses 11 weld sections, rather than the original 6 sections. The steady-current at $6 \mathrm{~V}$ from the third to the ninth weld section, as predicted by COMSOL, was constant at $42.5 \mathrm{~A}$. The weld speed was increased to $7 \mathrm{in} / \mathrm{min}$ to achieve a centerline temperature of approximately $200^{\circ} \mathrm{C}$ in simulation. Figure 4.7 presents the resulting temperatures in COMSOL after welding four consecutive weld sections. For each of the four weld sections, it is evident from the curve that the pre-heat temperature is constant from section to section away from the boundary of the coupon. The resulting preheat temperature is approximately $116^{\circ} \mathrm{C}$. For simulation and control purposes, the temperature was rounded to $120^{\circ} \mathrm{C}$ to start from a clean start point. 


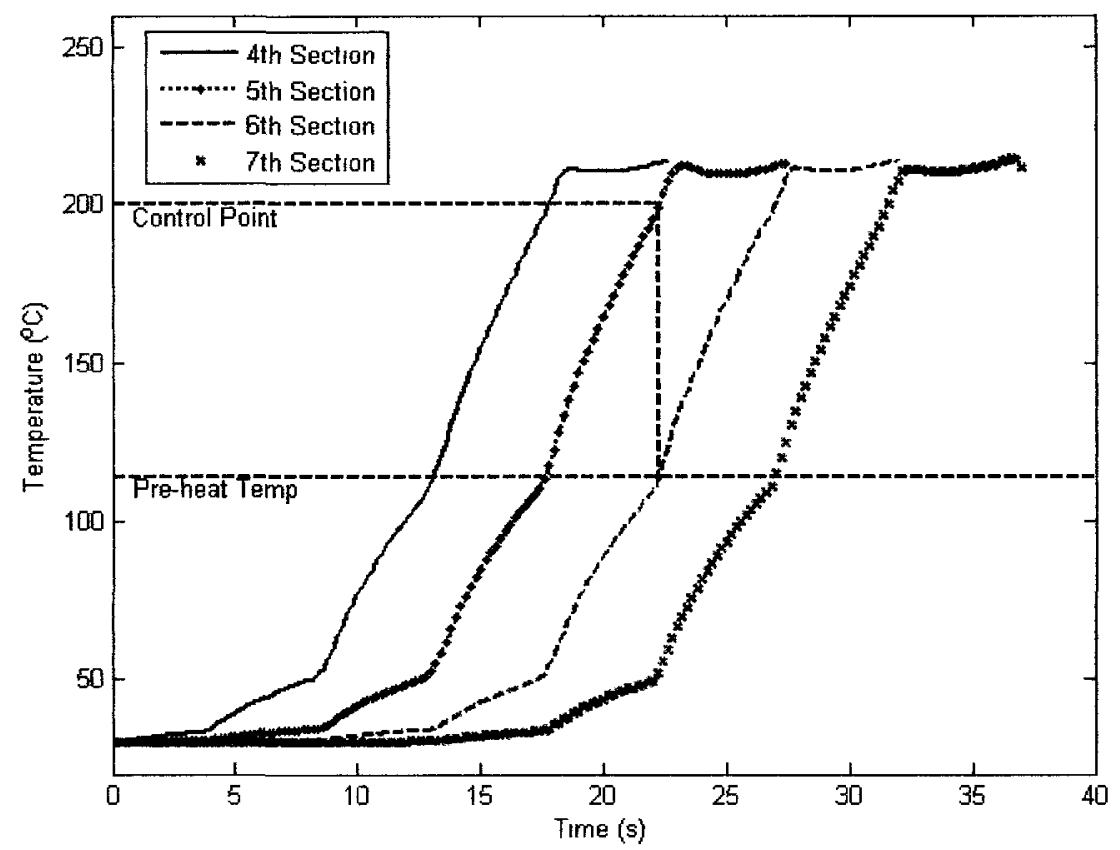

Figure 4.7 - Temperature profiles in COMSOL at $6 \mathrm{~V}$ and $7 \mathrm{in} / \mathrm{min}$ for four consecutive weld sections showing a constant pre-heat temperature.

\subsubsection{Temperature Linear Model}

As discussed earlier, measuring the weld temperature online is difficult because the heating element is sandwiched between the two workpieces being welded. This poses a significant challenge in controlling the weld temperature because it is not possible to control the temperature without measuring it. Instead, it is proposed to use a linear model online to estimate the weld temperature variations in time, with the input being weld current, and the output being estimated weld temperature. This approach generates a temperature feedback signal that can then be used in a control loop.

To define the linear system, temperature data was extracted from the 3D model at the midpoint of the weld section. Since the data from the 3D model was going to be used to generate the linear model, it was important to choose the proper input voltage so that the online estimate would be accurate. It will be shown in the next section that the defuzzified output on the high voltage case has a center of position of $5.65 \mathrm{~V}$ when the degree of membership is one. The $3 \mathrm{D}$ model was therefore solved from the initial 
condition of $25^{\circ} \mathrm{C}$ using $5.65 \mathrm{~V}$ applied only at the fourth weld section for 15 seconds. At this voltage, the current was $40 \mathrm{~A}$, creating the temperature profile shown in Fig. 4.8. The pre-heat temperature of $120^{\circ} \mathrm{C}$ was used as the initial condition temperature, and the temperature data above that temperature was used generate the temperature linear model.

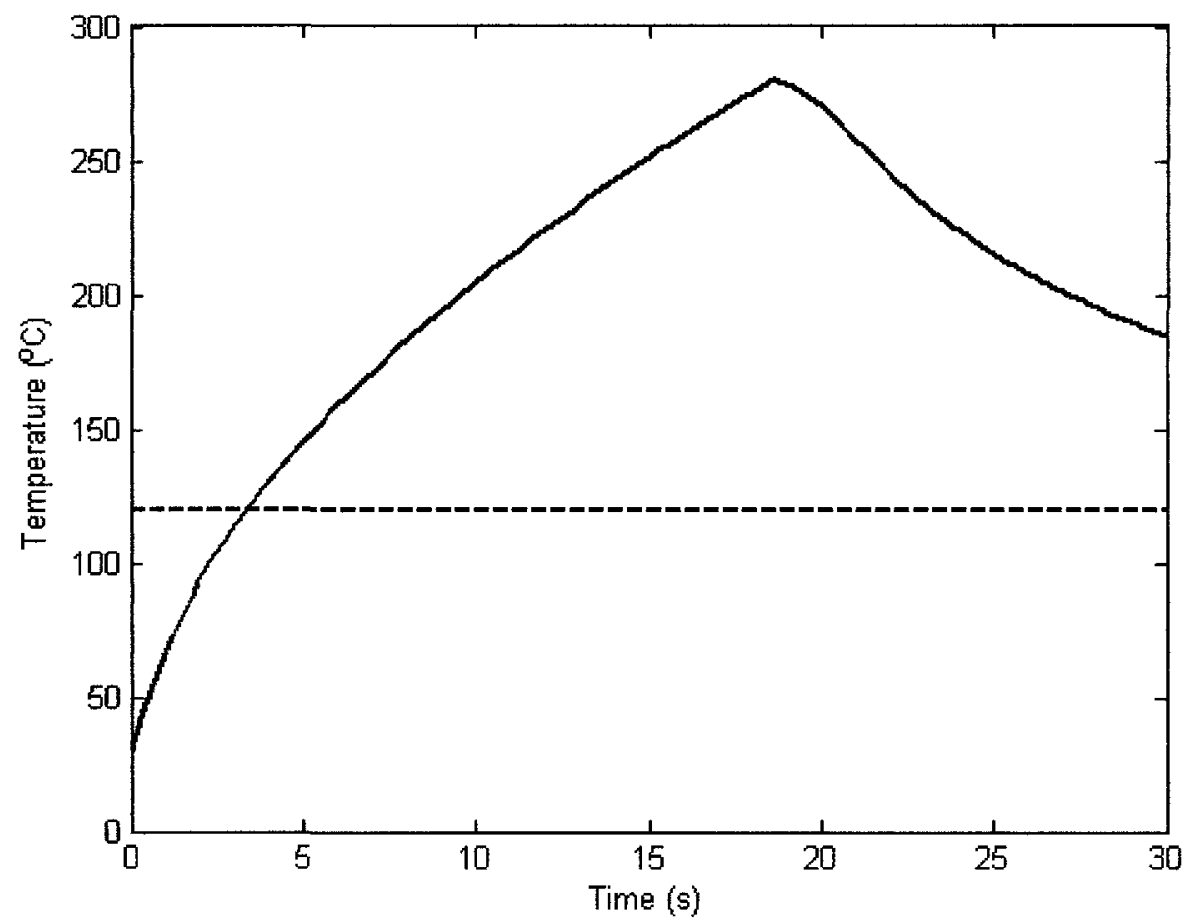

Figure 4.8 - Temperature profile at midpoint of fourth weld section from $3 \mathrm{D}$ model at $5.65 \mathrm{~V}$. The horizontal line denotes the pre-heat temperature of $120^{\circ} \mathrm{C}$.

Mathworks® "System Identification Toolbox" was utilized to identify a linear model from the data. The current was set as the input to the model, with the output being the temperature. The horizontal line in Fig. 4.8 represents the pre-heat temperature. Second and third order state space models were identified as,

$$
\begin{gathered}
\dot{x}=\left[\begin{array}{cc}
-0.4789 & -0.008652 \\
1 & 0
\end{array}\right] x+\left[\begin{array}{l}
1 \\
0
\end{array}\right] u \\
y=\left[\begin{array}{ll}
0.5500 & 0.1026
\end{array}\right] x, \quad x=\left[\begin{array}{ll}
x_{1} & x_{2}
\end{array}\right]^{T}
\end{gathered}
$$




$$
\begin{gathered}
\dot{\boldsymbol{x}}=\left[\begin{array}{ccc}
-1000.7 & -729.2 & -19.613 \\
1 & 0 & 0 \\
0 & 1 & 0
\end{array}\right] x+\left[\begin{array}{l}
1 \\
0 \\
0
\end{array}\right] u \\
y=\left[\begin{array}{lll}
0 & 686.34 & 224.02
\end{array}\right] x, \quad x=\left[\begin{array}{ll}
x_{1} & x_{2}
\end{array}\right]^{T}
\end{gathered}
$$

where $y$ is the weld temperature in ${ }^{\circ} \mathrm{C}$, and $u$ is the measured weld current in A. Since these models were created using experimental data, the states of the equations, $x$, have no physical meaning. The comparison of both models with the original 3D model, and the resulting errors, are shown in Figures 4.9 and 4.10. Both models represent the trend of the original model well, with the third order model converging faster to a steady-state error of approximately 5\%. However, the temperature range in which the model is used is less than $225^{\circ} \mathrm{C}$. Within that range, the second order model is more accurate, with an error less than 5\%. Also, within that range, the second order model slightly underpredicts the temperature, where as the third order model over-predicts the temperature. In this particular process, a higher temperature than the control point is more acceptable than a lower one because a bond will still form. On the other hand, over-predicting temperature results in a lower actual temperature, which is undesirable because it may result in a poor weld. For these reasons, the second order model was chosen for online estimation. 


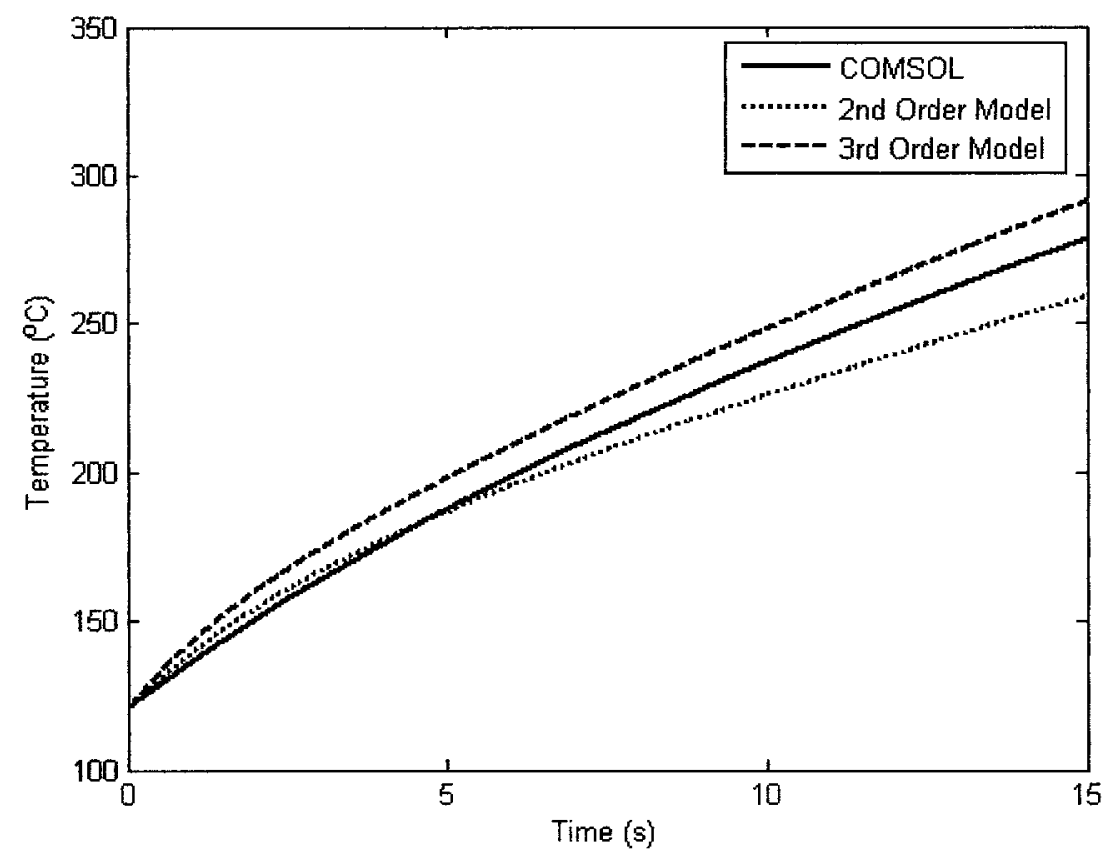

Figure 4.9 - Comparison of temperature between the $2^{\text {nd }}$ and $3^{\text {rd }}$ order state-space models with the COMSOL model .

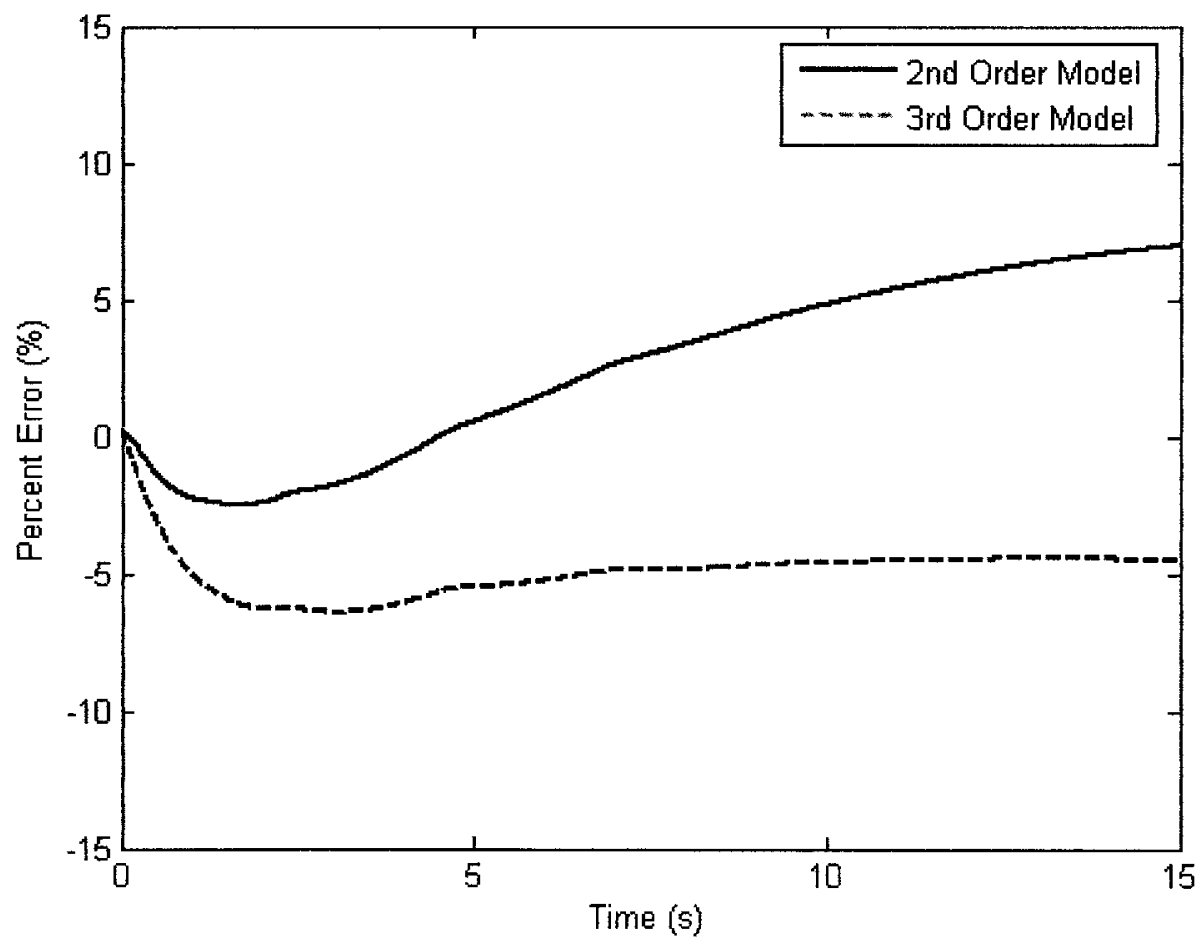

Figure 4.10 - Percentage error between the $2^{\text {nd }}$ and $3^{\text {rd }}$ order models and the $3 \mathrm{D}$ model. 


\subsection{Fuzzy Logic Controller (FLC) Development}

Typical fuzzy controllers have two inputs; an error signal generated from subtracting the feedback signal from a reference value, and the rate at which that error signal is changing [34]. The two outputs are the process voltage, and linear weld speed. The control loop for the resistance welding process is shown in Fig. 4.11. In simulation, the voltage signal is divided by $0.14 \Omega$, the total resistance of the heating element, to approximate the resulting current. The current is then used as the input to the temperature estimator. In the real-time setup the current will be read directly from the power supply, which is an accurate measurement.

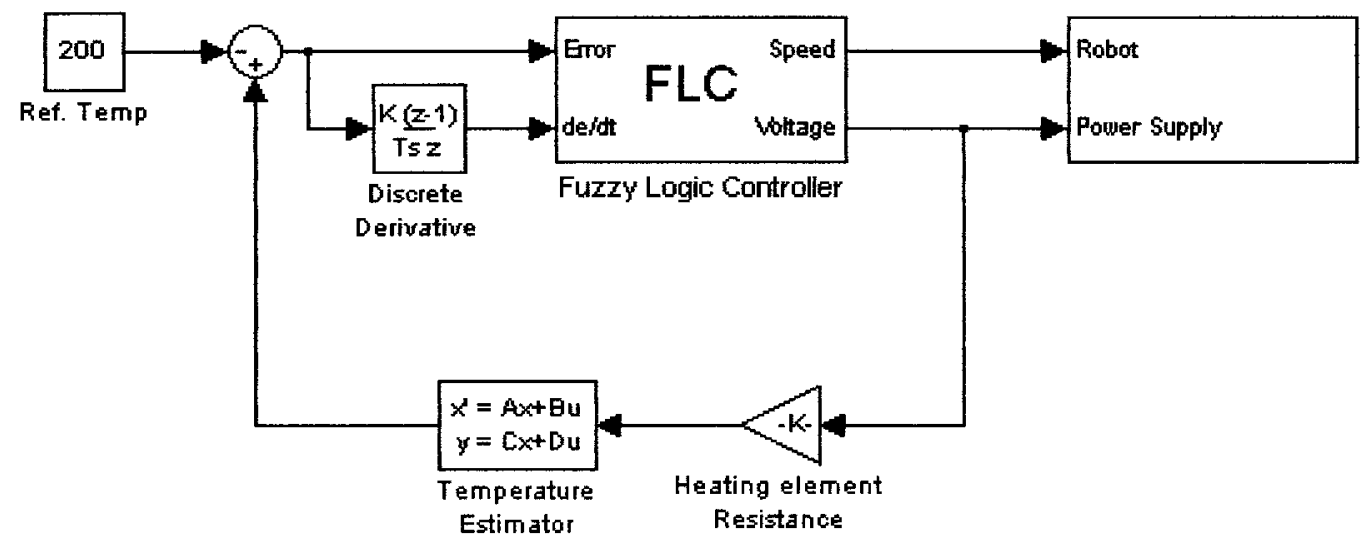

Figure 4.11 - Simple control loop in Simulink showing the controller inputs and outputs as well as the location of the temperature estimator.

\subsubsection{Fuzzy Logic Controller Structure}

The error signal was divided into seven triangular membership functions across a range of $-20^{\circ} \mathrm{C}$ to $20^{\circ} \mathrm{C}$. This is $10 \%$ of the reference temperature of $200^{\circ} \mathrm{C}$. Initially $+/-$ $10^{\circ} \mathrm{C}, 5 \%$ of the reference temperature, was considered as the range but it was thought that the voltage would have to drop too rapidly as the temperature approached the reference temperature. Also, having a range of $5 \%$ of the reference temperature is an 
insufficient range. Figure 4.12 presents the fuzzified error signal which is divided into the following seven membership functions:

- VC - Very cold

- MC - Medium Cold

- SC - Slightly Cold

- Z - Zero

- SH - Slightly Hot

- MH - Medium Hot

- VH - Very Hot

If the error is outside the range of $+/-20^{\circ} \mathrm{C}$ error then it is defined to be "VC" or "VH" depending on which boundary the error signal crossed. The membership functions were also slightly narrowed as the temperature error approaches zero. This kept the control a little more aggressive keeping the voltage higher for a longer period of time before the error reached the "Zero" membership function. Once the error reaches the "Zero" membership function the voltage should start to drop significantly.

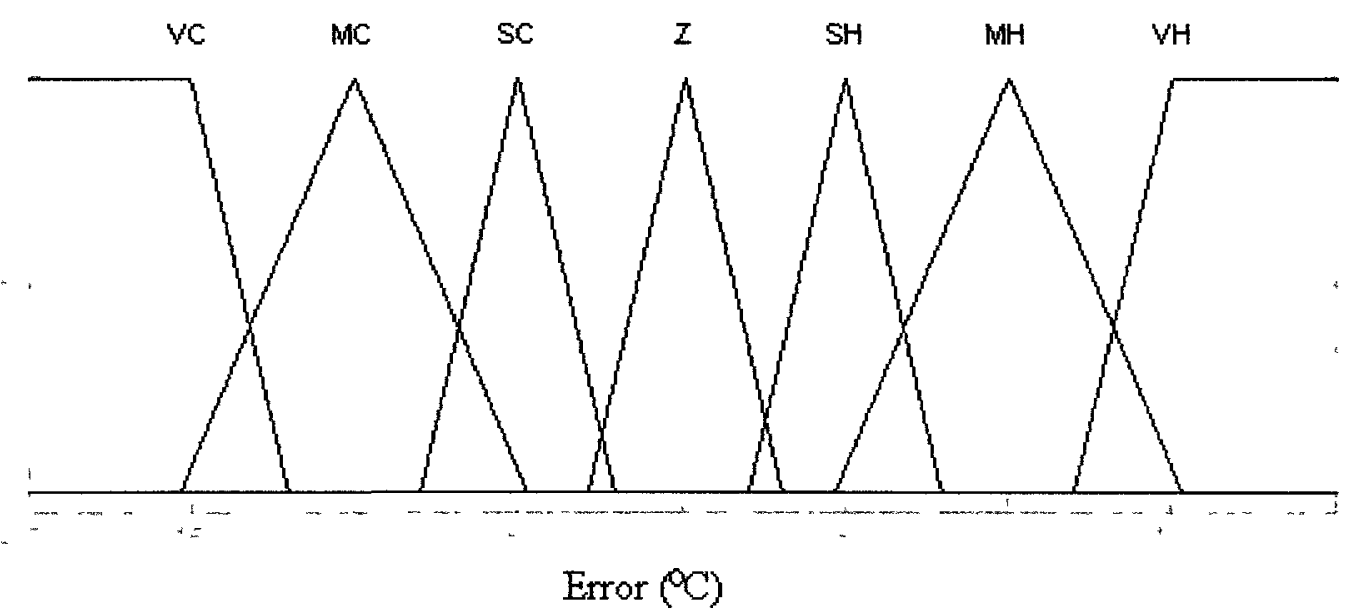

Figure 4.12 - Membership functions assigned to the temperature error signal.

The rate of change of the error signal was also divided into seven membership functions ranging from $-25^{\circ} \mathrm{C} / \mathrm{s}$ to $25^{\circ} \mathrm{C} / \mathrm{s}$. This particular universe of discourse was chosen for the error rate because it was the first maximum reached in the temperature 
gradient while welding at $6 \mathrm{~V}$, shown in Fig. 4.13. The seven membership functions, displayed in Fig. 4.14 are,

- GVC - Getting Very Cold

- GMC - Getting Medium Cold

- GSC - Getting Slightly Cold

- Z -Zero

- GSH - Getting Slightly Hot

- $\mathrm{GMH}$ - Getting Medium Hot

- GVH - Getting Very Hot

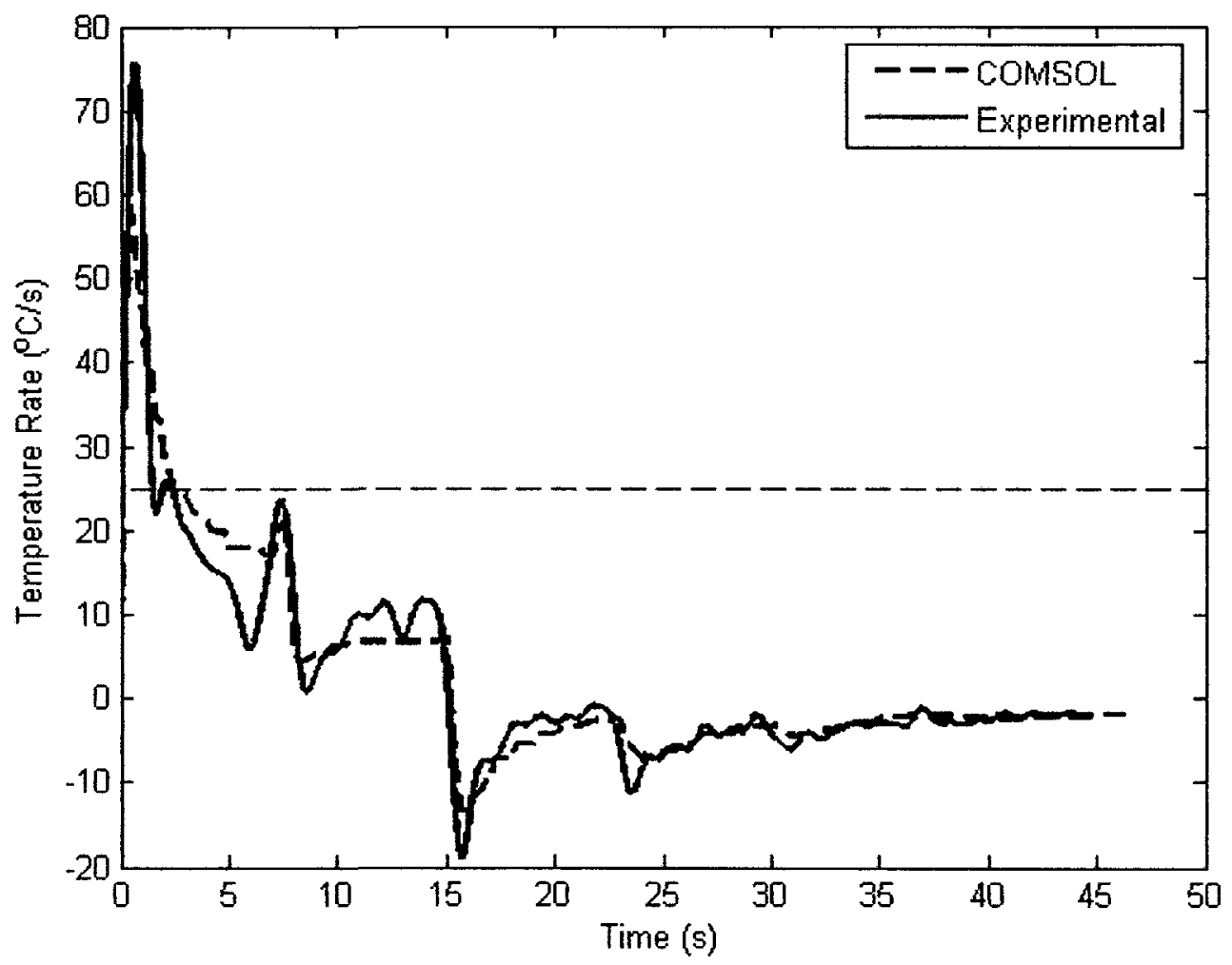

Figure 4.13 - Temperature gradient taken from Fig. 3.29 for both the model and experiment. The $-25^{\circ} \mathrm{C} / \mathrm{s}$ horizontal line is defined as the universe of discourse for the error rate.

The word "Getting" in the membership functions is to indicate that the error is changing, signifying a rate. As is the case with the error signal, any error rate outside the 
universe of discourse of $+/-25^{\circ} \mathrm{C} / \mathrm{s}$ is set to "GVC" or "GVH" depending on which boundary the signal has crossed.

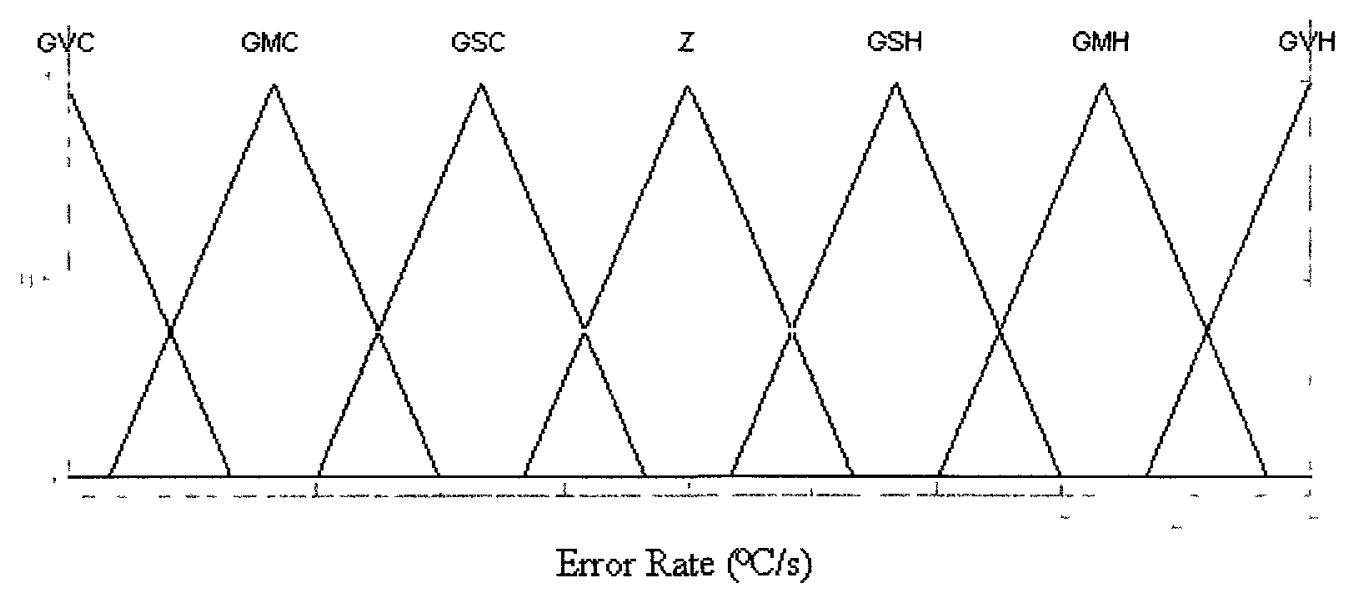

Figure 4.14 - Membership functions assigned to the error rate.

For the output of the fuzzy controller, the speed was divided into four triangular membership functions, Fig. 4.15, ranging from $3 \mathrm{in} / \mathrm{min}$ to $8 \mathrm{in} / \mathrm{min}$. This particular range was determined experimentally. A weld speed of $3 \mathrm{inch} / \mathrm{min}$ was the slowest we ever welded, and over $8 \mathrm{inch} / \mathrm{min}$ resulted in a lack of a weld because the compaction time was too short. Of course, this does depend on the input voltage. The speed was divided into only four membership functions to reduce the controller complexity. These membership functions, shown in Fig. 4.15, are defined as,

- S - Slow

- SM - Slow-Medium

- M - Medium

- F - Fast

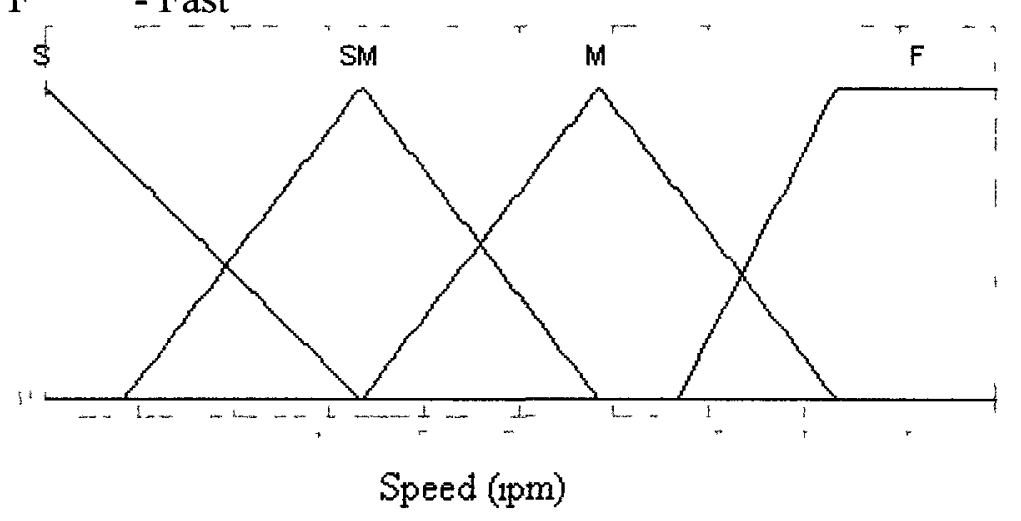

Figure 4.15 - Membership functions assigned to the speed output. 
The voltage was also divided into seven triangular membership functions, Fig. 4.16 , ranging from $0 \mathrm{~V}$ to $6 \mathrm{~V}$. Six volts was chosen as the maximum because it was the highest reached during experiments. The notation of these membership functions are defined as,

- VL -Very Low

- ML -Medium Low

- SL -Slightly Low

- MID -Middle

- SH -Slightly High

- MH -Medium High

- VH -Very High

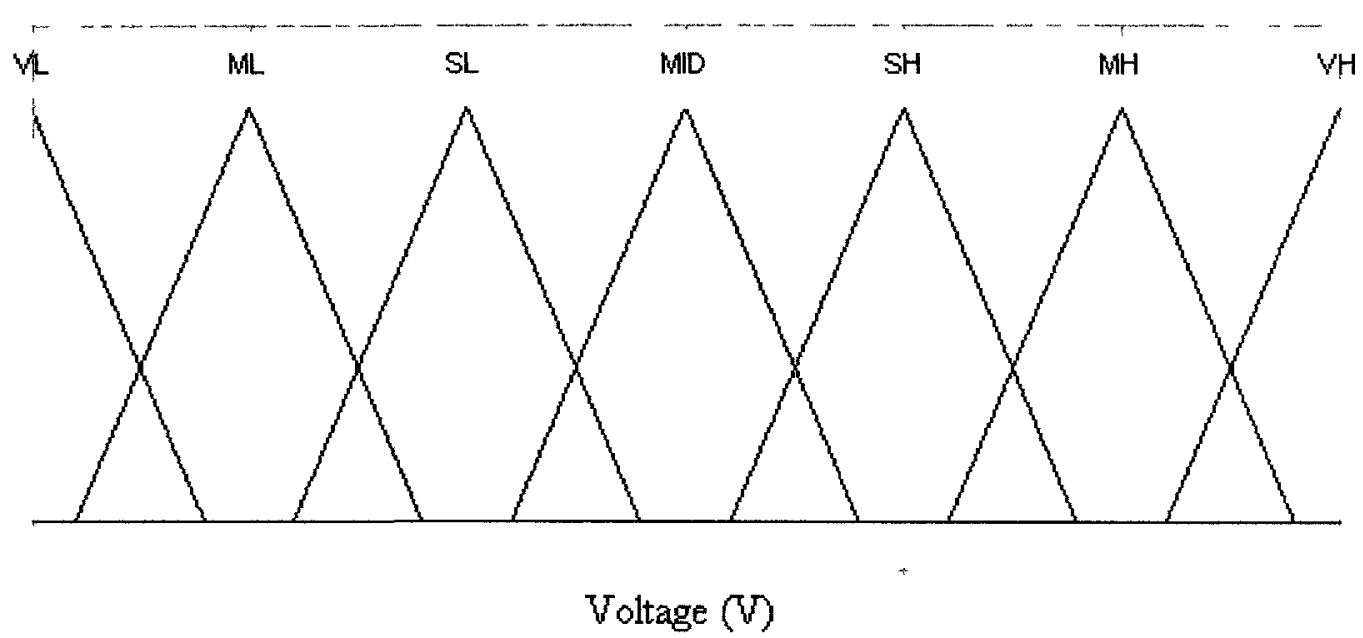

Figure 4.16 - Membership functions assigned to the voltage output.

After the membership functions were set, the rule base was created. The first set of rules were defined from the experience obtained from working with the resistance welding process. The initial rule base is presented in Table 4.1. Some of these rules were immediately set, and did not change upon control iteration. For example, if the error is "very cold" and the error rate was "getting very cold" than the only option for the voltage would be "very high". However, some were set more or less arbitrarily because they were more or less in a grey area where it was thought that there could be more than one evaluation for the rule. For example if the error was "slightly cold" and the error rate was "getting slightly cold" then the voltage output could be set to "slightly high", or 
could be set to "middle". It could be the case that the "slightly high" voltage would be too high, and may cause an overshoot in temperature.

\begin{tabular}{|c|c|c|c|c|c|c|c|c|}
\hline \multicolumn{2}{|c|}{ VOLTAGE } & \multicolumn{7}{|c|}{ ERROR } \\
\hline \multirow{8}{*}{$\begin{array}{l}\text { ERROR } \\
\text { RATE }\end{array}$} & & VC & MC & SC & $\mathbf{Z}$ & SH & MH & VH \\
\hline & GVC & VH & $\mathrm{VH}$ & $\mathrm{SH}$ & - & - & - & MID \\
\hline & GMC & $\mathrm{VH}$ & $\mathrm{VH}$ & $\mathrm{SH}$ & - & - & - & - \\
\hline & GSC & $\mathrm{VH}$ & $\mathrm{VH}$ & $\mathrm{MHH}$ & MID & - & - & - \\
\hline & $\mathbf{Z}$ & VH & $\mathrm{VH}$ & MID & - & - & - & - \\
\hline & GSH & $\mathrm{VH}$ & VH & $\mathrm{SL}$ & $\mathrm{SL}$ & - & - & - \\
\hline & GMH & $\mathrm{VH}$ & $\mathrm{VH}$ & $\mathrm{ML}$ & - & - & - & - \\
\hline & GVH & $\mathrm{VH}$ & $\mathrm{VH}$ & MID & $\mathrm{ML}$ & - & - & $\mathrm{VL}$ \\
\hline
\end{tabular}

Table 4.1 - Initial rule base for the voltage output from the fuzzy logic controller.

In Table 4.1 there are several omitted entries. This is because it was not immediately clear as to what the controllers response should be. To be able to fill the gaps in the table, the rules were plotted as a surface to get an idea of how the rules are changing overall. The rule surface is presented in Fig. 4.17. It is noted that any entries that are omitted in Table 4.1 were assigned a value of three volts. It is clear immediately upon looking at Fig. 4.17 that there are not enough rules defined to show a smooth transition from rule to rule. The flaw here is that a non-smooth rule surface would not allow the controller to output a smooth control signal. For example, a discontinuous rule surface would result in a voltage signal that is itself discontinuous. This is crucial to avoid, since abrupt changes in the signal could not only cause oscillations in the temperature, but could also potentially damage the power supply if these sharp variations are high enough. 


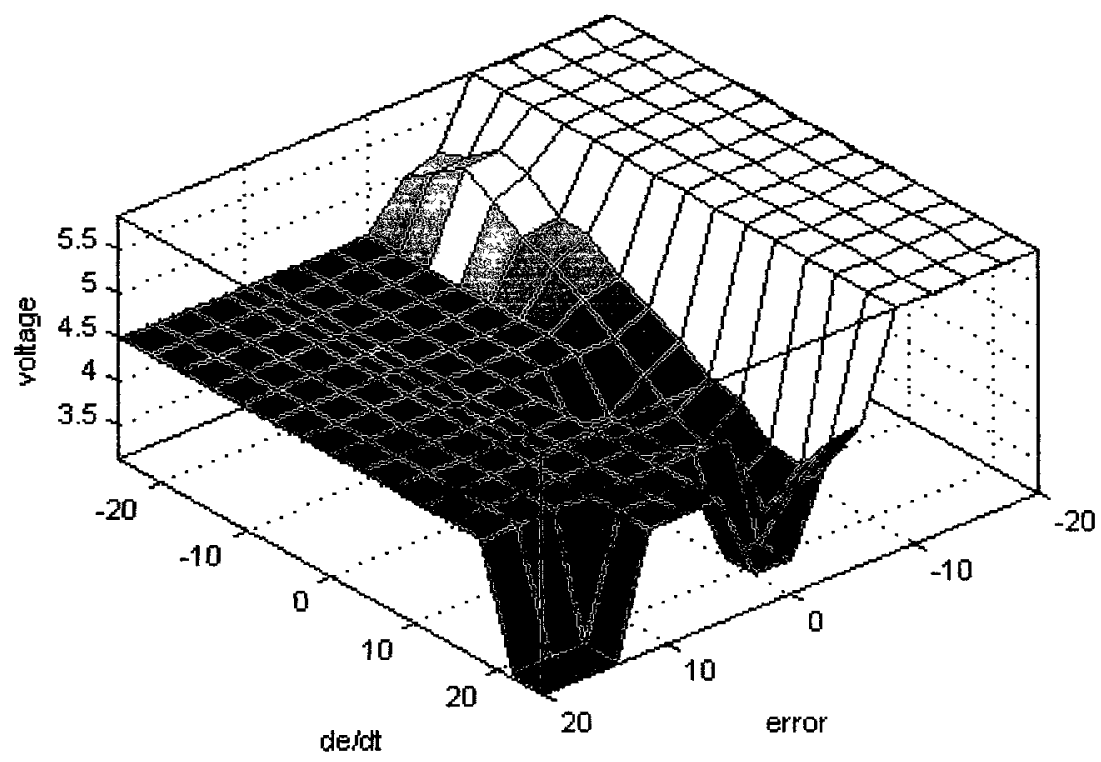

Figure 4.17 - Rule surface according to rule base outlined in Table 4.1.

The next step was to fill in the gaps in Table 4.1, as well as modify some of the existing rules. Since some of the rules were difficult to determine, the approach was to modify the rules to obtain a rule surface that was relatively smooth, without any peaks from rule to rule. This resulted in the rule surface shown in Fig. 4.18, which corresponds to the rule base in Table 4.2. The bold items in Table 4.2 are the rules modified from the initial rule base in Table 4.1. The surface has a smoother voltage drop off across the full range. The voltage was configured to drop as the error approached zero. The contours of the surface are not constant across both error and error rate. The voltage drops as the error drops, as well as when the error rate becomes large. It is understood that if the temperature is rising quickly the voltage may need to be reduced slightly to prevent any overshoot from happening during control. However, that is not the case when the error is "very low". Conversely, if large error rates are accompanied with "very low" errors, the technique to reduce the voltage is abandoned for high voltages to compensate for a temperature that is too low. In these cases, the dampening effect the error rate term has on the voltage is not required. 


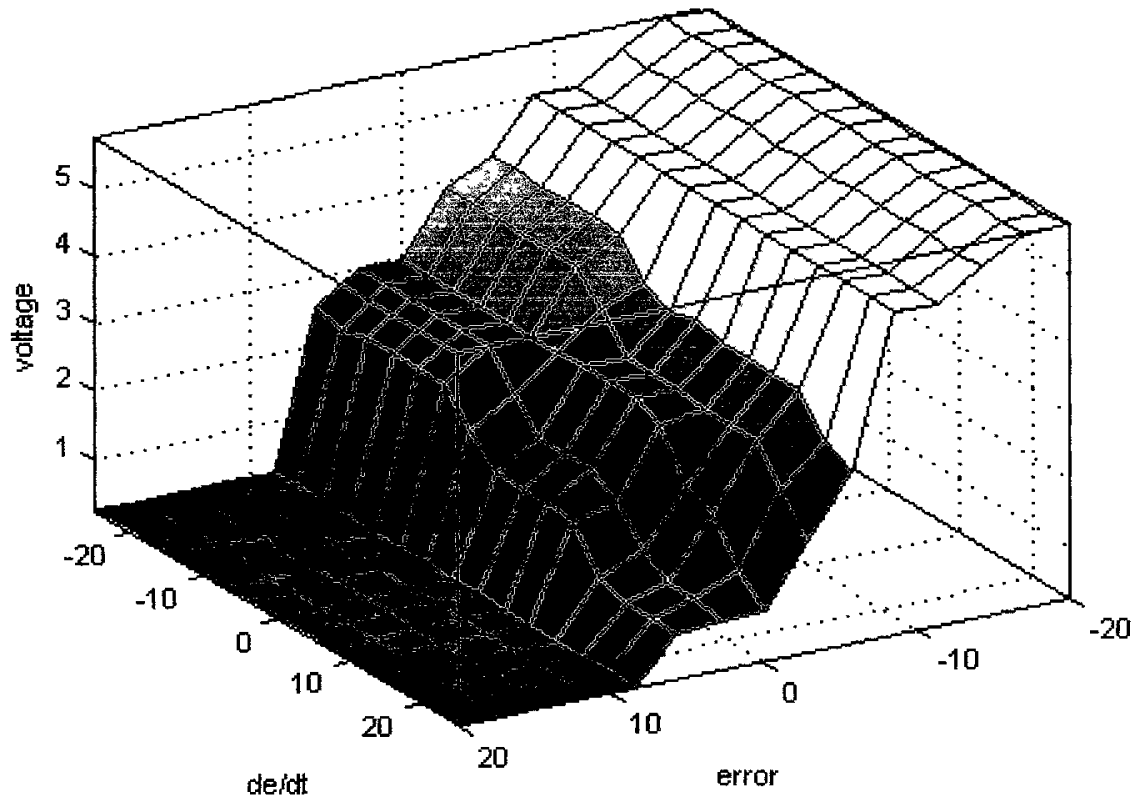

Figure 4.18 - Rule surface corresponding to modified rule base in Table 4.2.

\begin{tabular}{|c|c|c|c|c|c|c|c|c|}
\hline \multicolumn{2}{|c|}{ VOLTAGE } & \multicolumn{7}{|c|}{ ERROR } \\
\hline \multirow{8}{*}{$\begin{array}{c}\text { ERROR } \\
\text { RATE }\end{array}$} & & VC & MC & SC & $\mathbf{Z}$ & SH & $\mathbf{M H}$ & VH \\
\hline & GVC & VH & MH & $\mathrm{SH}$ & MID & MID & VL & VL \\
\hline & GMC & $\mathrm{VH}$ & MH & SH & MID & MID & $\mathbf{V} \mathbf{L}$ & $\mathbf{V L}$ \\
\hline & GSC & $\mathrm{VH}$ & MH & $\mathrm{SH}$ & MID & MID & $\mathbf{V L}$ & VL \\
\hline & $Z$ & $\mathrm{VH}$ & MH & MID & MID & $S L$ & $\mathbf{V L}$ & VL \\
\hline & GSH & $\mathrm{VH}$ & MH & MID & MID & SL & $\mathbf{V} \mathbf{L}$ & $\mathbf{V L}$ \\
\hline & GMH & $\mathrm{VH}$ & MH & MID & ML & ML & $\mathbf{V L}$ & VL \\
\hline & GVH & $\mathrm{VH}$ & MH & $\mathbf{S L}$ & $\mathrm{ML}$ & $\mathbf{M L}$ & $\mathbf{V L}$ & $\mathrm{VL}$ \\
\hline
\end{tabular}

Table 4.2 - Modified rule base for voltage that resulted in a smooth rule surface for control.

A similar approach was taken when creating the rule base for the weld speed. A smooth surface was desired to obtain a control signal without any unnecessary jumps. The speed was set to increase as the temperature error approached zero. It would then saturate at the maximum. There was no additional effect added as the error rate changed, because as mentioned earlier, the speed is not used to control the power, it is set to speed up the process according to the temperature value only. This is consistent with the control strategy where once the temperature set point is reached, the speed should be high to transition to the next weld section quickly. The resulting rule base is shown in Table 
4.3. It is clear from Fig. 4.19 that the weld speed is set to be "fast" for all conditions where the temperature error is "zero" and above.

\begin{tabular}{|c|c|c|c|c|c|c|c|c|}
\hline \multicolumn{2}{|c|}{ SPEED } & \multicolumn{7}{|c|}{ ERROR } \\
\hline \multirow{8}{*}{$\begin{array}{c}\text { ERROR } \\
\text { RATE }\end{array}$} & & VC & MC & SC & z & SH & MH & VH \\
\hline & GVC & $S$ & SM & $M$ & $\mathrm{~F}$ & $F$ & $F$ & $\mathrm{~F}$ \\
\hline & GMC & $S$ & SM & $M$ & $F$ & $F$ & $F$ & $\mathrm{~F}$ \\
\hline & GSC & $\mathrm{S}$ & SM & $M$ & $F$ & $F$ & $F$ & $F$ \\
\hline & $\mathbf{Z}$ & $S$ & SM & $M$ & $F$ & $F$ & $F$ & $F$ \\
\hline & GSH & $S$ & SM & $M$ & $F$ & $F$ & $F$ & $F$ \\
\hline & GMH & $S$ & SM & $M$ & $F$ & $F$ & $F$ & $\mathrm{~F}$ \\
\hline & GVH & $\mathrm{S}$ & SM & $M$ & $\mathrm{~F}$ & $\mathrm{~F}$ & $\mathrm{~F}$ & $F$ \\
\hline
\end{tabular}

Table 4.3 - Rule base used for the weld speed

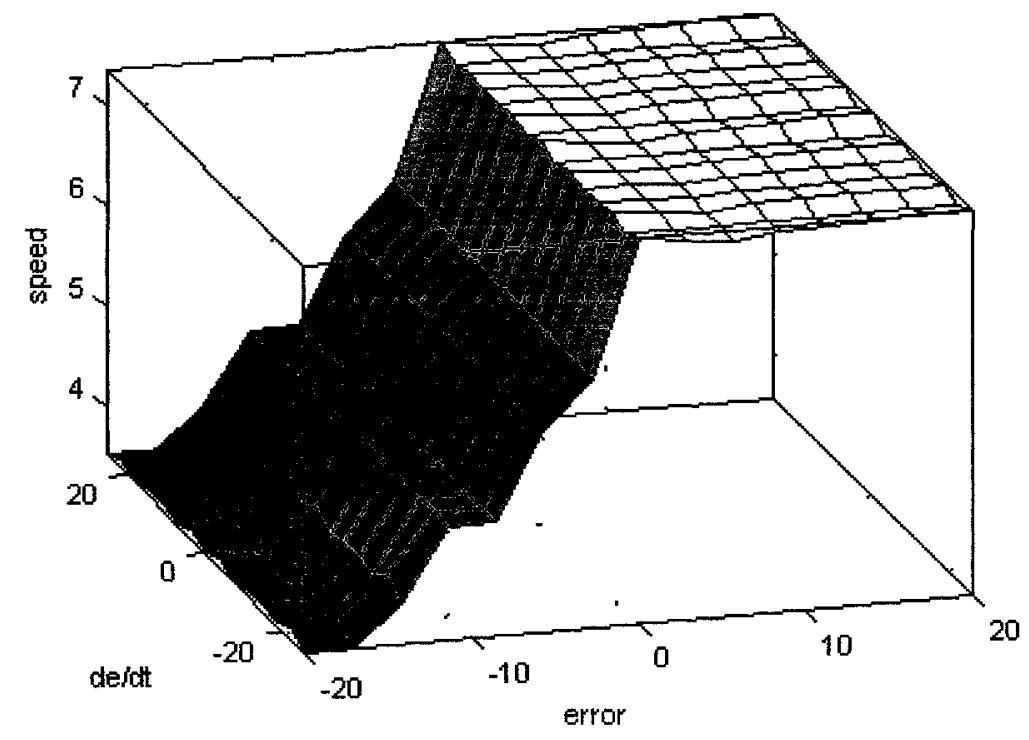

Figure 4.19 - Rule surface for the weld speed defined by the parameters in Table 4.3.

\subsubsection{Controller Simulation}

\subsubsection{Simulation Diagram}

The next step was to verify the effect of the fuzzy controller with the linear model to investigate its capability. Simulink $($ was used to simulate the controller shown in Fig. 4.20. The linear model was set up in such a way to mimic the discrete nature of the 
process. The switch, shown in Fig. 4.21, was how it was implemented. The weld speed, was converted to inches per second and integrated to get the distance travelled. To recall, the width of a copper block is 0.48 inches, with a gap of 0.02 inches in between blocks. The distance was monitored by means of an "if-else" statement. When the distance was less than 0.49 in the linear model was evaluated using the current, subsystem "IF-SS model" in Fig. 4.21. When the distance was greater than 0.49 in, the subsystem "Trigger" would generate a rising step curve to reset the integrator to its initial conditions of zero. At the same time, subsystem "IF-SS model", the contents of which are shown in Fig. 4.22, had the states of the temperature linear model set back to their initial value of zero. The pre-heat temperature is then added to these initial conditions to ensure that the temperature starts from $120^{\circ} \mathrm{C}$. Physically this depicts one section being welded, followed by the next. The resetting of the temperature linear model indicates that the copper electrodes have moved to the next weld section and the control point has moved to the midpoint of this weld section. The distance was used to determine when the temperature linear model would reset back to initial conditions, signifying when the electrodes are directly atop the next weld section. The unit-delays were used to avoid any algebraic loops.

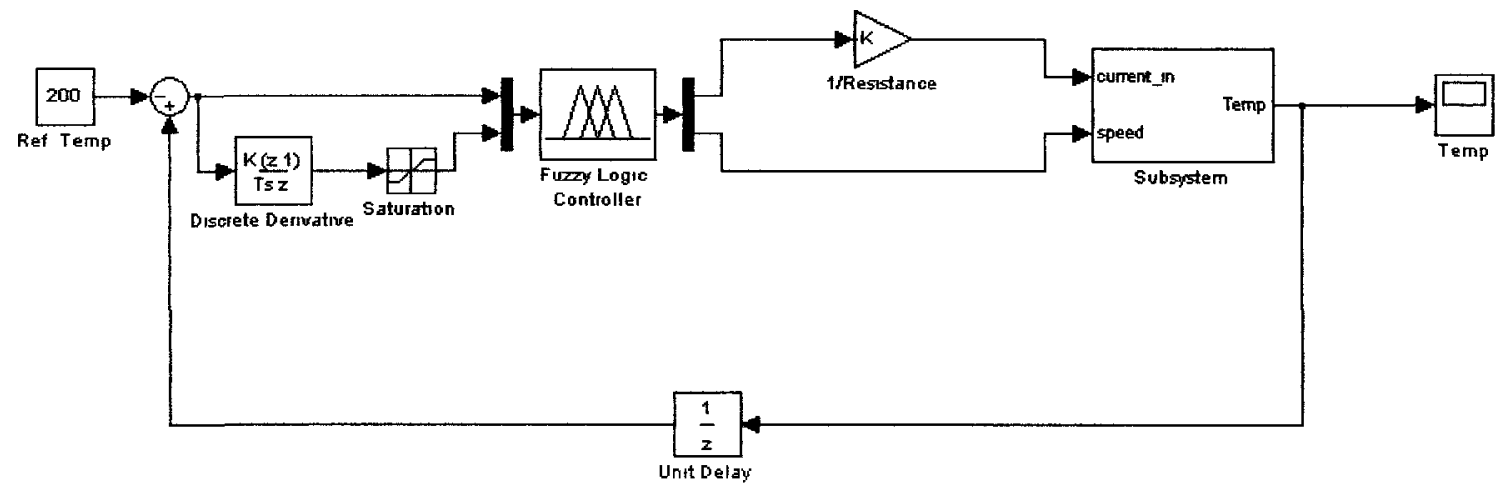

Figure 4.20 - Closed-loop used in Simulink $($ to simulate the effectiveness of the fuzzy logic controller. 


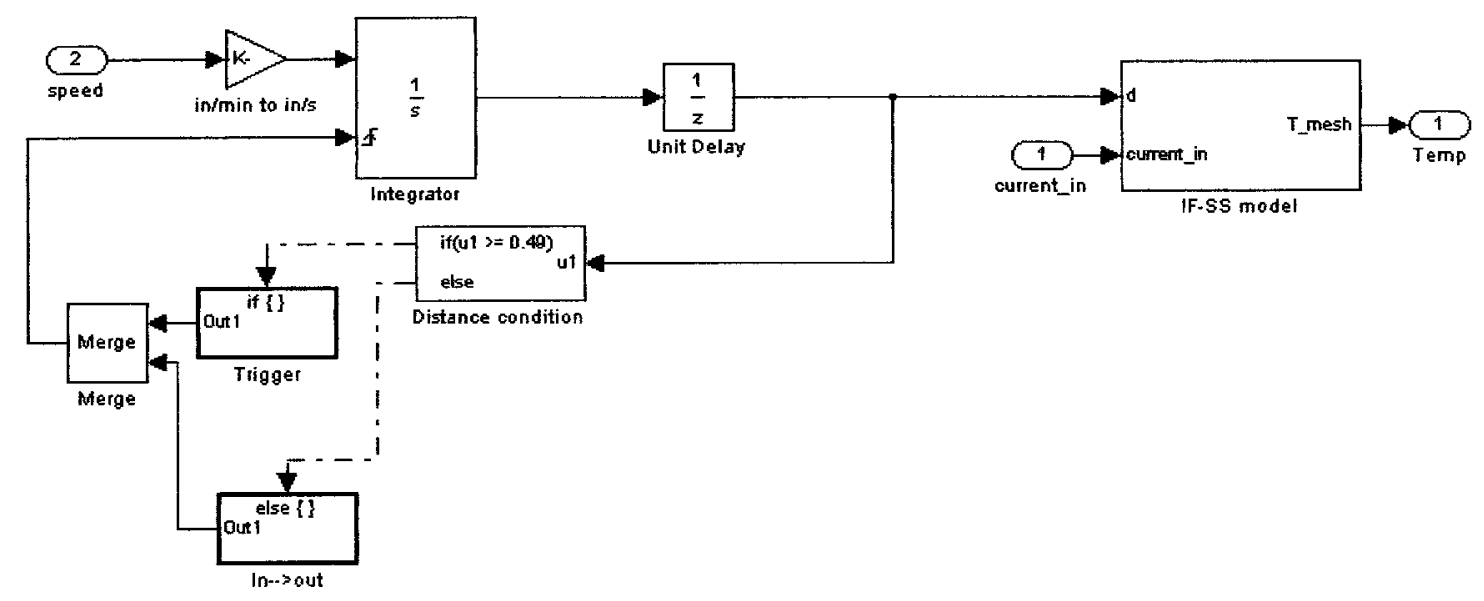

Figure 4.21 - Switch used to model the position resetting that occurs in the process from weld section to weld section.

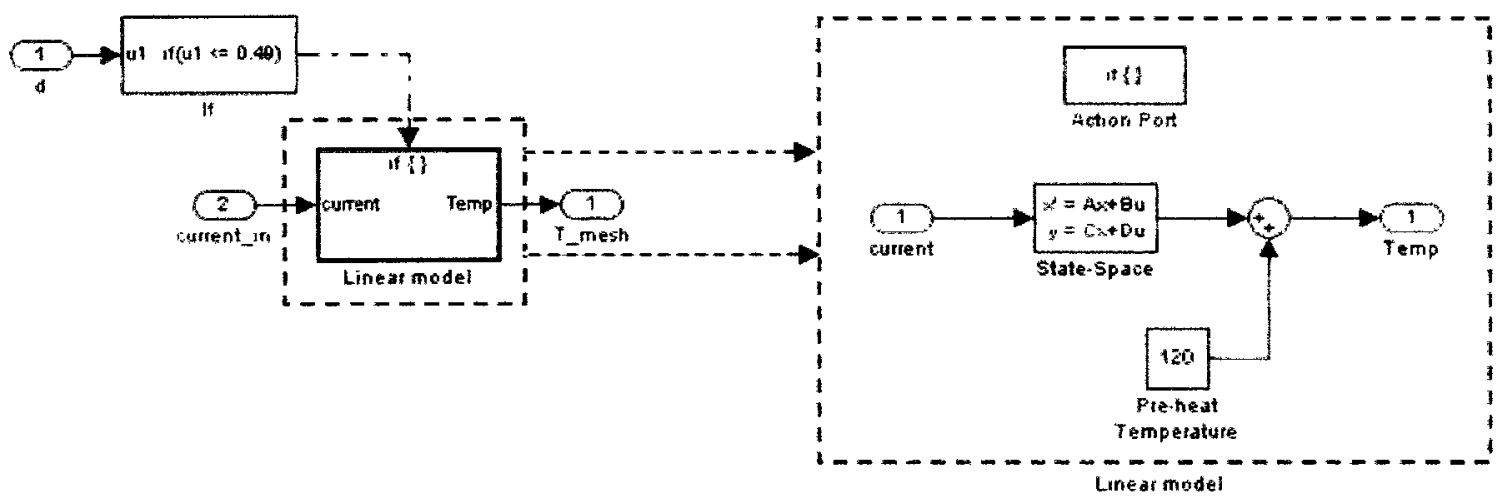

Figure 4.22 - Contents of subsystem "If-SS model" from Fig. 4.21. The "if" conditions resets the states of the linear model when the distance is larger than 0.49 inches.

\subsubsection{Simulation Results}

The Simulink ${ }^{\circledR}$ model was simulated for five consecutive weld sections. The temperature predicted by the linear model is shown in Fig. 4.23. Each curve in Fig. 4.23(a) represents the temperature reached at the midpoint of a single weld section. The reference temperature was set at $200^{\circ} \mathrm{C}$. Figure 4.23 (b) shows the controlled temperature profile of one weld section. A temperature of $195^{\circ} \mathrm{C}$ was reached in 7.18 seconds, translating to an error of $2.5 \%$. After this time, the temperature was reset back to the preheat temperature of $120^{\circ} \mathrm{C}$. At this point the distance travelled was greater than 0.49 in, indicating that the next weld section had been reached, triggering both the integrator and 
linear model to reset simultaneously. The voltage signal is shown in Fig. 4.24. The voltage was held at is maximum of approximately $5.7 \mathrm{~V}$ for 3.72 seconds, at which point it begins to drop reaching a minimum just above $3.0 \mathrm{~V}$.

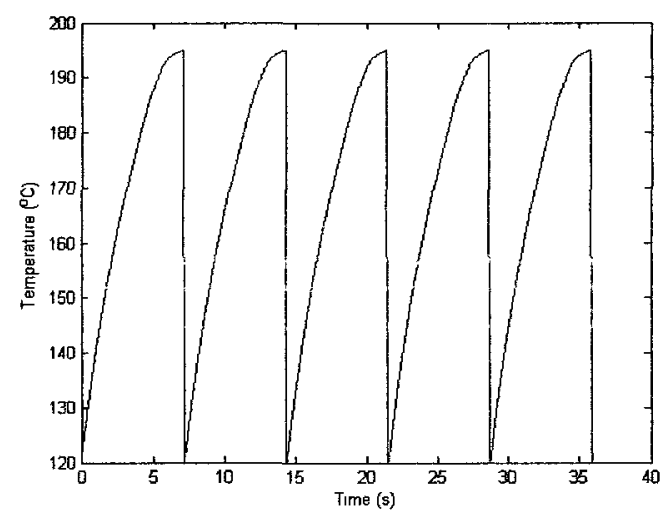

(a)

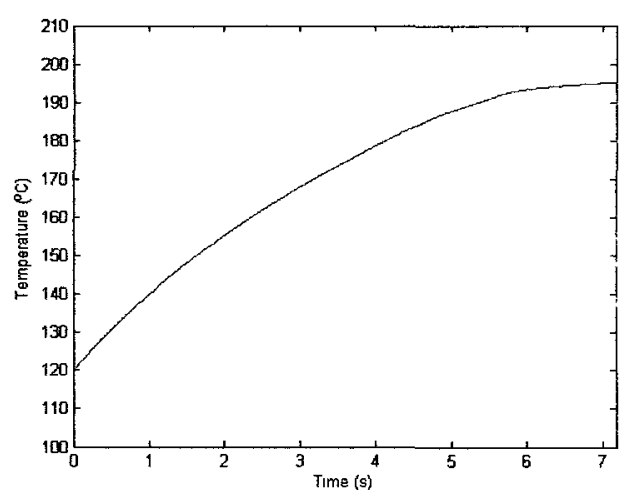

(b)

Figure 4.23 - Temperature variations for (a) five consecutive blocks, and (b) for the first block.

The weld speed, shown in Fig. 4.25, was initiated at approximately $3.5 \mathrm{in} / \mathrm{min}$, and began to rise after 4.6 seconds. The weld speed has the opposite effect of the voltage. As the temperature approaches the set point, the voltage drops, while the speed increases.

The fuzzy logic controller outputs the same control signal for each weld section in its attempt to reach the controller set point. As a direct result of this, the temperature for each weld section has the exact same profile. The current may fluctuate slightly during experiments on a weld section as was depicted in Figures 3.12 to 3.16. Although the 3D model predicted accurately the current, the linear model will not be able to estimate the temperature if the current fluctuates significantly. However, as will be discussed later, the significance of this effect will have to be determined when the model is used in realtime control experiments. 


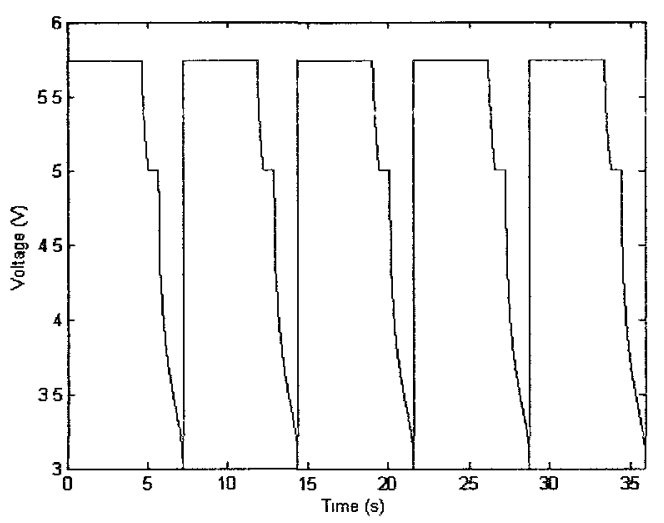

(a)

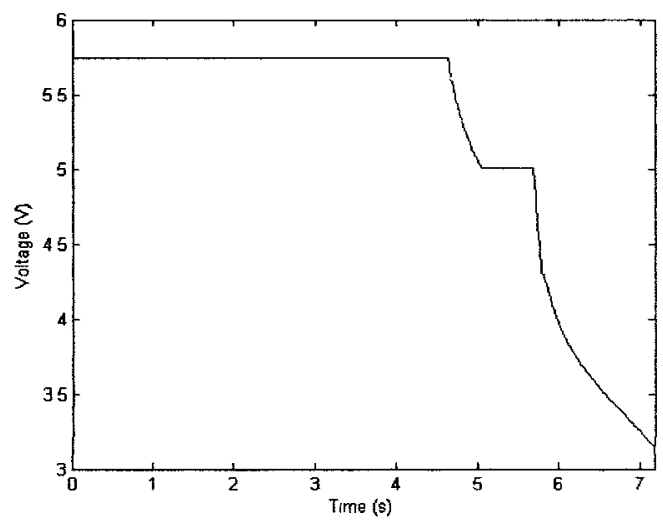

(b)

Figure 4.24 - Voltage control signal for (a) five consecutive blocks, (b) for the first block.

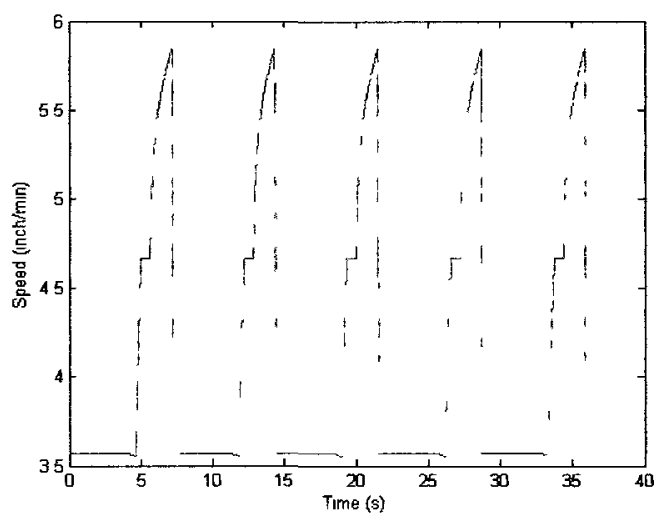

(a)

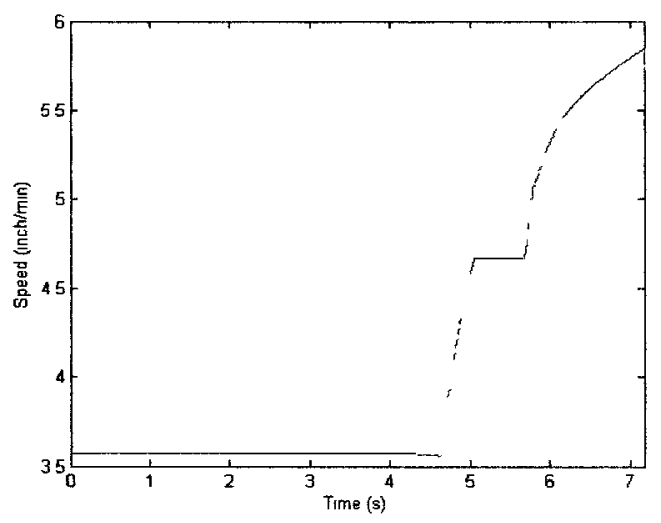

(b)

Figure 4.25 - Speed control signal for (a) five consecutive blocks, (b) for the first block.

Due to the copper block strips, this resistance welding process is accomplished section by section, rather than continuously. This adds a significant challenge when trying to control the centerline temperature because the process is inherently discrete. Since the process is discrete, the efficient way to control it would be discretely. The approach taken was to control the midpoint temperature of a single weld section, and then repeat for all weld sections. The result was a fuzzy logic controller that reached the reference temperature of $200^{\circ} \mathrm{C}$ with $2.5 \%$ error. The next step is to implement this system in real-time with the experimental setup to investigate the controller's performance in real-world experiments. To accomplish this, the fuzzy logic controller was coded in C-language and uploaded to the real-time experimental setup in the lab. 


\section{Chapter 5}

\section{Real-Time Control Implementation}

\subsection{Real-Time Experimental Setup}

The fuzzy logic controller was implemented with the experimental setup using RT-Lab ${ }^{\mathrm{TM}}$ system supplied by Opal-RT Inc. The RT-Lab ${ }^{\mathrm{TM}}$ system is a real-time platform that allows real-time execution of Simulink ${ }^{\circledR}$ models generated by the RealTime Workshop Toolbox on a QNX operating system [36]. The physical plant in this case is the resistance welding process, and the control program will run on the QNX realtime target node after compilation and communicates with the system through $\mathrm{I} / \mathrm{O}$ boards. RT-Lab ${ }^{\mathrm{TM}}$ consists of two components, a command station and a target node. The command station is a Windows platform PC that is used to create the Simulink® model, start/stop it, edit it, generate code, and see model data. The target node is a real-time processing and communication computer connected to the command station via Ethernet.

The diagram in Fig. 5.1 represents the loops present in the experimental setup with RT-Lab ${ }^{\mathrm{TM}}$. The RT-Lab ${ }^{\mathrm{TM}}$ real-time node is responsible for writing the voltage set from the controller to the power supply unit (PSU), and the weld speed to the robot controller. The voltage signal is passed through the KUKA robot controller before being set to the copper electrodes. It is routed through the emergency stops on the robot teach 
pendant for safety reasons. The voltage is then read across the electrodes and fed-back to the PSU, and then re-routed to the RT-Lab ${ }^{\mathrm{TM}}$ node. The weld speed is written directly to the KUKA robot controller. Unfortunately the parameter that sets the robot linear speed is write-protected by the robot controller. However, there exists a parameter known as the Program Override which can modify the movement of the robot on a percent basis.

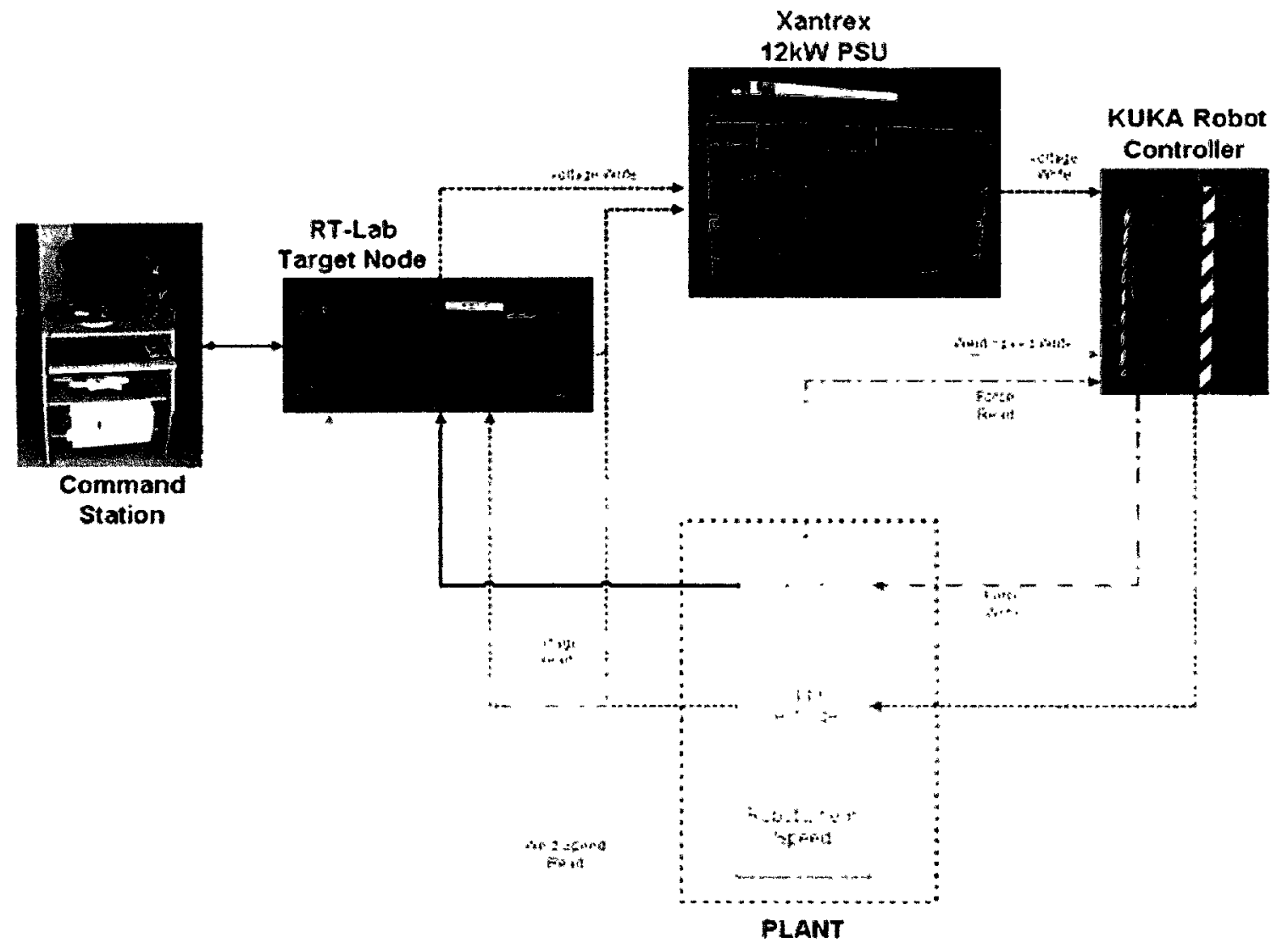

Figure 5.1 - Block diagram displaying a loops present in the experimental setup with RT-Lab ${ }^{\text {TM }}$ implemented.

In the robot program, the weld speed is defined to be 8 inches per minute, the maximum value defined in the fuzzy logic controller. The speed signal is then converted to a percent of that maximum speed and mapped to the Program Override variable. The robot weld speed is then multiplied by this percentage and then sent to the RT-Lab ${ }^{\mathrm{TM}}$ node. The force is controlled through the Robot Sensor Interface (RSI) by means of a PI controller. 


\subsection{Simulink ${ }^{\circledR}$ Model for RT-Lab ${ }^{\mathrm{TM}}$}

The Simulink ${ }^{\circledR}$ model is divided into two main subsystems as shown in Fig. 5.2. The SM_Master subsystem is responsible for the model's real-time execution as well as any I/O communication. The SC_Console subsystem contains all the blocks for viewing the data as the system is running in real-time.

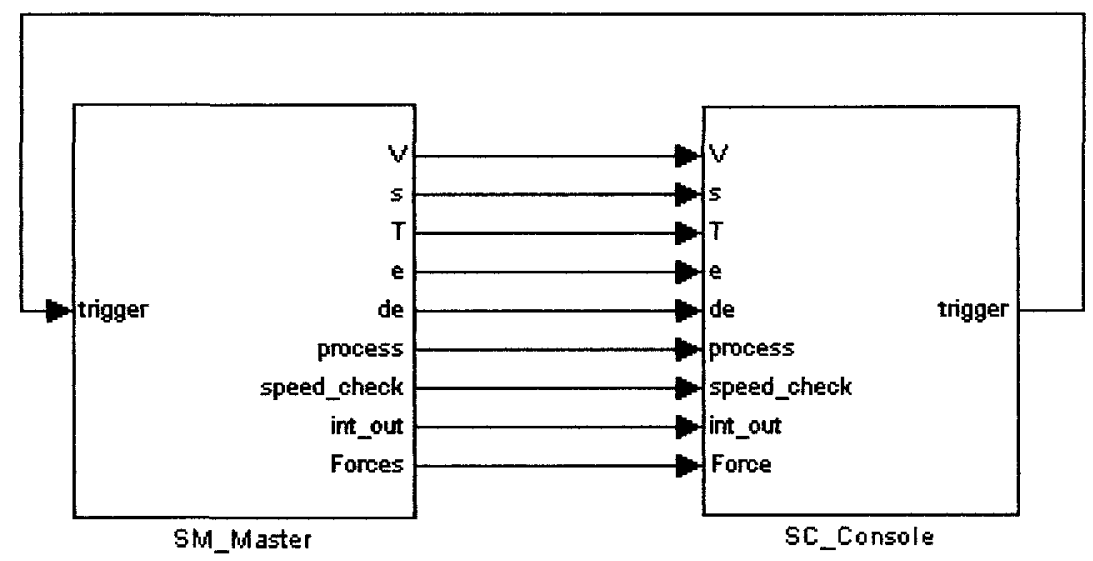

Figure 5.2 - Two major subsystems used in the Simulink ${ }^{\circledR}$ model with RT-Lab ${ }^{\mathrm{TM}}$.

\subsubsection{SM_Master Subsystem}

The master subsystem contains all the I/O blocks for data acquisition. The model is shown in Fig. 5.3. The Linear Model Subsystem has three inputs; current, speed, and distance travelled. This distance is used as the trigger for the switch shown in Fig. 5.4. The steady current changes significantly for the first two weld section, as was shown in Figures 3.12 to 3.16 ; therefore, the linear temperature estimator is not valid within the first two weld sections. The switches are used to set the input to the temperature estimator to zero until the electrodes have travelled one inch, the distance to the third weld section. Since there is no temperature estimation for the first two weld sections, the fuzzy controller is prevented from outputting its voltage during that time. Instead SWITCH $A$ in Fig. 5.3 is used to set the initial voltage at $6 \mathrm{~V}$ with a weld speed of 5 in $/$ min. The $3 \mathrm{D}$ model was used to determine these parameters, which yield a temperature of approximately $200^{\circ} \mathrm{C}$ for the first weld section. The contents of the 
Linear Model Temperature Estimator subsystem in Fig. 5.4 are identical to the subsystem used in offline simulation. 


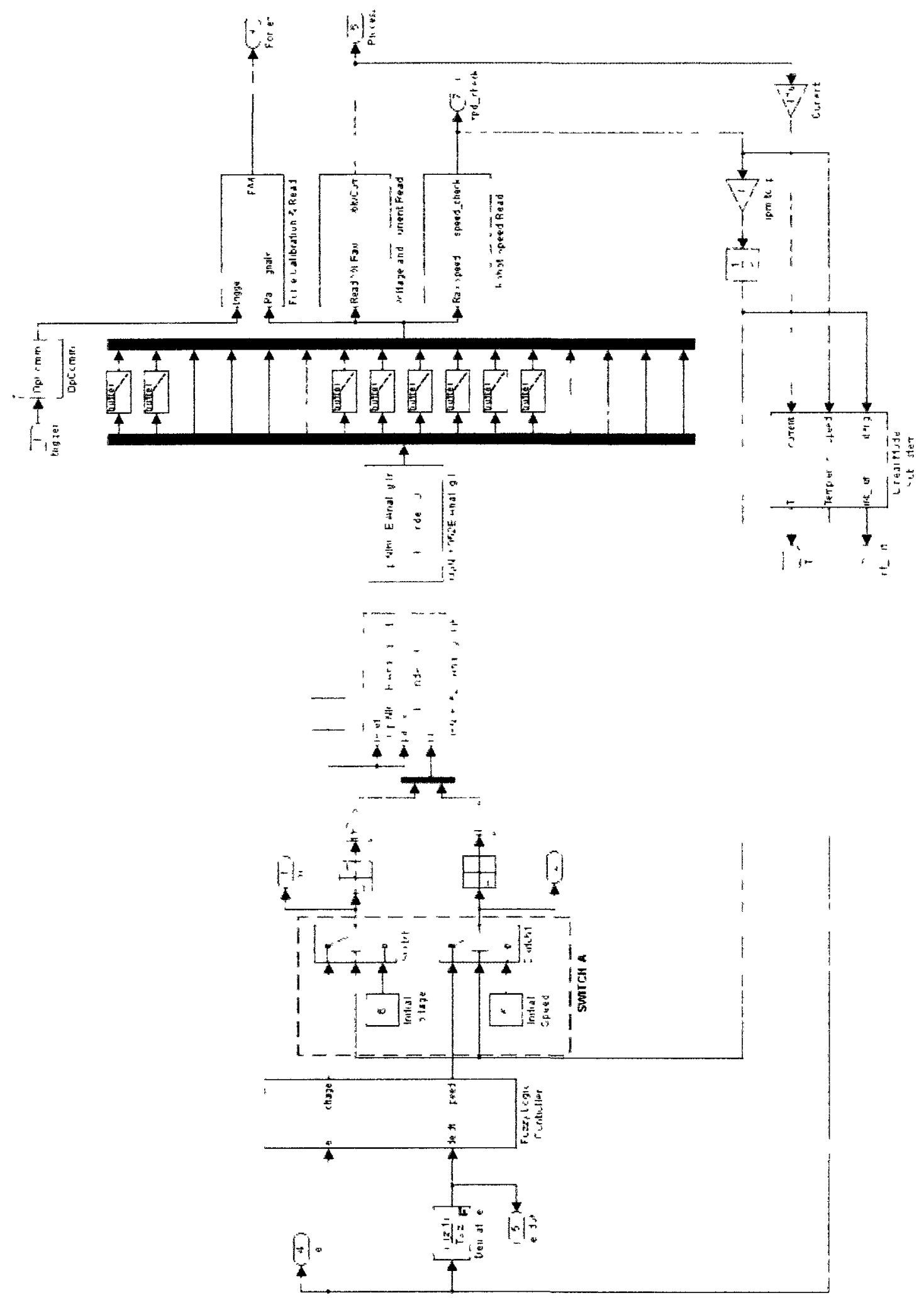

Figure 5.3 - SM_Master subsystem containing all I/O communications and the fuzzy logic controller. 
All input and output signals were sent using a National Instruments ${ }^{\mathrm{TM}} 6052 \mathrm{E}$ DAQ card with 16 analog input, and two analog output channels. Low-pass butterworth filters were used with a passband edge frequency of $30 \mathrm{rad} / \mathrm{sec}$. This frequency was chosen because they were used by others using the RT-Lab ${ }^{\mathrm{TM}}$ system in the past. The gain blocks at the output of the fuzzy logic controller converted the voltage and speed settings from physical units to raw voltages that could be sent to the PSU and KUKA robot controller. The fuzzy logic controller written in $\mathrm{C}$ was implemented as an $s$ function using "S-Function Builder" in the Simulink $®$ environment.

The three subsystems to the right of Fig. 5.3 are each used to convert the raw voltage signals read by the DAQ card to meaningful physical units. Figure 5.5 shows the contents of the Force Calibration \& Read subsystem. The signals are multiplied by a conversion matrix supplied by the manufacturer that converts the raw voltage into units of Newtons for force and Newton-meters for couples. The trigger is sent from $S C \_C o n s o l e$ and used to initialize the force manually. 


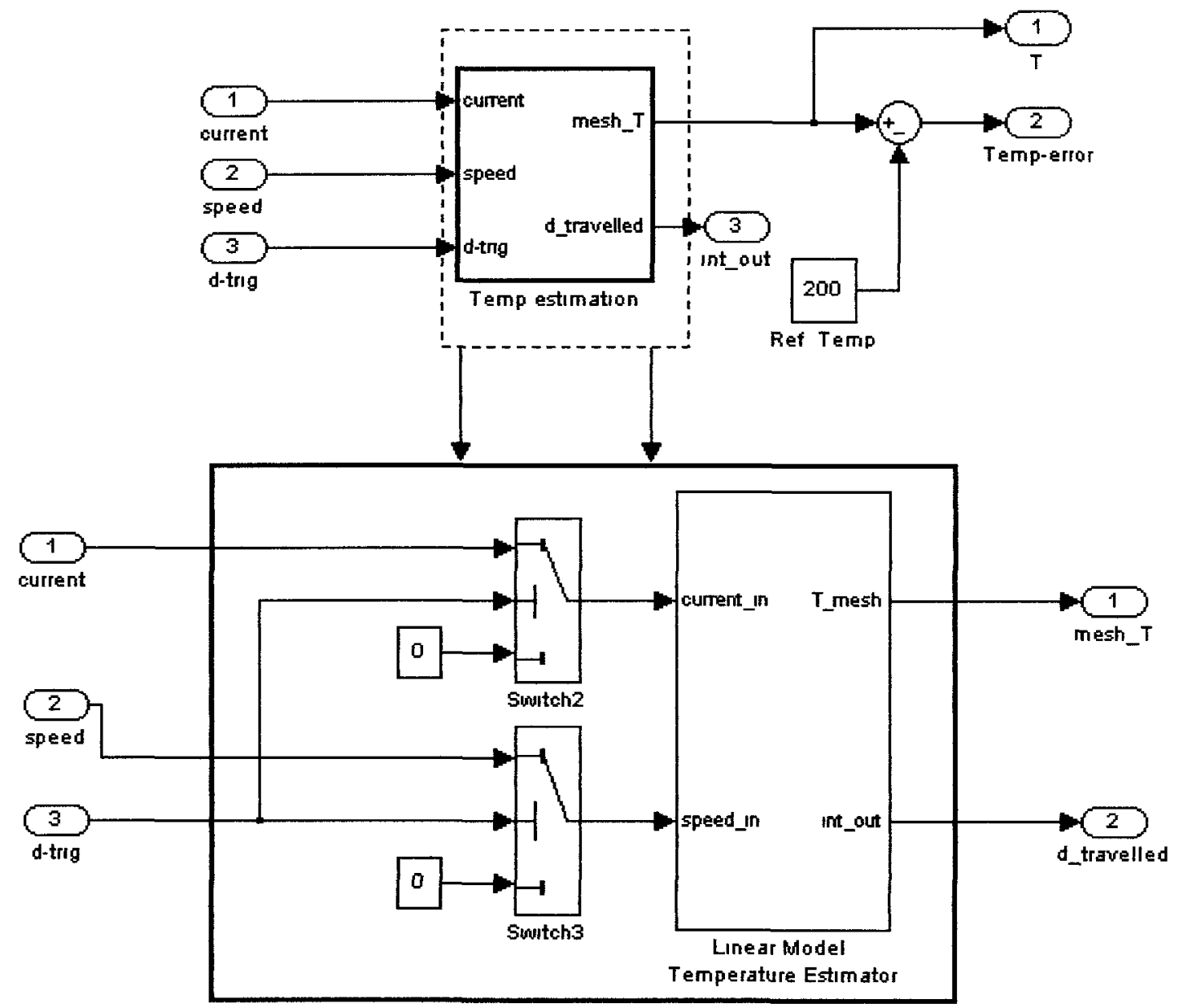

Terrip estirnation

Figure 5.4 - Temperature estimation subsystem contents revealing the distance switch.

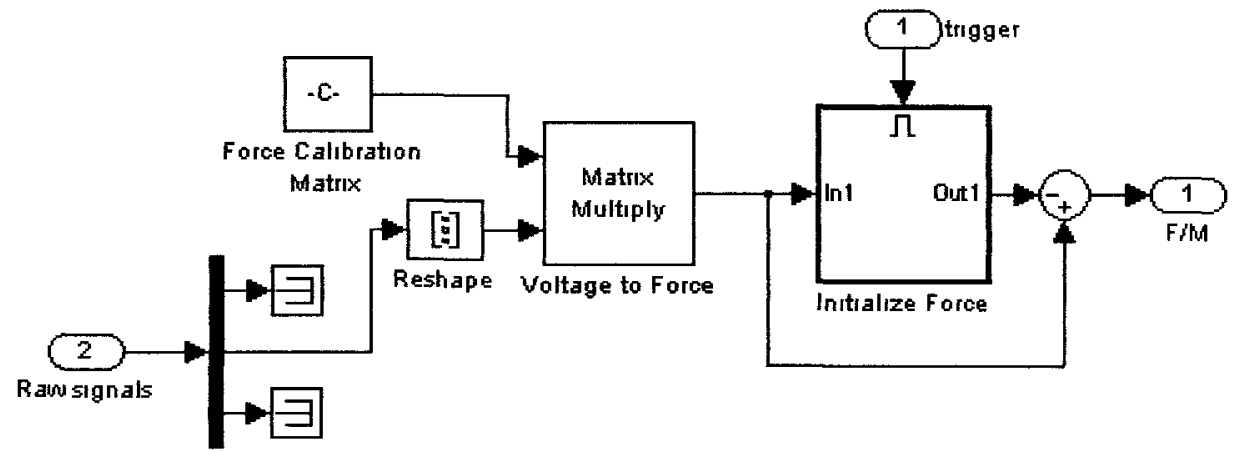

Figure 5.5 - Force Calibration \& Read subsystem contents from Fig. 5.3. 


\subsubsection{SC_Console Subsystem}

As mentioned earlier, the SC_Console subsystem is used to interact with the model during real-time execution. The voltage and speed output from the fuzzy controller, the estimated temperature, temperature error, error rate, voltage and current readback, weld speed readback, distance travelled, and force are all sent from SM_Master to $S C_{-}$Console for viewing and storing during execution. The contents of SC_Console are shown in Fig. 5.6. All parameters are made viewable by means of a scope, and are stored as Paramaters in the MATLAB® workspace. The switch is the trigger used by the Force Calibration \& Read subsystem in Fig. 5.5 used to zero the force manually if desired.

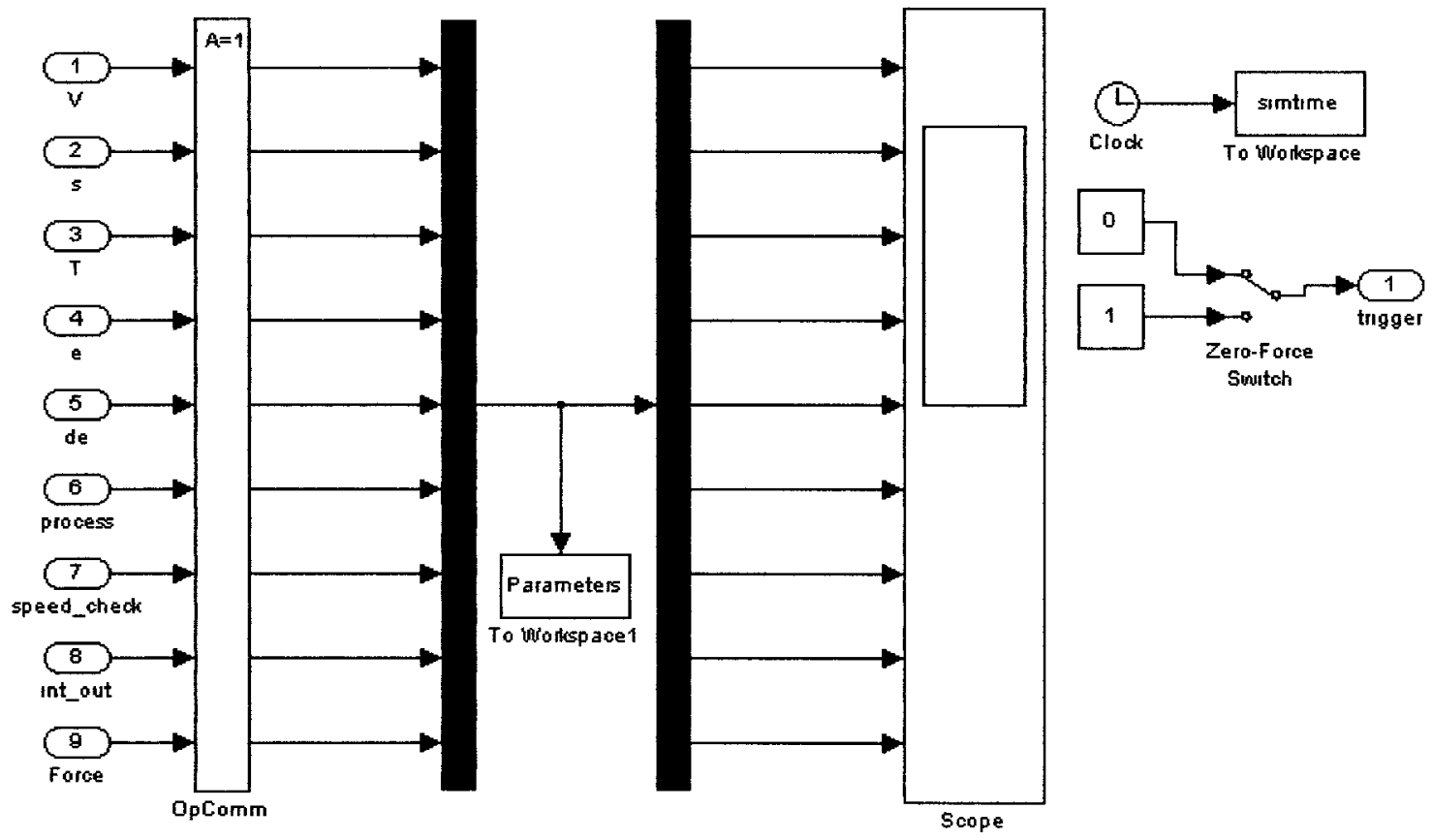

Figure 5.6 - Contents of SC_Console subsystem used to view and store parameters during real-time exectution. 


\subsection{Closed-Loop Experiments}

A series of experiments were done to measure the temperature at the midpoint of three consecutive copper block sections. The same k-type thermocouples were used to measure the temperature. The coupon size was also increased to 5.5 inches which encompasses 11 weld sections. Ignoring the first and last two sections due to the lower current in those sections, there exists seven sections that the model can be used to predict the temperature on the heating element.

\subsubsection{Fuzzy Logic Controller Results}

The temperatures of three consecutive weld sections are shown in Fig. 5.7. It is clear from the figure that the temperatures reached approximately $160^{\circ} \mathrm{C}$, far from the $200^{\circ} \mathrm{C}$ set point. This large error can be attributed to the large variation in the current used to estimate the temperature. Recall that the current input used to create the linear temperature estimator was $40 \mathrm{~A}$. Figure 5.8 shows the voltage and resulting current that was generated while welding under fuzzy logic control. The $\mathrm{x}$-axis is normalized to start from zero but represents the voltage signal while welding a single weld section. The current is fairly steady at approximately $39 \mathrm{~A}$ with a voltage of $5.65 \mathrm{~V}$. When the voltage drops initially to $5 \mathrm{~V}$, the result is a current of approximately $36 \mathrm{~A}$, a difference of $10 \%$. Once the voltage drops to $3 \mathrm{~V}$ the current is $50 \%$ lower at $20 \mathrm{~A}$. The linear model still predicts a steady increase in temperature across all these settings as evident in Fig. 5.7. However, the actual temperature begins to decrease as the voltage drops.

The speed output from the fuzzy logic control, shown in Fig. 5.9 is similar to that during simulation. The speed is constant at approximately $3.7 \mathrm{in} / \mathrm{min}$, and increases to a maximum of $6.3 \mathrm{in} / \mathrm{min}$. If the speed was lowered even further, then it would be possible to reach the temperature reference. However, with the voltage dropping low, as was stated above, the linear model still would not predict the temperature accurately. 


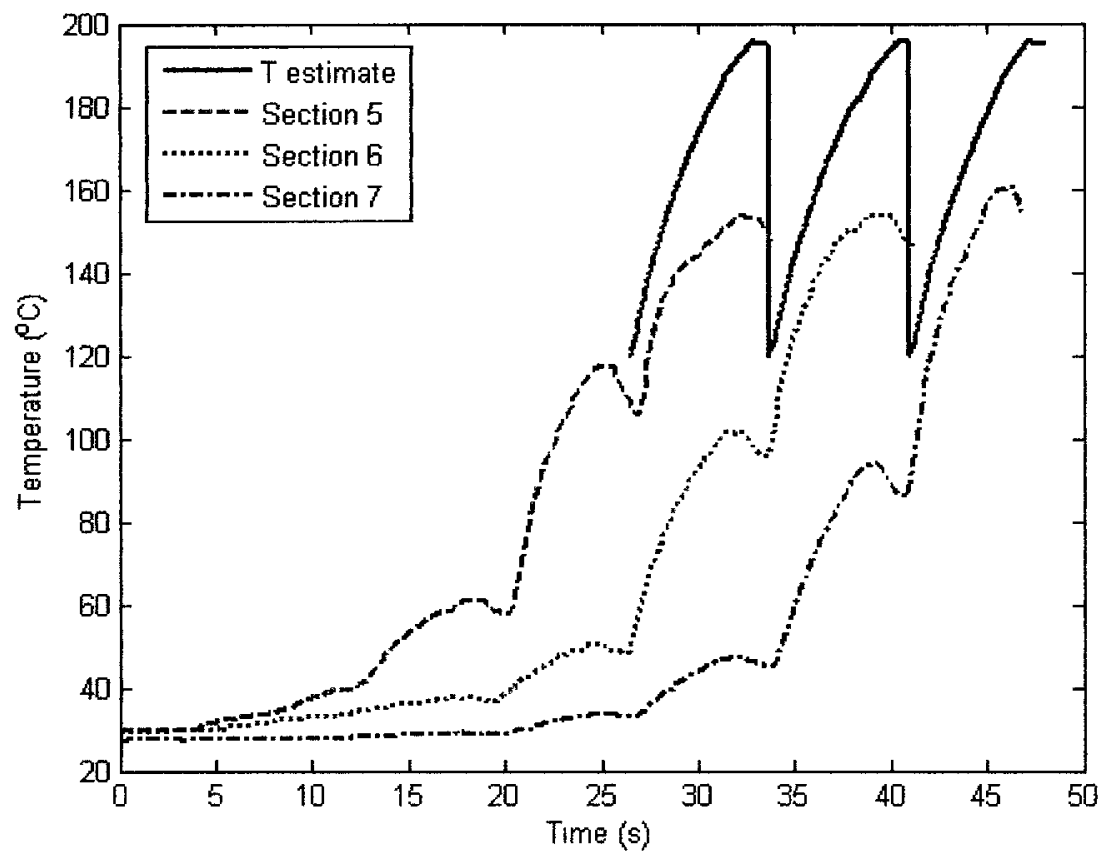

Figure 5.7 - Temperature measured at three consecutive weld sections by thermocouples, while welding under fuzzy logic control.

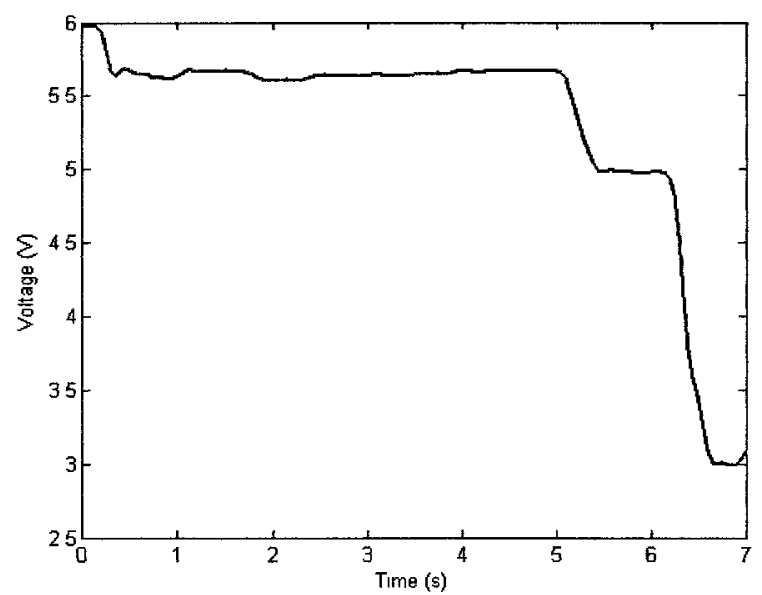

(a)

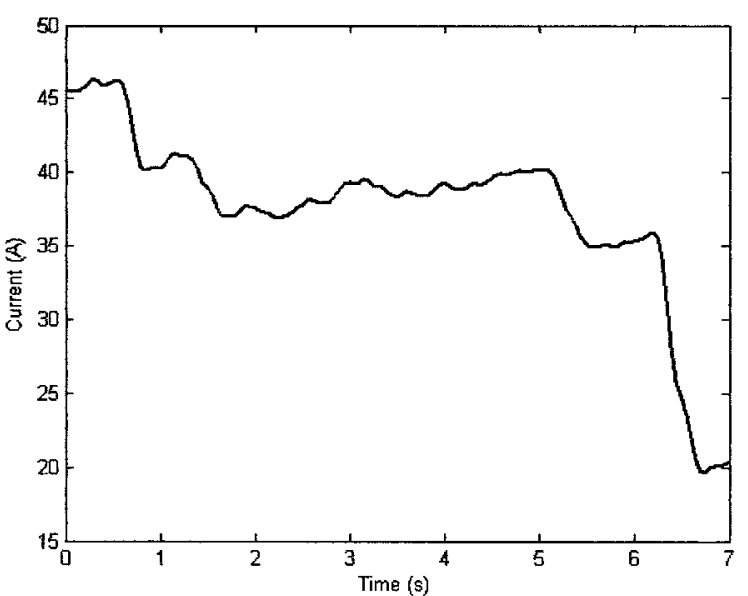

(b)

Figure 5.8 - (a) Voltage and (b) resulting current signals generated while welding a single section under fuzzy logic control. Time is scaled to start from zero. 


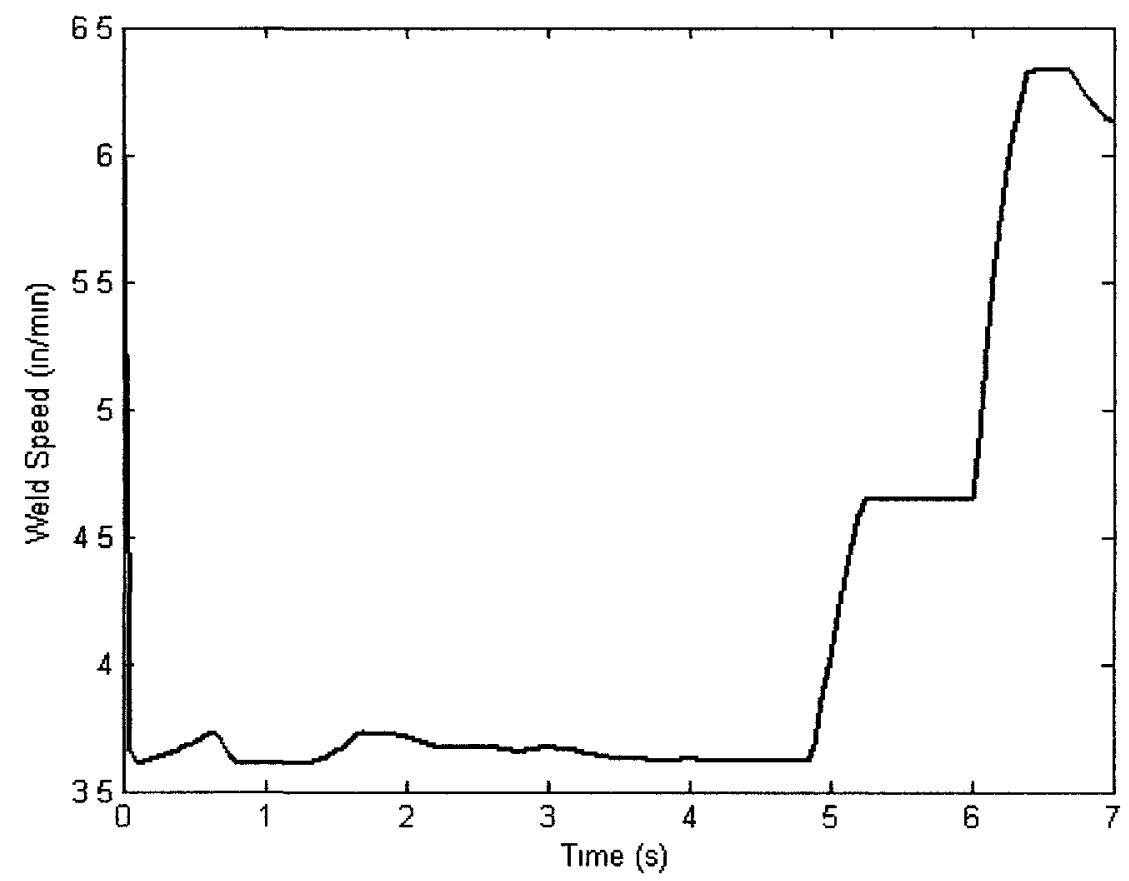

Figure 5.9 - Weld speed in a single weld section as commanded by the FLC.

The pre-heat temperature was also lower than the $120^{\circ} \mathrm{C}$ set point. There are two possible reasons for this. Firstly, the temperature measured is lower than the $200^{\circ} \mathrm{C}$ expected resulting in a pre-heat temperature in the adjacent section being lower. Secondly, the position of the thermocouple may have been off the midpoint slightly, possibly resulting in a measured temperature that is lower than expected.

The inside of the weld coupon is shown in Fig. 5.10 and Fig. 5.11. The position of the thermocouple is between the resin film and the heating element. The resin film is barely melted indicating a poor weld. Upon further inspection, there is a section directly in the middle of the weld coupon, directly above the thermocouple, that is clearly not welded. This section is shown in Fig. 5.11. It is the only portion of the glass/PP fibers that have not been torn from the base material. 


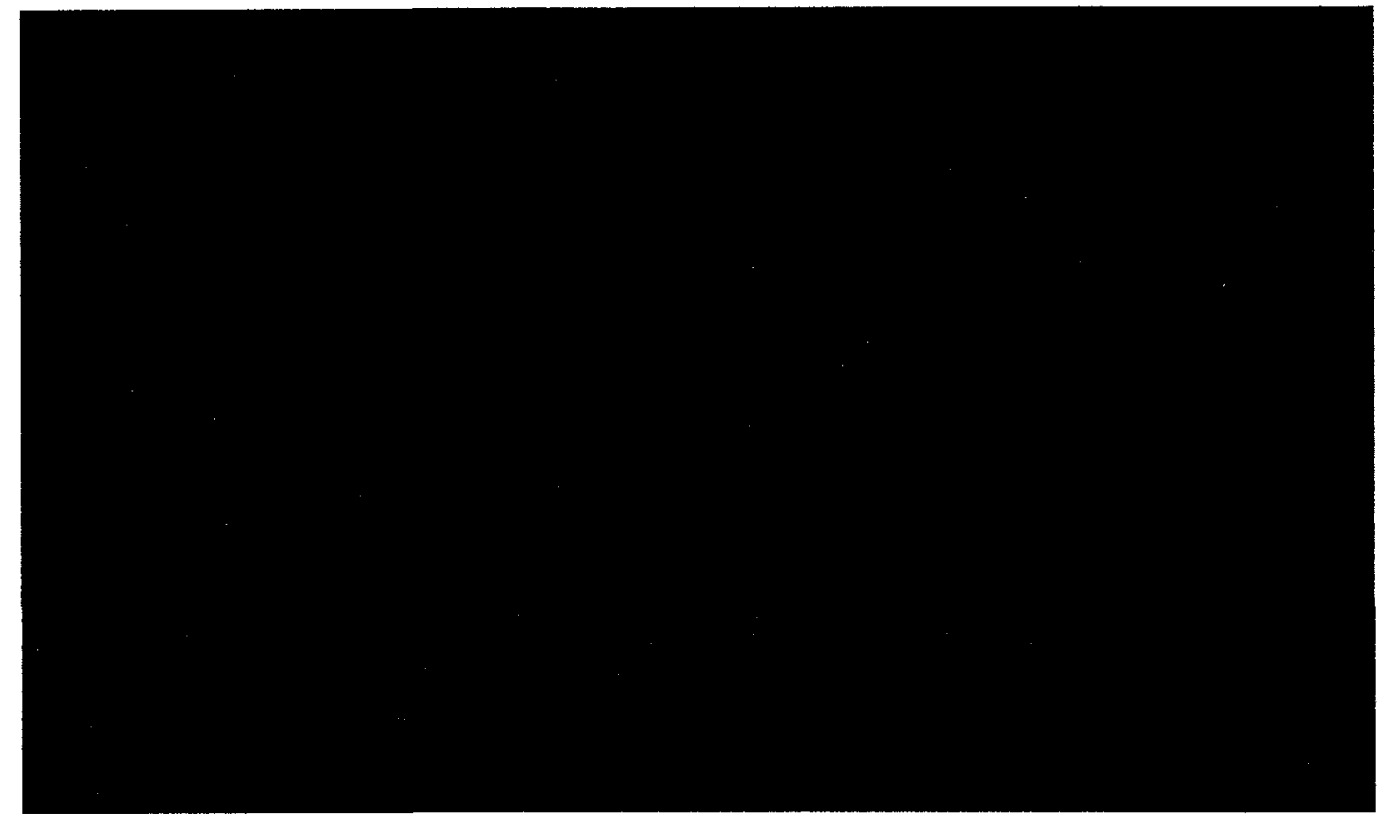

Figure 5.10 - Internal view of a coupon after welding under fuzzy logic control.

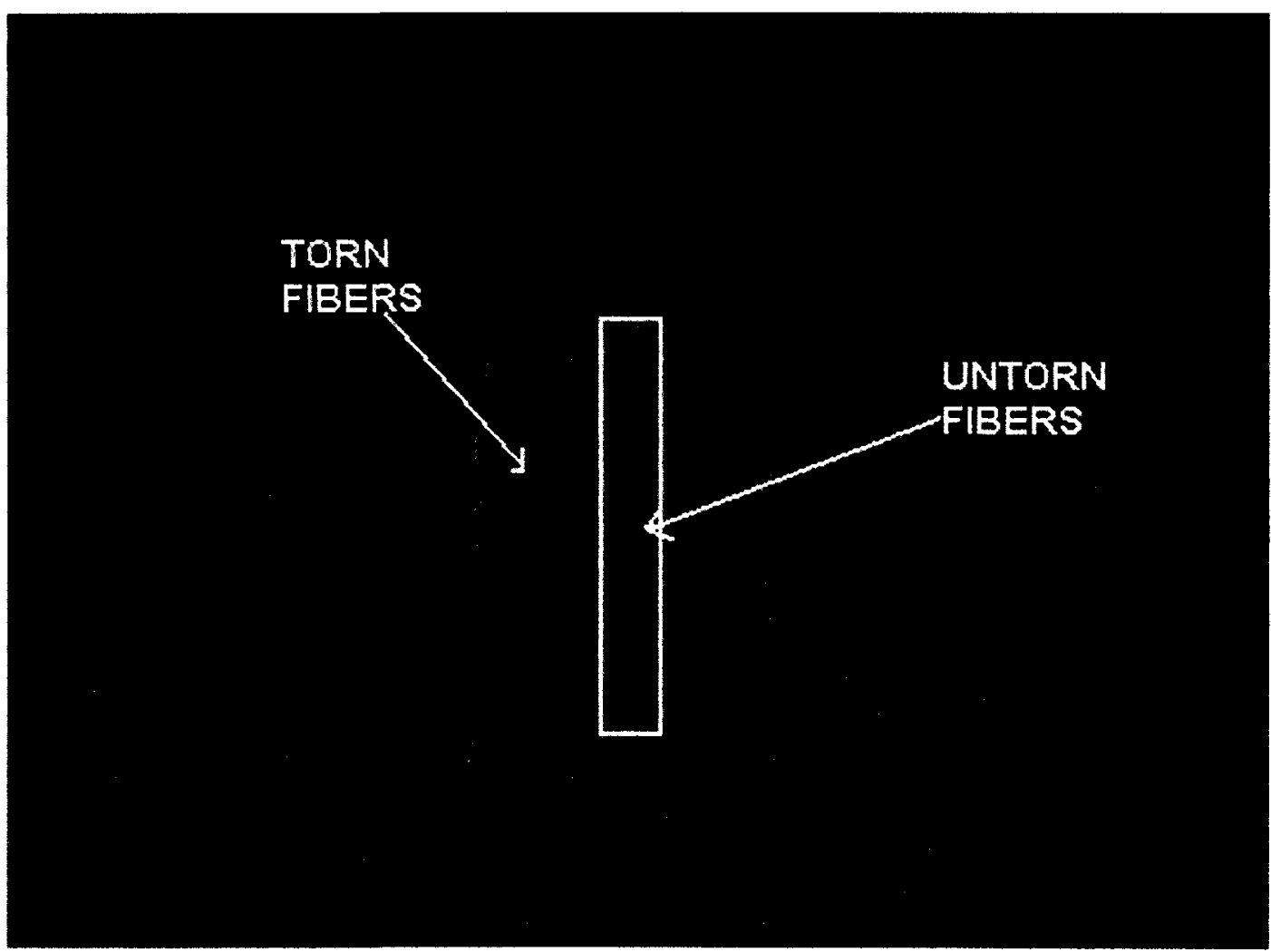

Figure 5.11 - View of the glass/PP laminate at the weld interface after welding under fuzzy control. It is evident that the mid-section of the coupon has not been welded. 


\subsubsection{Modified Fuzzy Logic Controller}

To correct the issues discussed in section 5.3.1 the fuzzy logic controller was modified to sustain a higher voltage for a longer duration. The modified rule base, in Table 5.1, has the modifications highlighted in bold, and the resulting rule surface is presented in Fig. 5.12. The modified closed-loop voltage signal, displayed in Fig. 5.13, holds the voltage at its maximum for 5.7 seconds, $14 \%$ longer than the previous controller.

\begin{tabular}{|c|c|c|c|c|c|c|c|c|}
\hline \multicolumn{2}{|c|}{ VOLTAGE } & \multicolumn{7}{|c|}{ ERROR } \\
\hline \multirow{8}{*}{$\begin{array}{c}\text { ERROR } \\
\text { RATE }\end{array}$} & & VC & MC & SC & $\mathbf{Z}$ & SH & $\mathbf{M H}$ & VH \\
\hline & GVC & VH & VH & MH & MID & MID & VL & VL \\
\hline & GMC & $\mathrm{VH}$ & VH & MH & MID & MID & VL & $\mathrm{VL}$ \\
\hline & GSC & VH & VH & MH & MID & MID & $\overline{V L}$ & VL \\
\hline & $\mathbf{Z}$ & VH & VH & MH & MID & SL & VL & $\overline{V L}$ \\
\hline & GSH & VH & VH & MH & MID & $\mathrm{SL}$ & $\mathrm{VL}$ & $\mathrm{VL}$ \\
\hline & GMH & VH & VH & MH & $M L$ & $\mathrm{ML}$ & $\mathrm{VL}$ & VL \\
\hline & GVH & $\mathrm{VH}$ & VH & MH & $\mathrm{ML}$ & $\mathrm{ML}$ & $\overline{V L}$ & $\overline{\mathrm{VL}}$ \\
\hline
\end{tabular}

Table 5.1 - Modified rule base to extend the time spent at the "very high" voltage case

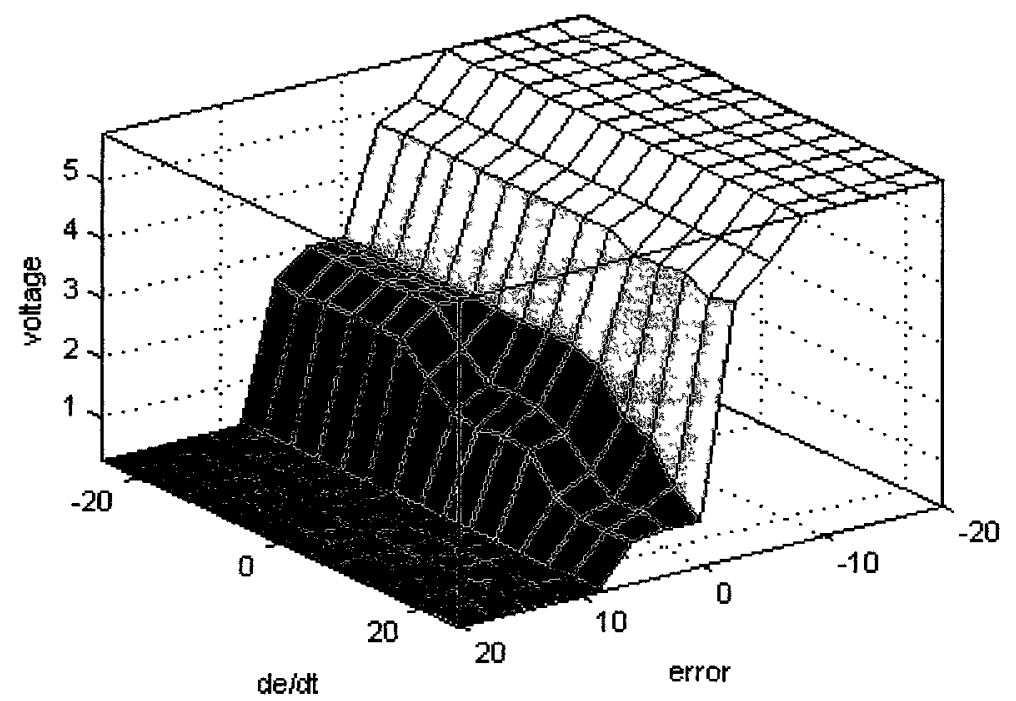

Figure 5.12 - Modified rule surface plotted from the modified rule base in Table 5.1. 


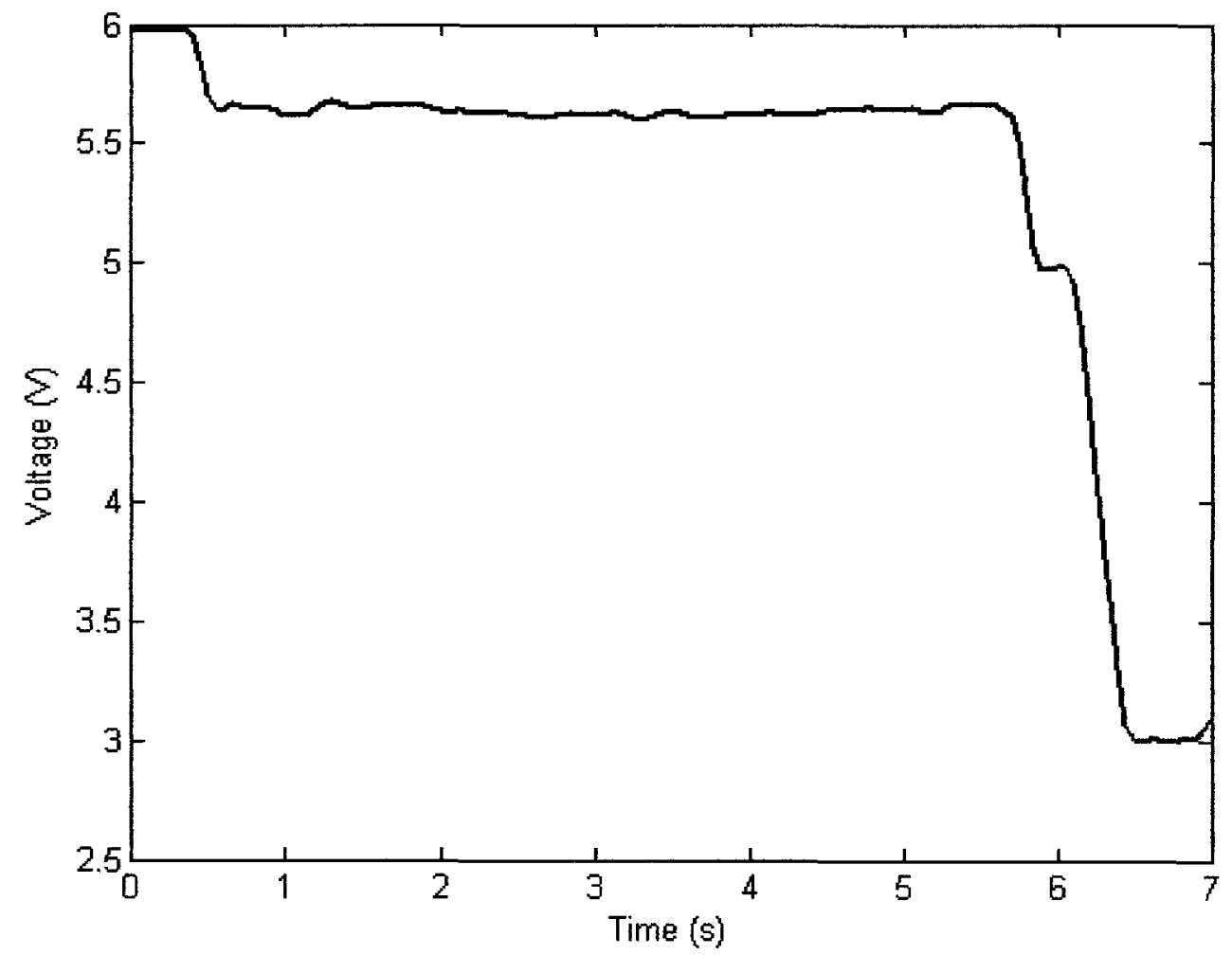

Figure 5.13 - Closed-loop voltage signal using the modified fuzzy logic controller.

The temperature for the fourth and fifth weld sections shown in Fig. 5.14 are a maximum at approximately $188^{\circ} \mathrm{C}$, while the seventh section was $199^{\circ} \mathrm{C}$. However, it is clear from Fig. 5.14 that the temperature profiles for each section are much more consistent with the temperature estimate as shown by the error graphs in Figures 5.15 to 5.17. The error is typically less than $10 \%$ for all three weld section until the maximum temperature is reached. All three error graphs clearly show that when the temperature maximum is reached there is a sharp increase in error. This, as was discussed earlier, is due to the linear temperature model's inability to predict the temperature when the voltage drops significantly. 


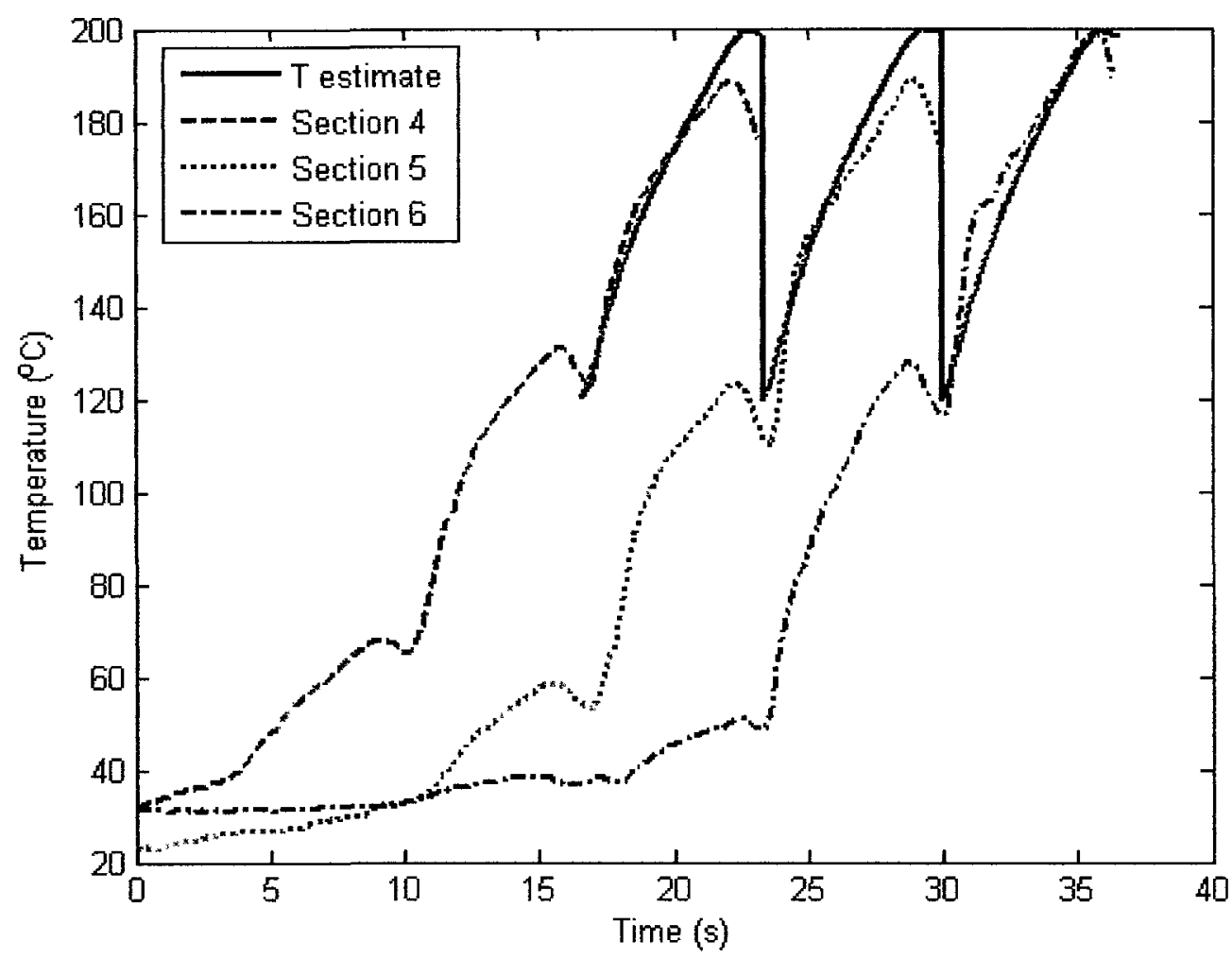

Figure 5.14 - Temperature measured at three consecutive weld sections while welding under the modified fuzzy logic control.

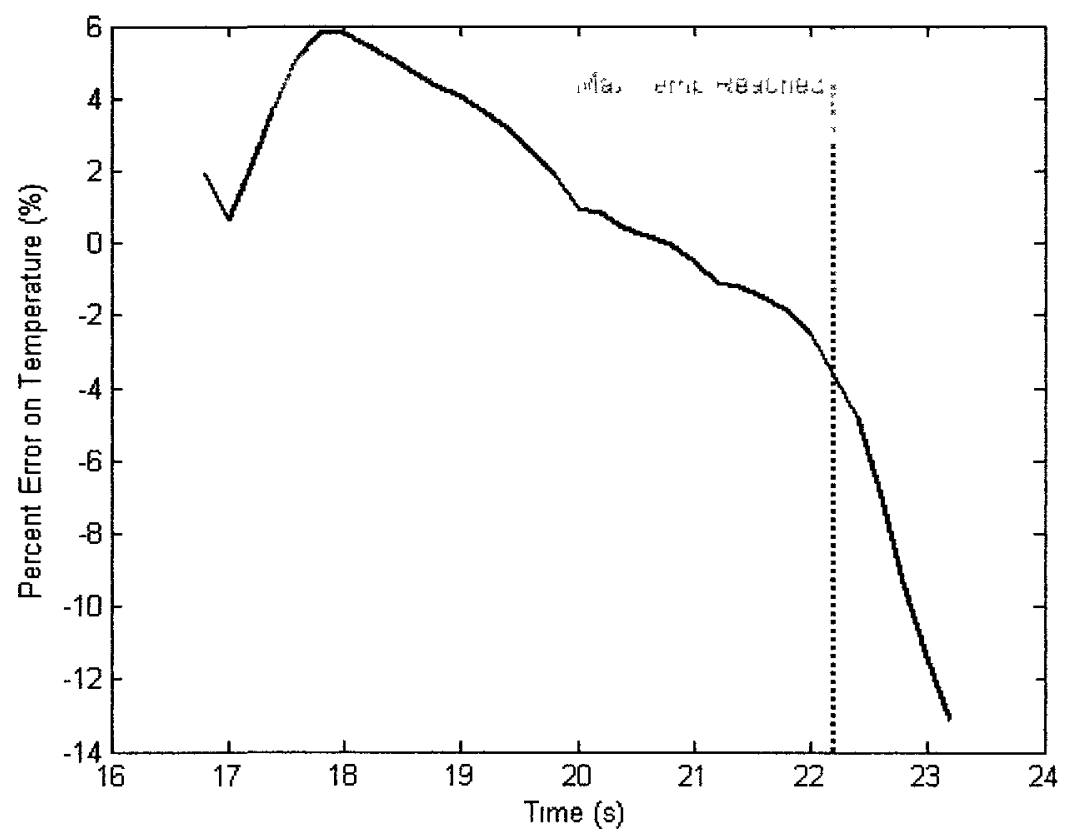

Figure 5.15 - Error between the measured temperature and the estimated temperature for the $4^{\text {th }}$ weld section of Fig. 5.14. 


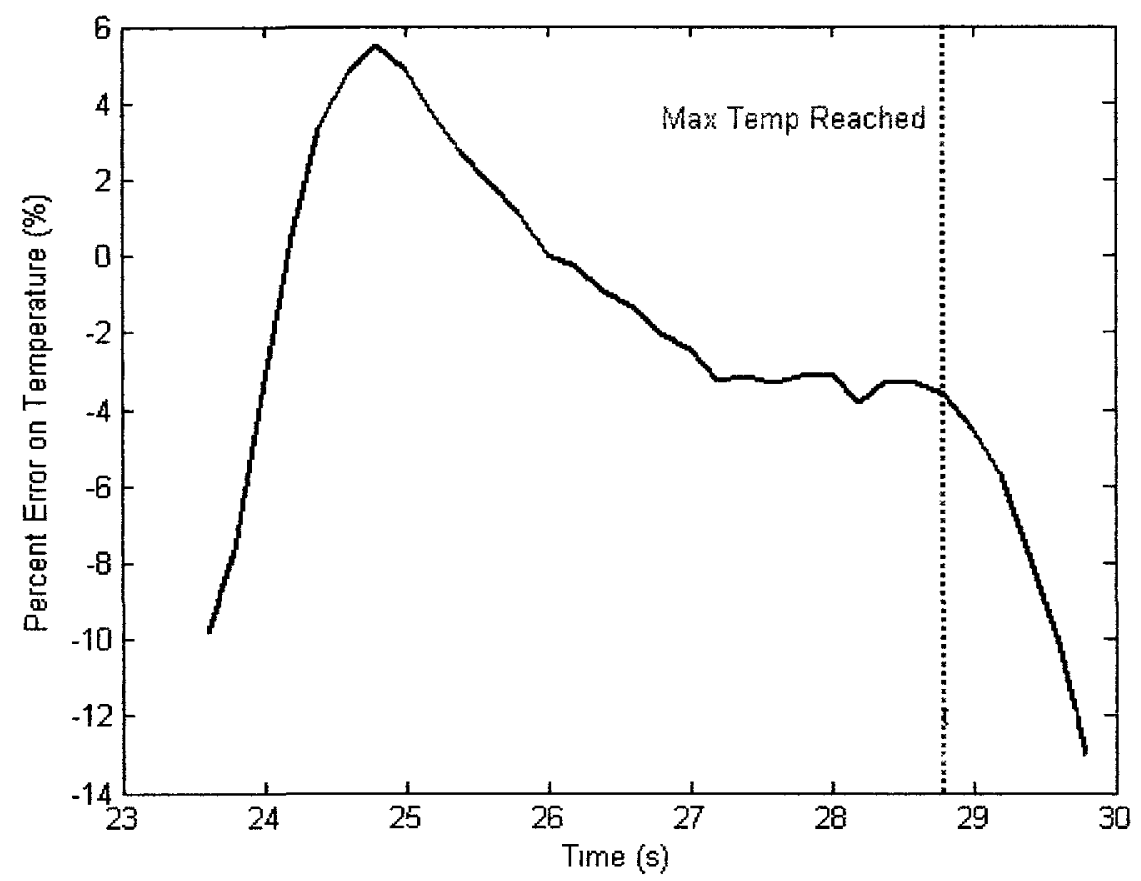

Figure 5.16 - Error between the measured temperature and the estimated temperature for the $5^{\text {th }}$ weld section of Fig. 5.14 .

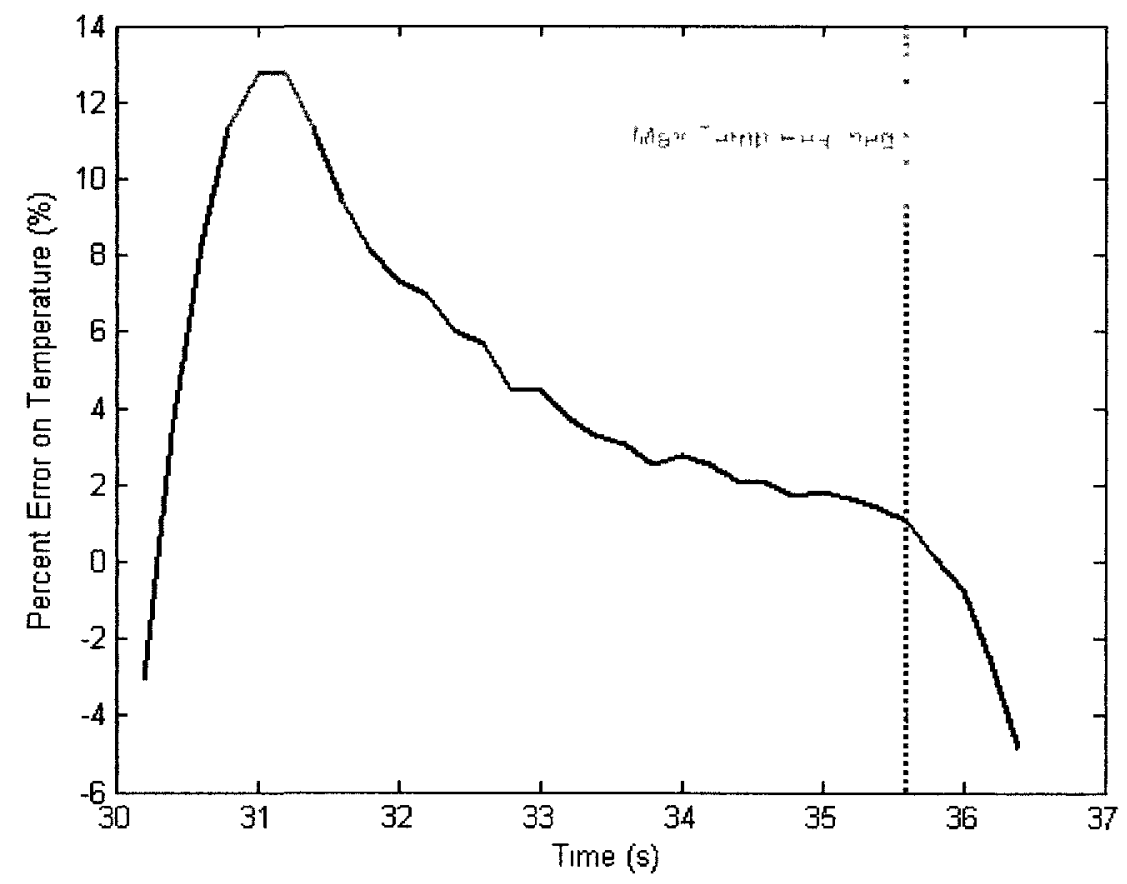

Figure 5.17 - Error between the measured temperature and the estimated temperature for the $6^{\text {th }}$ weld section of Fig. 5.14. 
According to the results presented in Fig. 5.14, the pre-heat temperature can drop by as much as $11 \%$ from its peak. However, the maximum error on the pre-heat temperature, when compared to the estimate of $120^{\circ} \mathrm{C}$, for each consecutive weld section was $9.1 \%, 9.8 \%$ and $6.7 \%$. These are acceptable deviations especially when considering the fact that the pre-heat temperature quickly begins to drop once the voltage drops. From Fig. 5.18 there is a definite increase in the quality of the weld. With the modified controller, the fibers throughout the width of the coupon are visibly torn from the base material. It clearly shows that the laminate peeled away from itself rather than from the heating element.

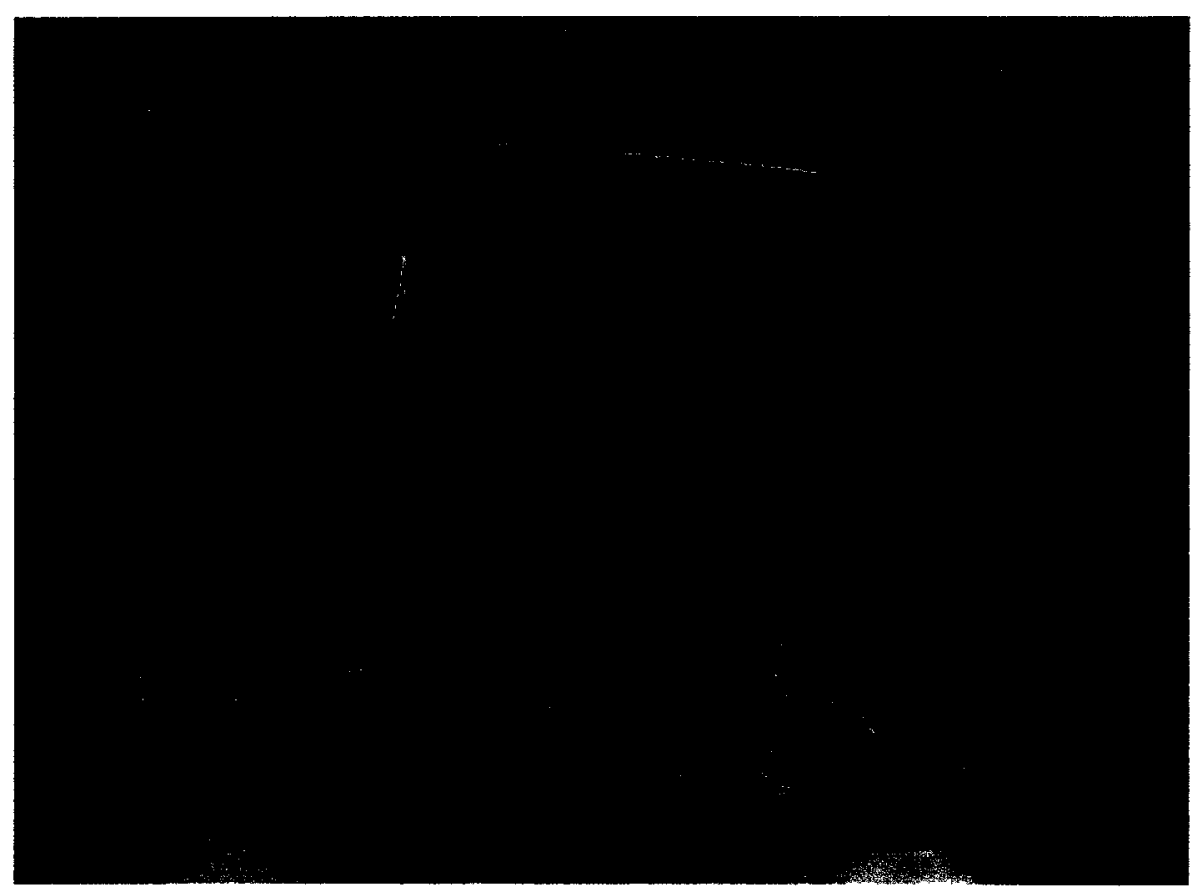

Figure 5.18 - Interior of the weld after a closed-loop weld performed with the modified fuzzy logic controller.

To evaluate the performance gain of the controller, a comparison of temperatures must be made between the open-loop and closed-loop welds. The open-loop case was taken from data generated from the $3 \mathrm{D}$ model at $6 \mathrm{~V}$. The average weld speed during fuzzy control was set at $4.17 \mathrm{in} / \mathrm{min}$. However, the $3 \mathrm{D}$ model solves in 0.2 second intervals, so the speed was rounded to $4.0 \mathrm{in} / \mathrm{min}$ to give a weld time of 7.2 seconds. Since the robot speed is high during the transition from weld section to weld section, the 
transition time was set to zero. The temperature comparison for the fifth and sixth weld section are shown in Fig. 5.20 and Fig. 5.21. The closed-loop and open-loop curves do not overlap well because during closed-loop control, the first two weld sections were welded in open-loop at $5 \mathrm{in} / \mathrm{min}$. Nonetheless, the maximum temperature reached during an open-loop weld was $221^{\circ} \mathrm{C}$. Damage to the exposed portion of the heating element is much more profound in the open-loop case. The higher duration of voltage during the weld in the open-loop causes thermal damage to the heating element as shown by the burn marks in Fig. 5.19. These burn marks cause local degradation of the composite laminate which is obviously unacceptable. In the closed-loop case there are no present burn marks on the exposed portion of the heating element. There still exists some burning directly along the edge of the laminate. This is due to the high temperatures that exist on the edge of the laminate, and require some form of external cooling to reduce the temperature.

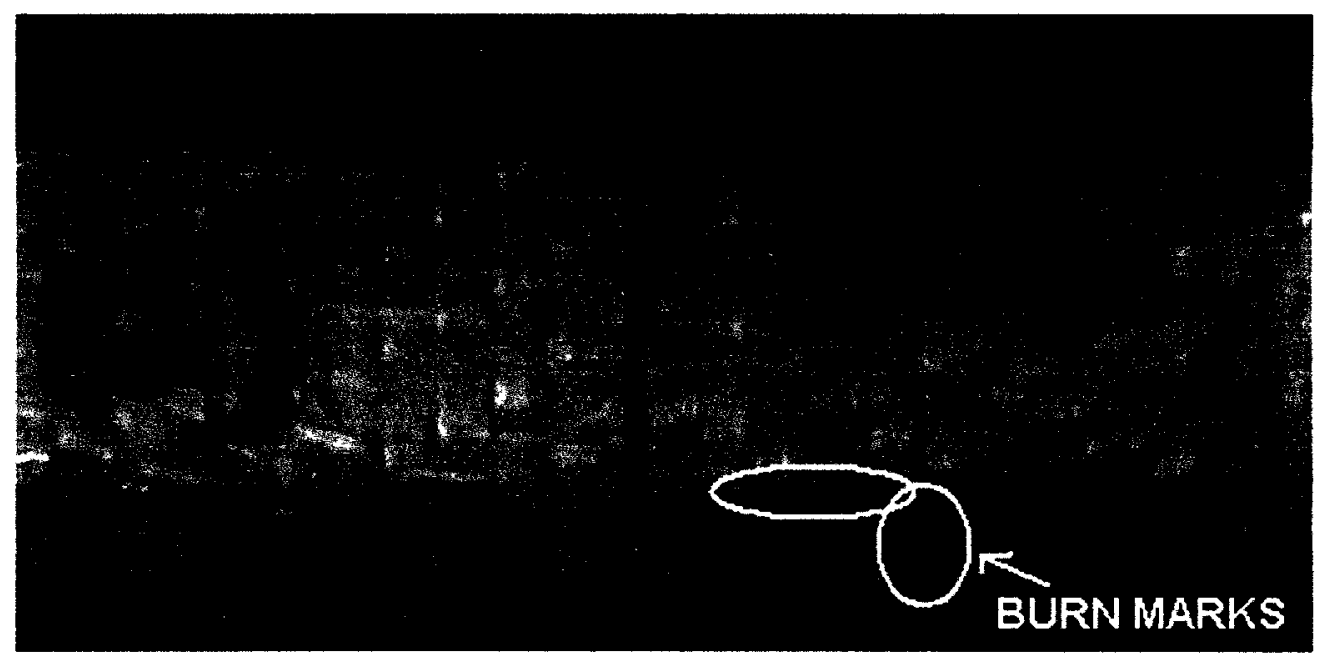

Figure 5.19 - Comparison of the heating element in both closed-loop (left) and openloop (right) welds in terms of damages. 


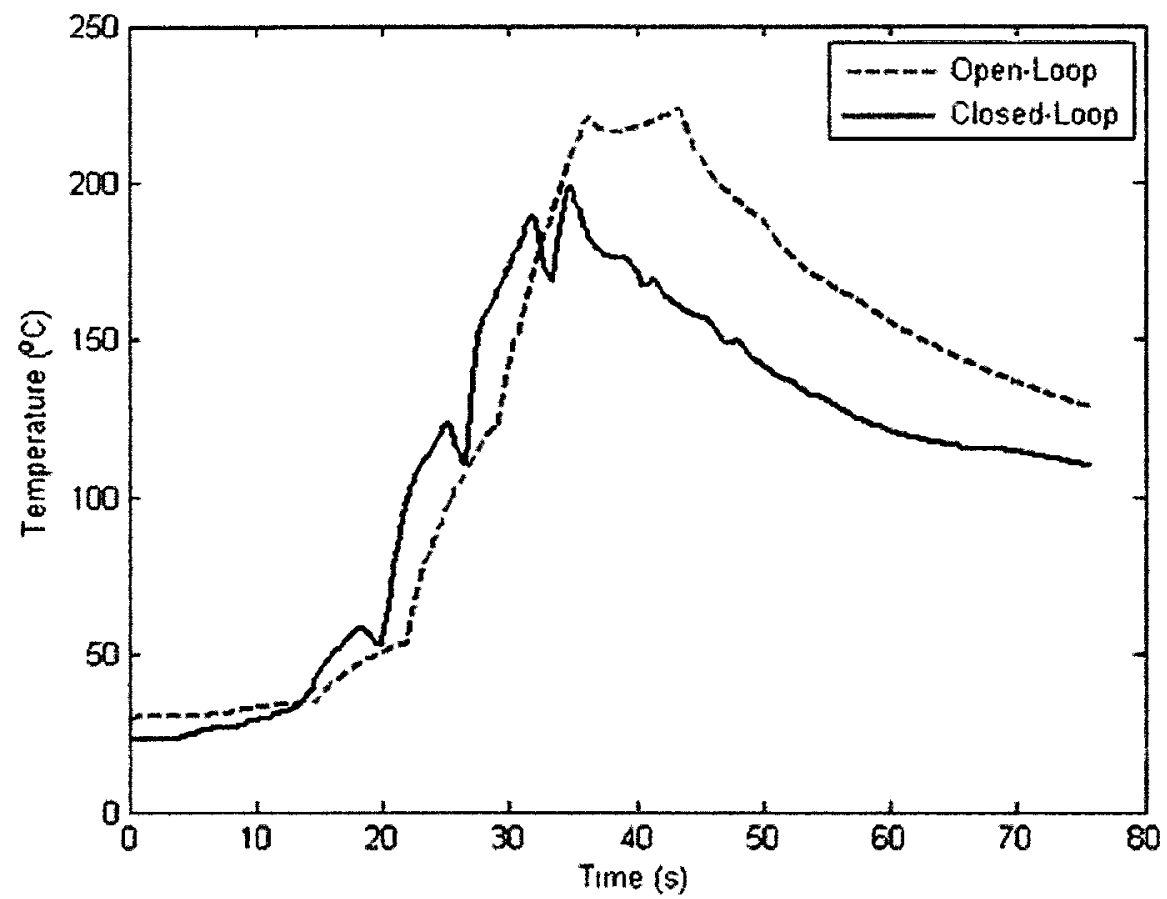

Figure 5.20 - Comparison of the temperature of the $5^{\text {th }}$ weld-section under open-loop and closed-loop conditions.

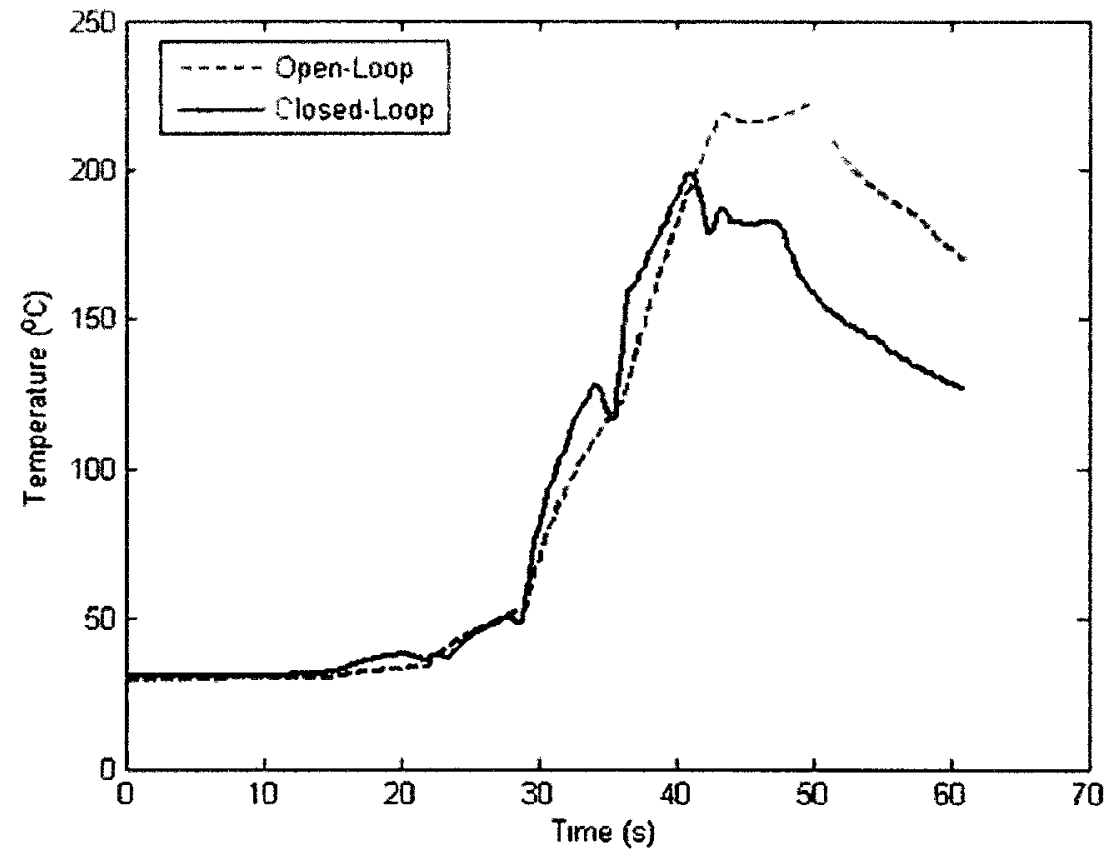

Figure 5.21 - Comparison of the temperature of the $6^{\text {th }}$ weld-section under open-loop and closed-loop conditions. 
Since it is difficult to measure the temperatures of several locations during a weld, an infrared camera, the FLIR A20 Infrared Camera, was used to observe the top surface temperature while welding. The goal here was to see if the temperature at the surface remained constant throughout the weld during closed-loop control, indicating perhaps a consistent temperature for each weld section. The infrared camera was connected to the robot end-effector by means of a 5 DOF brace. This allowed the temperature directly behind the compaction track to be measured at all times. The location of the spot is shown in Fig. 5.22. The resulting temperature variation directly behind the compaction wheel is shown in Fig. 5.23. Due to the length of the compaction wheel, the temperature measurement is approximately 1.5 inches behind the electrodes. So initially, the spot measures room temperature until the end-effector has moved 1.5 inches. Once that happens, there is a sharp rise in the temperature as the spot is now on top of the laminate. Ignoring these initial effects, the temperature on the top surface is almost constant with an average temperature of $98.2^{\circ} \mathrm{C}$, and standard deviation of $1.43^{\circ} \mathrm{C}$.

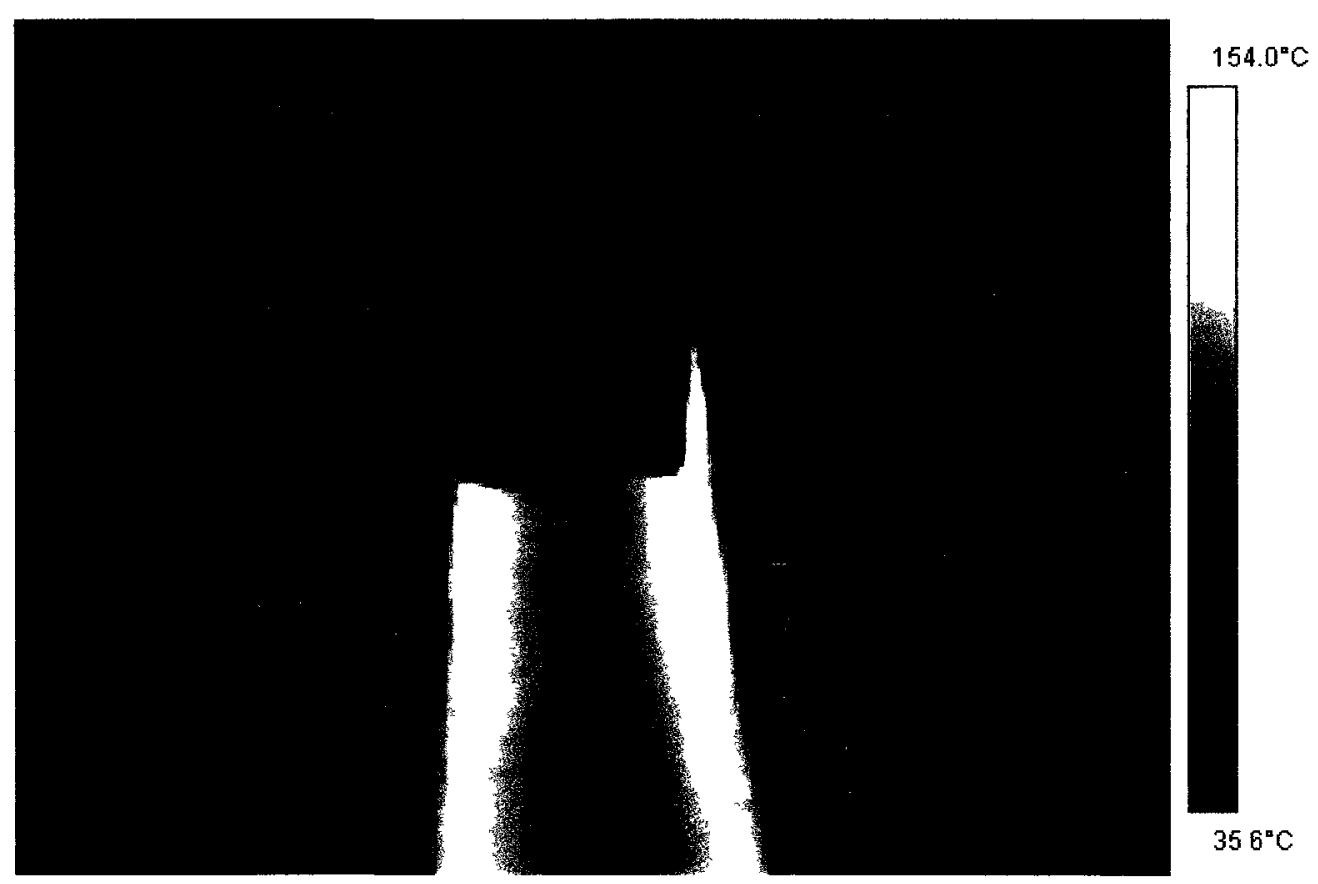

Figure 5.22 - Infrared image showing the location of the spot used to measure the top surface temperature during a controlled weld. 


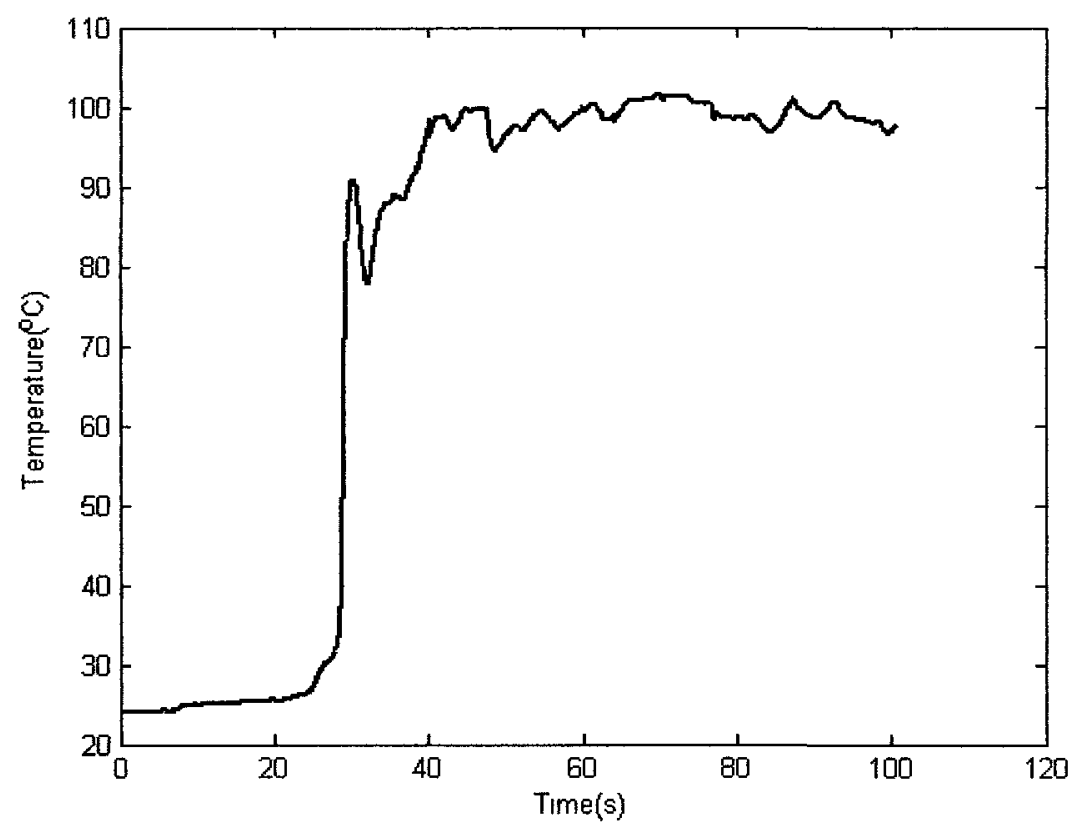

Figure 5.23 - Top surface temperature measured using a FLIR A20 Infrared Camera.

The purpose of the closed-loop control was to have the temperature at the midpoint of each weld section be consistent. The initial experimental results showed that the controlled temperature was about $20 \%$ lower than the reference temperature. The problem was the poor accuracy of the linear temperature model as the voltage control signal dropped. To accommodate for this the fuzzy rules were modified to maintain a high voltage for a longer period of time. The result was closed-loop temperature values that were within $10 \%$ of the reference temperature. Since the thermocouples were only used to measure the temperature at the midpoint of the weld, the infrared camera was used to see if the temperature was consistent from weld section to weld section on the top surface. The result was a top surface temperature variation of less than $2 \%$. These results suggest that using the weld current to estimate the weld temperature online can yield accurate results. However, care must be taken using a linear model to estimate the temperature because the results also showed that a linear model can be limiting if the current varies significantly. 


\section{Chapter 6}

\section{Conclusions and Recommendations}

\subsection{Summary}

A three-dimensional model was created for the continuous resistance welding of thermoplastic materials. This model included the electrostatics as well as the heat transfer physics that are present in the process. One of the major items gained from the model was the knowledge of how the resistive heating is distributed throughout the heating element as the rollers move along the workpieces. In the static welding case a typical current of $12 \mathrm{~A}$ at $4 \mathrm{~V}$ would exist, where as in the continuous case the current would be upwards of $20 \mathrm{~A}$.

Data was extracted from the model to generate a linear state-space model that would estimate the temperature online. This was done because there was no feasible way to measure the temperature at any point in the weld online. It was either sealed in the weld interface, or blocked by the end-effector's compaction track. A fuzzy logic controller was created, and three iterations were done on the controller to refine it. The first was determined directly from experience working with the process. The second was a modification of the first where the rule surface was modified to create a smooth control 
signal. Lastly, the controller was modified after implementing it online and observing the limitations of the linear model.

\subsection{Research Conclusions}

The copper electrodes in the end-effector cause the copper track to bend slightly during welding. This created a slight gap between the adjacent copper blocks and the heating element. The resulting sparks created by this gap caused the heating element to rupture, and stop all electrical flow. To address this, a set of rubber wheels were installed ahead of the copper blocks to apply pressure to the adjacent copper blocks to prevent any gaps.

The three-dimensional model proved to be sufficiently accurate in both physics models with an error less than $5 \%$ on the electrical current, and typically less than $10 \%$ in the temperature. Due to the discrete nature of the process there is no continuous accumulation of heat. The pre-heat temperature at a given voltage and speed is the same for all weld sections away from the boundary of the coupon. This was advantageous because it allowed the use of a linear model to estimate the weld temperature, and assume a constant initial temperature for all weld sections. It was shown that this is indeed the case, and that the pre-heat temperature at $6 \mathrm{~V}$ was only a function of the prior two weld sections.

The temperature estimation model was chosen as a linear model because of its simplicity, and ease at which it could be created. The linear model was initiated at the pre-heat temperature of $120^{\circ} \mathrm{C}$. In closed-loop experiments this was consistently reached within $10 \%$ error. While taking this approach can work as shown above, the variation of the controlled inputs are limited. For example, the controlled voltage signal from the fuzzy controller dropped the voltage from $5.65 \mathrm{~V}$ to $3 \mathrm{~V}$ in just under one second. In that short period of time the current dropped approximately $50 \%$, and the resulting estimation from the linear model was extremely poor. The fuzzy logic controller was modified to account for this by increasing the voltage duration. The maximum temperature reached 
was typically around $190^{\circ} \mathrm{C}$, which is within $5 \%$ of the reference temperature of $200^{\circ} \mathrm{C}$. The limitation in the work is not the fuzzy controller. In fact, the fuzzy logic controller showed good stability, and boundedness throughout all weld samples. The limitation of the work is the validity of the linear model approximation over the whole operating range. As the FLC lowered the voltage to accommodate for a lower temperature error, the temperature error rose significantly from approximately $5 \%$ to upwards of $10 \%-15 \%$. This was because the estimated temperature from the temperature linear model was poor because the voltage setting by the FLC was far off the operating point of $6 \mathrm{~V}$ of the linear temperature model. However, taking all this into account, the linear model estimator was essentially a proof-of-concept that the process could be controlled online even though the temperature could not be measured.

\subsection{Future Recommendations}

Large scale applications of this process would likely not be for straight pieces. For example, stiffeners used to support skin sections are typically curved. The only way to weld them with the current setup is to create a copper block strip that has the same curve that is desired. Although this could be done, over time the strip can warp, and any gaps between the copper blocks and the heating element are obviously detrimental to the weld. Instead, a modified robot end-effector should be created that implements the concept of the copper blocks directly on it, effectively replacing them. Creating this under some type of spring suspension would help eliminate any variations in geometry from piece to piece. Also, the change of focus from linear geometry to curved geometry would require a more sophisticated force control system. However, this could potentially be replaced with a pneumatic system that is set to operate within a specific weld pressure, rather than force.

For future work on the control side, the focus should be to improve the temperature estimation online. A non-linear model may have a larger operating range, allowing for a more complete temperature estimation. A dynamic neural network could be trained according to COMSOL data, and used online. Another option is to use the 
FEM model online directly. The 3D model is large, and does require over an hour to solve and is not feasible. However, this model could be scaled back to a lower-order model that could be used directly online to estimate the temperature. For example, a 2D model created in COMSOL, using the same conditions as the 3D model, and with 2594 mesh points solved for 10 seconds at $10 \mathrm{~Hz}$ required only 4.6 seconds to solve. That is approximately solving at $20 \mathrm{~Hz}$. If a COMSOL subroutine was running only the solver online, without launching the core COMSOL software, the solve time would likely decrease because of the reduced memory and CPU demand on the system. 


\section{List of References}

[1] Yousefpour, A., Hojjati, M., Immarigeon, J., "Fusion Bonding/Welding of Thermoplastic Composites", Journal of Thermoplastic Composite Materials 17: 303341 , July 2004 .

[2] Internet resource: "Boeing 787 Dreamliner Program Fact Sheet", Accessed May 2009, http://www.boeing.com/commercial/787family/programfacts.html

[3] Moentjens, A., Degrieck, J., Paepegem, W., "Experimental Characterisation of the Impact Behaviour of Fibre Reinforced Thermoplastics for Aerospace Applications", 9th FirW PhD Symposium, 2006

[4] Jakobsen, T., Don, T., Gillespie, J. Jr., "Two-Dimensional Thermal Analysis of Resistance Welded Thermoplastic Composites", Polymer Engineering and Science, 29(23): 1722-1729, 1989

[5] Ageorges, C., Ye, L., Mai, Y., Hou, M., "Characteristics of Resistance Welding of Lap Shear Coupons, Part I: Heat Transfer", Applied Science and Manufacturing, 29(8): 899-909, 1998.

[6] Ageorges et al., "Heat Transfer and Consolidation Modelling in Resistance Welding of Thermoplastic Composite Coupons", $8^{\text {th }}$ Euro Conf. on Composite Materials, June 1998

[7] Colak, Z., Sonmez, O., Kalenderoglu, "Process Modeling and Optimization of Resistance Welding for Thermoplastic Composites", Journal of Composite Materials, 36(6): 7721-744, 2002

[8] Stavrov, D., Nino, G., Bersee, H., "Process Optimization for Resistance Welding of Thermoplastic Composites", AIAA/ASME Structures, Structural Dynamics and Materials Conference, May 2006.

[9] Xiao, X., Hoa, S., "Process and Modelling of Resistance Welding of APC-2 Composite", Journal of Composite Materials, 26(7):1031-1049, 1992

[10] Lambing, C., Don, R., Andersen, S., Holmes, S., Leach, B., Gillespie, W., "Design and Manufacture of an Automated Resistance Welder for Thermoplastic Composites", ANTEC '91, pp. 2527-2531

[11] Holmes, S., Gillespie, W., "Thermal Analysis for Resistance Welding of LargeScale Thermoplastic Composite Joints", Journal of Reinforced Plastics and Composites, 12: 723-736, 1993.

[12] Crawford, R., Cook, G., Strauss, A., Harman, D., "Adaptive Voltage Control of Gas Tungsten Arc Welding", Int. J. of Modelling, Identification and Control, 1(2): $133-139,2006$ 
[13] Ozcelik, S., Moore, K., Naidu, S., "Application of MIMO direct Adaptive Control to Gas Metal Arch Welding", Proceedings of the American Control Conference, June 1998.

[14] Koseeyaporn, P., Smithmaitrie, P., Cook, G., Stauss, A., "Intelligent Arc Voltage Control", $6^{\text {th }}$ Int. Trends in Welding Research Conference Proceedings, April 2002

[15] Messler, R., Jou, M., Li, J., "An Intelligent Control System for Resistance Spot Welding Using a Neural Network and Fuzzy Logic", Industrial Applications Conference, 2: 1757-1763, Oct. 1995

[16] Farson, D., Chen., J., Ely, K., Frech, T., "Monitoring Resistance Spot Nugget Size by Electrode Displacement", Journal of Manufacturing Science and Engineering, 391-394, 2004.

[17] Williams, N., Parker, J., "Review of Resistance Spot Welding of Steel Sheets: Part 1 Modelling and Control of Weld Nugget Formation", International Materials Reviews 49(2): 45-75, 2004.

[18] Smiley, A., Halbritter, A., Cogswell, F., Meakin, P., "Dual Polymer Bonding of Thermoplastic Composite Structures", Polymer Engineering and Science 31(7): 526$532,1991$.

[19] COMSOL AB, COMSOL Multiphysics Modeling Guide v3.5a, COMSOL AB, Boston, MA, November 2008, p. 85.

[20] Rossiter, P., The Electrical Resistivity of Metals and Alloys, Cambridge University Press, New York, NY, 1987, p. 1-2.

[21] Lienhard IV, J., Lienhard V. J, A Heat Transfer Textbook: $3^{\text {rd }}$ Ed, Phlogiston Press, Cambridge, MA, 2006, pp. 13-55.

[22] Harvey, P., Engineering Properties of Steel, ASME, Metals Park, OH, 1982, p. 273.

[23] Yen, C., Tseng, H., Wang. Y., Hsieh, K., "Thermal Conductivity of Glass Fiber Reinforced Polypropylene under High Pressure", Journal of Applied Polymer Science, 42: 1179-1184, 1991.

[24] Uhlmann, E., Spur, G., Hocheng, H., Liebelt, S., Pan, C., "The Extent of LaserInduced Thermal Damage of UD and Crossply Composite Laminates", International Journal of Machine Tools \& Manufacture, 39: 639-650, 1999.

[25] Jun'Ichi, F., Tomohiro, H., "Specific Heat of the Molten Polyethylene, Polypropylene, and Polyethylene Terephthalate", $27^{\text {th }}$ Symposium Thermophysical Properties and $42^{\text {nd }}$ Japanese Conference on Calorimetry and Analysis, 27: 346-348, 2006. 
[26] Hsieh, K., Wang, Y., "Heat Capacity of Polypropylene Composite at High Pressure and Temperature", Polymer Engineering and Science, 30: 476-479, 1990.

[27] Talbot, E., Manufacturing Process Modeling of Thermoplastic Composite Resistance Welding, MASc thesis McGill University, June 2005.

[28] Talbot, E., Yousefpour, A., Hubert, P., Hojjati, M., "Thermal Behaviour During Thermoplastic Composites Resistance Welding", Annual Technical Conference (ANTEC) of the Society of Plastics Engineers, Boston, Massachusetts, USA; 2005.

[29] Holmes, S., Gillespie, J., "Thermal Analysis for Resistance Welding of LargeScale Thermoplastic Composite Joints", Journal of Reinforced Plastics and Composites", 12: 723-736.

[30] Stavrov, D., Nino, G., Bersee, H., "Process Optimization for Resistance Welding of Thermoplastic Composites", $47^{\text {th }}$ AIAA Structures, Structrual Dynamics, and Materials Conference, May 2006.

[31] Tan, S., Zak, G., Bates, P., "Resistance Welding of Glass-Fiber-Reinforce PP: Modeling and Experiments", ANTEC, May 2006.

[32] DuPont Electronics, "Summary of Properties for Kapton® Polyimide Film", Accessed Sept. 2009, http://www2.dupont.com/Kapton/en_US/assets/downloads/pdf/summaryofprop.pdf

[33] Jantzen, J., Tutorial on Fuzzy Logic, Technical University of Denmark, Aug. 1998.

[34] Jantzen, J., Design of Fuzzy Controller, Technical University of Denmark, Aug. 1998.

[35] The Mathworks, Fuzzy Logic Toolbox ${ }^{\mathrm{TM}} 2$ : User's Guide, The Mathworks ${ }^{\mathrm{TM}}$, Natick, MA, 2009.

[36] Opal-RT Technologies, "RT-Lab Professional: Overview", Accessed: Nov 2009, http://www.opal-rt.com/product/rt-lab-professional

[37] Opal-RT Technologies, "RT-Lab" v6.2 User's Manual, Revision A, Jan. 2003. 
APPENDIX A

VOLTAGE BOUNDARY CONDITIONS 
The voltage boundary conditions were set using a modified version of a step function, called the Heaviside function that is $\mathrm{C}^{2}$-continuous when stepping. The inputs to the function, known as $f l c 2 h s$, are defined as,

$$
F=f l c 2 h s(A, b)
$$

In the above equation $\mathrm{A}$ is the step time and $\mathrm{b}$ is the step transition centered at $\mathrm{A}$. The result of $F$ when $A$ is one, and $b$ is 0.25 is shown in Fig. A.1.

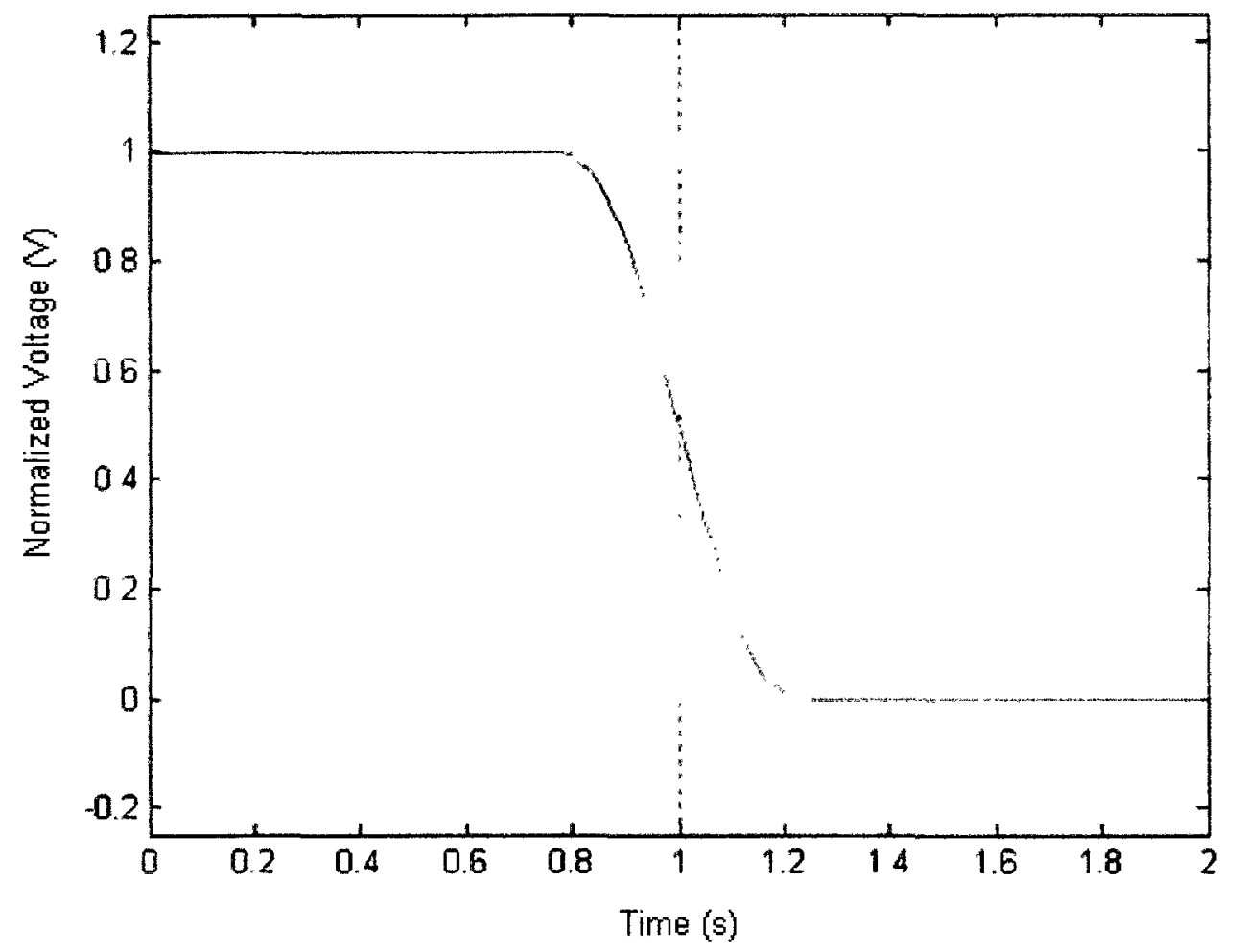

Figure A.1 - Heavisde function show $\mathrm{C}^{2}$-continuity at a threshold of $1 \mathrm{~s}$ and a transition of $0.5 \mathrm{~s}$.

To modify this to obtain a certain voltage eqn. (A1) is multiplied by some variable Vin. This input voltage will only be required to be set for a limited amount of time, $A$, so once the run time is larger than $\mathrm{A}$ the boundary condition cannot become zero to prevent multiple grounds from forming. The solution is to set the value to $V$, the solution variable COMSOL uses when solving the electrostatics equation. Two 
Heaviside functions are used in conjunction with each other for all weld sections that are not on the boundary of the model. The resulting equation would be,

$$
\text { Voltage }=\operatorname{Vin}\left(f l c 2 h s\left(t-A_{1}, b\right)-f l c 2 h s\left(t-A_{2}, b\right)\right)
$$

If the express $\left(t-A_{1}\right)$ is less than or equal to zero, then the function will be zero. Otherwise it will evaluate to $\mathrm{Vin}$. The result of eq. (A2) when $A_{1}$ is $2, A_{2}$ is 4 , and $b$ is 0.5 is shown in Fig. A.2.

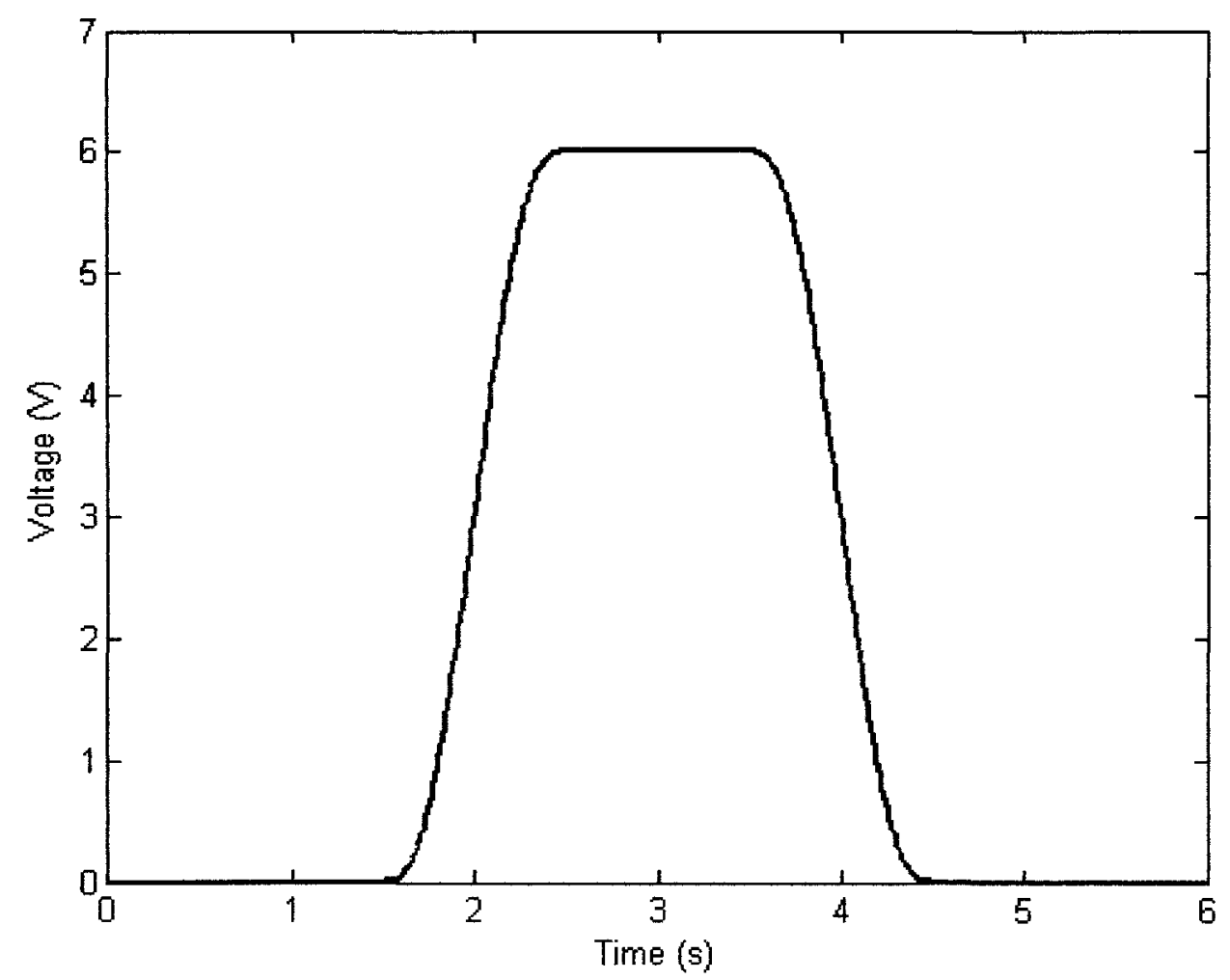

Figure A.2 - Two Heaviside functions used to create a voltage set for a fixed time frame.

Adding eq. (A3) to eq. (A2) will set the voltage to $V$, the COMSOL solution variable, instead of zero, preventing multiple grounds.

$$
\text { Voltage }=V *\left(f l c 2 h s\left(A_{1}-t, b\right)+f l c 2 h s\left(t-A_{2}, b\right)\right)
$$

For first two consecutive weld sections the boundary equations become, 


$$
\begin{gathered}
\text { Voltage }=\operatorname{Vin} * f l c 2 h s((t i m+b)-t, b)+V * f l c 2 h s(t-(\text { time }+a), a) \\
\begin{array}{c}
\text { Voltage }=\operatorname{Vin}(f l c 2 h s(t-(\operatorname{tim} e+a), a)-f l c 2 h s(t-(2 * \text { time }+3 a), a)) \\
+V(f l c 2 h s((t i m e+a)-t, a)+f l c 2 h s(t-(2 * \text { time }+3 a), a))
\end{array}
\end{gathered}
$$

In the above equations, the parameter time is defined as width of the copper block, divided by the weld speed. The result of eq. (A4) and eq. (A5) are shown in Fig. A.3 for a time of 7 seconds, a transition of 1 second, an input voltage, Vin, of $6 \mathrm{~V}$, and a solution voltage, $V$, of $3 \mathrm{~V}$.

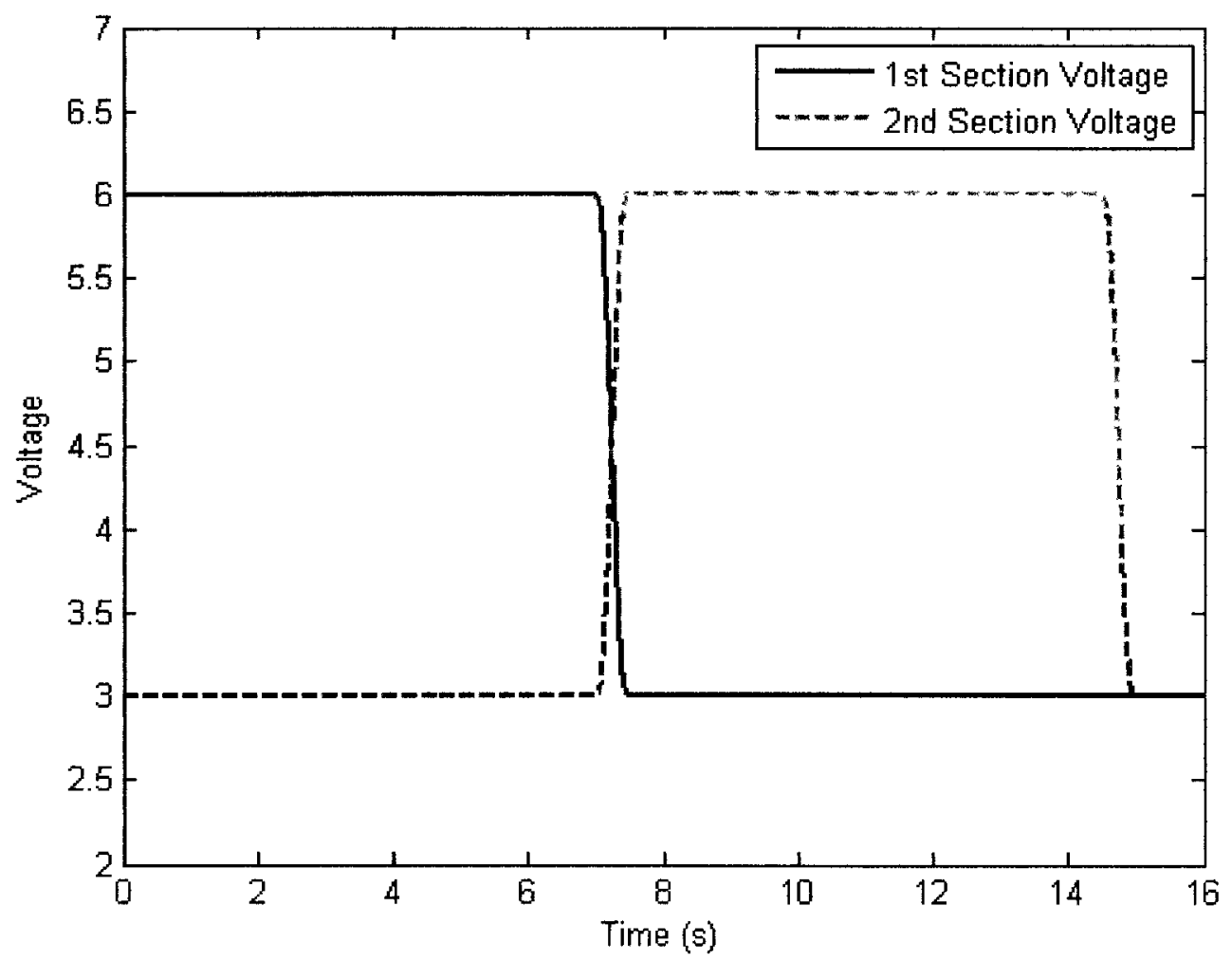

Figure A.3 - Voltage boundary conditions if the solution variable, $V$, is $3 \mathrm{~V}$. 